\title{
The interpretation of in situ soil tests
}

\author{
C. P. WROTH*
}

The purposes of in situ testing are set out, and the difficulties of the interpretation of the observations are emphasized. These difficulties are due to the complex behaviour of soils together with the lack of control and of choice of the boundary conditions in any field test. One notable exception is the pressuremeter test, from which soil properties can be derived directly without recourse to empirical correlations. The discussion is concentrated on the measurement of undrained shear strength. The results obtained from different tests (triaxial, plane strain, direct simple shear, pressuremeter and vane) are compared by expressing them in terms of the undrained strength ratio $s_{u} / \sigma_{v 0}$ as a function of the friction angle $\phi$. Special attention is paid to tests in which the principal axes of stress and of strain increment are free to rotate. In such tests, uncertainty exists regarding the definition of failure and the planes of maximum stress obliquity. To derive these functions Matsuoka's failure criterion is used. As a consequence a thcoretical hicrarchy of strengths is established which agrees qualitatively with experimental evidence. The importance to a designer of this variety of strengths is emphasized. A study is made of the piezocone and the interpretation of the pore pressures in terms of the overconsolidation ratio of the clay tested. A plea is made for the standardization of the equipment, the operation and the interpretation of in situ tests to obtain maximum benefit from them.

L'article décrit les buts des essais in situ et souligne les difficultés de l'interprétation des mesures. Ces difficultés sont dues au comportement complexe des sols, combiné avec le manque de contrôle et de choix des conditions limites qu'on a dans n'importe quel essai in situ. Une exception importante est l'essai pressiométrique-à partir duquel on peut evaluer directement des propriétés du sol sans être obligé de recourir à des correlations empiriques. La discussion se concentre sur la mesure de la résistance au cisaillement non-drainé. On compare les résultats obtenus à partir des différents essais (triaxial, déformation plane, cisaillement simple direct, pressiomètre et scissomètre) en les exprimant en fonction du rapport $s_{\mathrm{u}} / \sigma_{\mathrm{vo}}{ }^{\prime}$ de la résistance dans l'état non-drainé et en fonction de l'angle de friction $\phi$. On étudie plus particulièrement les essais dans lesquels les axes principaux de l'augmentation de la contrainte et de la déformation peuvent tourner librement. Dans de tels cas il existe une incertitude concernant la définition de la rupture et des plans de l'obliquité maximale des contraintes. Afin de trouver ces fonctions on emploie le critère de rupture de Matsuoka. On établit par conséquent une

* Department of Engineering Science, University of Oxford. hiérarchie théorique des résistances qui s'accorde qualitativement avec les résultats expérimentaux. On souligne l'importance pour le projeteur de ces diverses résistances. On étudie aussi le piézocône et l'interprétation des pressions interstitielles en fonction du rapport de surconsolidation de l'argile testée. On recommande que l'appareillage, l'exécution et l'interprétation des essais sur place soient uniformisés afin d'en tirer l'avantage maximal.

\section{INTRODUCTION}

In situ testing in geotechnical engineering serves four main purposes:

(a) site investigation

(b) measurement of a specific property of the ground

(c) control of construction

(d) monitoring of performance and back analysis.

The first of these, site investigation, is essentially a process of diagnosis, of discovering what the ground consists of at a particular site. This process may consist of direct identification of soil or rock by drilling a borehole, sampling and subsequent inspection on site, or in the laboratory, backed up by index tests and other laboratory tests. Alternatively, in situ tests may be used for the indirect identification of soil type, or more usually of stratification and geologic variation, e.g. by obtaining a continuous profile of the point resistance of a cone penetrometer.

The second purpose, the measurement of a particular soil or rock property, may be adopted either for economic or practical reasons, or more importantly because it is considered essential to measure the property in situ and not in the laboratory.

The third role, that of control of construction, may be an essential part of the satisfactory completion of the works. For example, it might be necessary at a particular site to improve the strength and stiffness of the ground by a means such as dynamic compaction, and the efficiency of the process could be directly monitored by carrying out continuous profiles of piezocone tests (Campanella, Gillespie \& Robertson, 1982). Another example is the staged construction of an embankment built on soft ground, with the increase in strength of the underlying 
clay being directly measured in situ, or monitored indirectly by the decay of excess porewater pressures.

The fourth purpose, the monitoring of performance of geotechnical works, may be a standard procedure such as the continuous observation of movement, of porewater pressures and of quantities of seepage in an earth dam, or in circumstances where there are special problems or uncertainties. A striking example of the latter was the monitoring and subsequent back analysis of the New Palace underground car park at the Houses of Parliament, London, reported by Burland \& Hancock (1977).

Most calculations carried out in the past by practising civil engineers for the design of foundations and earthworks have been restricled either to limit analysis for stability calculations or to predictions of settlement. Classical limit analysis is independent both of the deformation characteristics of the ground and of the level of the in situ lateral stress of the undisturbed ground; it depends solely on the groundwater conditions and on the properties of strength and unit weight of the soil or rock. In contrast classical methods of settlement prediction depend only on deformation properties.

In most instances the relevant properties have been evaluated from laboratory tests on supposedly undisturbed samples, and then been used in a simple analysis to lead to designs which have proved to be entirely satisfactory. Why, then, is it necessary to make in silu measurements of soil and rock properties?

The main reason for this need is that, as our knowledge of the behaviour of real soils increases, so our appreciation of the inadequacy of conventional laboratory testing grows. The marked consequences of the inevitable disturbance that is caused in any soil specimen, however carefully it has been sampled, transported and reconsolidated in the laboratory, are all too evident. The work at the Building Research Station has shown, for example, that the actual deformation moduli of the ground may be several times greater than those measured in good quality tests in the laboratory on good quality samples, as shown e.g. by Marsland (1973). Consequently predictions of the deformation of the ground around a foundation or excavation based on laboratory data may be grossly overestimated, and the resulting design may be unnecessarily conservative and expensive.

A separate but important advantage of in situ testing is that the soil in question will be tested at the appropriate level of effective stress, presuming that disturbance of the ground due to insertion of the instrument has been kept to a minimum.
Apart from good technical reasons for conducting in situ tests, there may be situations where the total cost of site investigation and testing makes them economically attractive, or where they must form the major part of the investigation such as in the exploration of offshore sites for oil production platforms.

In parallel with the major developments that have occurred in the last 25 years or more in experimental techniques, in instrumentation and in the understanding of soil behaviour have been the profound changes in analytical methods made possible by the electronic computer. New methods of numerical analysis not only allow complete solutions to be obtained to complex boundary value problems but also allow the use of non-linear, non-homogeneous, anisotropicand hence more realistic-models of soil or rock behaviour.

In the past few years there has been a marked growth in the use of in situ tests and in the variety of instruments that have reached a sufficiently developed stage that they can be used with confidence. It is not possible within the limits of this Paper to attempt a comprehensive review of these instruments or of the current state of in situ testing. The purpose of the Paper is to discuss the interpretation and use of the results of in situ tests, and to highlight some of the considerable difficulties and uncertainties associated with them. Most of the discussion is concentrated on

(a) in situ tests in clay (most of the principles involved will apply to other soils and rocks to a greater or lesser degree)

(b) results of self-boring pressuremeter tests and piezocone tests.

The reasons for this choice are given later.

\section{RELATIONSHIPS BETWEEN SOIL PROPERIIES}

The interpretation of data obtained from in situ tests is difficult, and for most tests it is both incomplete and imprecise. A number of separate factors contributes to this unsatisfactory situation. The factors fall into two distinct categories: those due to the behaviour of the soil and those due to the type of test being performed.

Soil behaviour is complex and depends on the complete geological history of the deposit as represented by the size, shape, mineral composition and packing of the particles, the stress history that has been experienced, the pore fluid and other factors. The response of the soil to a particular test will depend on the changes in effective stress that it undergoes, and, further, this response will be inadequately represented 
by a few simplistic properties such as undrained shear strength, shear modulus, coefficient of consolidation etc. The properties themselves may vary locally to a significant degree both laterally and vertically within the ground, owing to the microfabric of the material and the quirks of its history.

Any in situ test, when considered as a boundary value problem, is beset with difficulties. The boundaries of the problem are unknown and uncontrolled, so that there are insufficient data for a complete solution and for an unequivocal interpretation of the results. The fields of stress increment and strain induced around the instrument by the operation of the test vary significantly with distance from the instrument; this variation is not unique for the type of test but is itself dependent on the stress-strain properties of the soil being tested.

In all but fully drained situations, the nonhomogeneous fields of stress cause locally high hydraulic gradients so that some degree of partial consolidation will occur in what is supposed to be-or is interpreted as-an undrained test. This partial consolidation introduces an important rate effect, in addition to that attributable to the viscous nature of soil behaviour.

A further complication arises in that in all in situ tests (except the pressuremeter test) the principal axes of stress rotate within the soil, whereas they do not in the triaxial test, which is used as a standard form of comparison.

In addition, in all experimental work there are limits to the accuracy and reliability of the instrument, a situation which is worse in the field than in the laboratory.

Consequently any interpretation of an in situ test is open to question. To make the most of the interpreted results it is vital to correlate them with the results of all other data, whether from the field or the laboratory, and to draw on all available experience.

The choice of properties that should be used in any attempted correlation is crucial. Any successful relationship that can be used with confidence outside the immediate context in which it was established should ideally be

(a) based on a physical appreciation of why the properties can be expected to be related

(b) set against a background of theory, however idealized this may be

(c) expressed in terms of dimensionless variables so that advantage can be taken of the scaling laws of continuum mechanics.

An illustration of these points is provided by considering correlations of the undrained shear strength $s_{\mathrm{u}}$ of a clay. All soils are basically frictional materials with the strength being pro- vided by the frictional resistance between soil particles governed by the effective stress to which they are subjected. Starting $a b$ initio, the first relationship to be explored would be

$$
\frac{s_{\mathrm{u}}}{p_{\mathrm{f}}^{\prime}}=f(\phi)
$$

where $p_{\mathrm{r}}{ }^{\prime}$ is the mean principal effective stress at failure and $\phi$ is the angle of shearing resistance. In any real situation the value of $p_{\mathrm{f}}^{\prime}$ will not be known, and it has to be replaced by some other stress variable. If the initial conditions are selected, and the mean principal effective stress $p_{0}{ }^{\prime}$ is used, then its relationship with $p_{\mathrm{f}}{ }^{\prime}$ depends on the excess pore pressures generated during shearing to failure, which in turn depends on the overconsolidation ratio OCR of the clay. Hence a second approach would be to consider the relationship

$$
\frac{s_{\mathrm{u}}}{p_{0}{ }^{\prime}}=f(\phi, \mathrm{OCR})
$$

However, this relationship will in practice be subject to much uncertainty because the in situ mean principal effective stress $p_{0}{ }^{\prime}$ is unlikely to be known or to have been estimated with any accuracy. The single stress variable that can be estimated with most reliability is the in situ vertical effective stress $\sigma_{v 0}{ }^{\prime}$. Since this is related to $p_{0}{ }^{\prime}$ as a function of OCR, its use in lieu of $p_{0}{ }^{\prime}$ will not incrcase the number of variables in the relationship. Consequently a good engineering compromise is to adopt the expression

$$
\frac{s_{\mathrm{u}}}{\sigma_{\mathrm{v} 0}^{\prime}}=f(\phi, \mathrm{OCR})
$$

and to define $s_{\mathrm{u}} / \sigma_{\mathrm{v} 0}$ as the undrained strength ratio.

Historically in soil mechanics, much use has been made for normally consolidated clays of the relationship suggested by Skempton (1957)

$$
\frac{s_{\mathrm{u}}}{\sigma_{\mathrm{v} 0^{\prime}}}=0 \cdot 11+0 \cdot 0037 \mathrm{PI}
$$

where PI is the plasticity index of the clay. Within the context of these arguments, is this a sound relationship, and does it suggest a new variable PI that should be taken into account? At first sight, it is not evident that the undrained strength ratio should be related directly to the plasticity index. However, the value of $\phi$ can be expected to depend on the shape, size, packing and mineral composition of the clay particles, as will the plasticity index, so the two properties are related in some complex manner. Thus physical reasoning supports Skempton's relationship but suggests that it would be a weaker one than 
that of equation (3) in which $\phi$ is preferred to PI.

\section{CONDTTIONS AT FAILURE}

The majority of in situ tests induce local failure in the soil, and the most commonly deduced property is the undrained shear strength. Much of this Paper is therefore taken up with a detailed and critical look at undrained shear strength.

The symbol used in this Paper for undrained shear strength is $s_{\mathrm{u}}$, in accordance with common practice in the USA, rather than the symbol $c_{\mathrm{u}}$ as recommended by the British Standards Institution (1975). This is a deliberate choice, because the former relates to 'strength' whereas the latter relates to 'cohesion'; it is argued in this Paper that strength must be interpreted in terms of effective stresses and friction angle, and not total stresses and cohesion.

The basic definition of undrained shear strength is

$$
s_{\mathrm{u}}=\frac{1}{2}\left(\sigma_{1}-\sigma_{3}\right)
$$

i.e. half the difference between the major and minor principal stresses, or the radius of the largest Mohr circle. This is an unsatisfactory definition as it neither takes account of the intermediate principal stresses $\sigma_{2}$ nor distinguishes between the different types of test which are well known to give different results for identical soil specimens.

It is essential to distinguish between different test results by an inelegant plethora of suffices as follows:

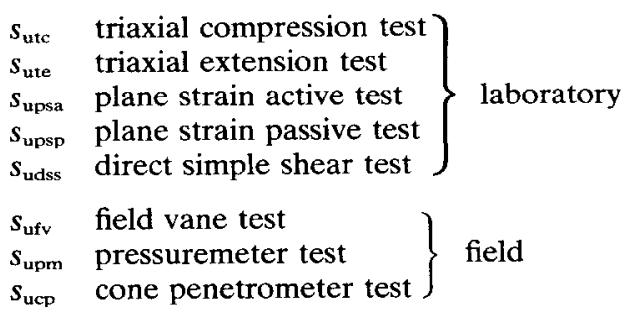

The major question to be faced is how these different measurements of strength are connected. An attempt is made to link them by means of the friction angle $\phi$.

The basic concept of an angle of shearing resistance or of internal friction comes from the classical experimental work of Coulomb in which (plane strain) tests were conducted in a shear box. The resulting definition of the friction angle in terms of principal effective stresses is

$$
\sin \phi=\frac{\sigma_{1}{ }^{\prime}-\sigma_{3}{ }^{\prime}}{\sigma_{1}{ }^{\prime}+\sigma_{3}{ }^{\prime}}
$$

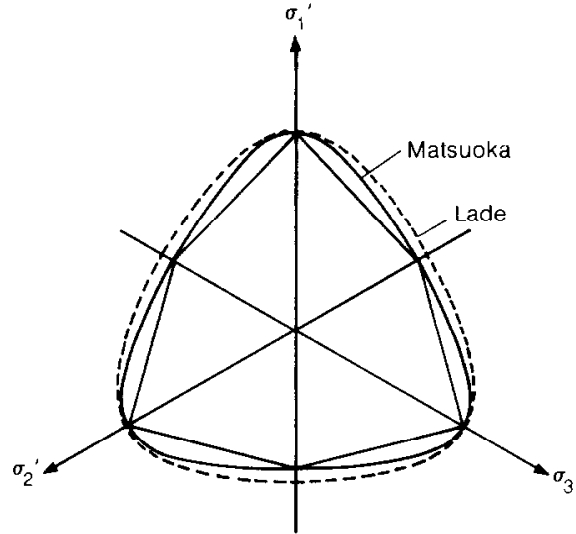

Fig. 1. Sections of failure surfaces in principal stress space

Unfortunately, as for undrained shear strength, this neither allows for the influence of $\sigma_{2}{ }^{\prime}$ nor does it distinguish between different types of test. Because it is absolutely essential to understand soil behaviour in terms of effective stresses, and not total stresses, the use of the symbol $\phi_{\mathrm{u}}$ should be abandoned and the use of the prime in the symbol $\phi^{\prime}$ can be dropped, both for convenience and for emphasis.

Furthermore, to make a proper comparison between failure conditions in different tests, the link will be established initially between results of tests on normally consolidated clays, so that the friction angle relates not to peak strength but to conditions at the end of a test when there is no further change in volume or effective stresses, i.e. at the critical state. Hence $\phi$ replaces $\phi_{\mathrm{cv}}$ ' or $\phi_{\mathrm{cs}}$ '.

Suffices are required to distinguish results, as follows:

$$
\begin{array}{ll}
\phi_{\text {tc }} & \text { triaxial compression test } \\
\phi_{\text {te }} & \text { triaxial extension test } \\
\phi_{\mathrm{ps}} & \text { plane strain tests. }
\end{array}
$$

On the basis of limited experimental evidence it is assumed that the critical state friction angle is the same for all plane strain tests including direct simple shear tests.

To take proper account of the effect of the intermediate principal effective stress $\sigma_{2}^{\prime}$ it is necessary to adopt a generalized failure criterion expressed in terms of all three principal effective stresses. Fig. 1 is a section of principal stress space made by a $\pi$ plane or octahedral plane, which is perpendicular to the space diagonal. The figure shows the sections of three possible failure surfaces, each of which emanates from the origin in the form of a cone. The inner 
irregular hexagon is the classical extended Mohr-Coulomb failure envelope given simply by the requirement that

$$
\phi=\text { constant }
$$

The outer, broken curve is a section of the failure surface proposed by Lade (1972). Since this criterion is expressed in terms of all three principal stresses it is best to make use of the stress invariants

$$
\left.\begin{array}{l}
I_{1}=\sigma_{1}{ }^{\prime}+\sigma_{2}{ }^{\prime}+\sigma_{3}{ }^{\prime} \\
I_{2}=\sigma_{2}{ }^{\prime} \sigma_{3}{ }^{\prime}+\sigma_{3}{ }^{\prime} \sigma_{1}{ }^{\prime}+\sigma_{1}{ }^{\prime} \sigma_{2}{ }^{\prime} \\
I_{3}=\sigma_{1}{ }^{\prime} \sigma_{2}{ }^{\prime} \sigma_{3}{ }^{\prime}
\end{array}\right\}
$$

and to write Lade's criterion as

$$
I_{1}{ }^{3} / I_{3}=\text { constant }
$$

An alternative failure criterion is that proposed by Matsuoka (1974) which has the form

$$
I_{1} I_{2} / I_{3}=\text { constant }
$$

and which is represented by the full, inner curve.

Both sections of the Lade and Matsuoka failure surfaces have been drawn so that they coincide with the Mohr-Coulomb criterion for triaxial compression tests (i.e. they pass through the vertices of the hexagon which lie on the positive stress axes). The Matsuoka curve also passes through the other three vertices of the hexagon, whereas the Lade curve does not. The two criteria are very similar, and the curves have the subtle property that the shape varies with the friction angle; as $\phi$ decreases the shape becomes more circular, and as $\phi$ increases the shape becomes more triangular.

Of the three criteria, Matsuoka's is chosen for the current analysis for three reasons.

(a) It was initially developed from theory and not from curve fitting of experimental data. The theory, which is complex, is based on the concepts of spatially mobilized planes within a soil specimen on which slip is assumed to occur (Matsuoka \& Nakai, 1977).

(b) It appears to fit experimental data best.* However, the data from complicated laboratory apparatus in which the principal stresses can be independently controlled are notoriously suspect.

(c) It is expressed in terms of all three stress invariants.

\footnotetext{
* Reference can be made to Matsuoka \& Nakai (1982), where data are presented for sand from the results of their tests, of Sutherland \& Mesdary (1969) and of Ramamurthy \& Rawat (1973), and for clay from Shibata \& Karube (1965).
}

A priori, there is no reason to omit the second invariant $I_{2}$, as Lade's criterion does.

Bishop (1966) introduced the parameter

$$
b=\frac{\sigma_{2}^{\prime}-\sigma_{3}^{\prime}}{\sigma_{1}^{\prime}-\sigma_{3}^{\prime}}
$$

as a convenient way of expressing the relative value of the intermediate principal effective stress. The value of $b$ varies between zero for triaxial compression and unity for triaxial extension. Its value for plane strain conditions has been much debated, but it has often been taken as 0.5 on the basis of the theory of perfect plasticity.

For the particular case of triaxial compression for which $\sigma_{2}^{\prime} \equiv \sigma_{3}{ }^{\prime}$ (and $b=0$ ) Matsuoka's criterion can be expressed as

$$
\begin{aligned}
\frac{I_{1} I_{2}}{I_{3}}= & \frac{\left(\sigma_{1}{ }^{\prime}+2 \sigma_{3}{ }^{\prime}\right)\left(\sigma_{3}{ }^{\prime 2}+2 \sigma_{1}{ }^{\prime} \sigma_{3}{ }^{\prime}\right)}{\sigma_{1}{ }^{\prime} \sigma_{3}{ }^{\prime 2}} \\
= & \frac{\left(\sigma_{1}^{\prime} / \sigma_{3}{ }^{\prime}+2\right)\left(1+2 \sigma_{1}{ }^{\prime} / \sigma_{3}{ }^{\prime}\right)}{\sigma_{1}^{\prime} / \sigma_{3}{ }^{\prime}}
\end{aligned}
$$

which can be rewritten in terms of $\phi_{\mathrm{tc}}$ as follows:

$$
\begin{aligned}
\frac{I_{1} I_{2}}{I_{3}} & =\frac{\left(3-\sin \phi_{\mathrm{tc}}\right)\left(3+\sin \phi_{\mathrm{tc}}\right)}{\left(1-\sin \phi_{\mathrm{tc}}\right)\left(1+\sin \phi_{\mathrm{tc}}\right)} \\
& =9+8 \tan ^{2} \phi_{\mathrm{tc}}
\end{aligned}
$$

For triaxial extension, an exactly similar derivation leads to

$$
\begin{aligned}
\frac{I_{1} I_{2}}{I_{3}} & =\frac{\left(3+\sin \phi_{\mathrm{te}}\right)\left(3-\sin \phi_{\mathrm{te}}\right)}{\left(1+\sin \phi_{\mathrm{te}}\right)\left(1-\sin \phi_{\mathrm{te}}\right)} \\
& =9+8 \tan ^{2} \phi_{\mathrm{te}}
\end{aligned}
$$

which confirms that for this criterion $\phi_{\mathrm{tc}} \equiv \phi_{\mathrm{te}}$.

It is required to relate, if possible, $\phi_{\mathrm{ps}}$ with $\phi_{\mathrm{tc}}$ by some simple relationship. Satake (1982) has shown that if an associated flow rule is applied to the Matsuoka failure criterion (treated as a yield surface) then for plane strain conditions $\phi_{\mathrm{ps}}$ is the maximum value that $\phi$ can have (for all values of $b$ ). This assumption of an associated flow rule is not valid for peak conditions but is suggested as acceptable for critical state conditions.

By finding the maximum value of the ratio $\sigma_{1}{ }^{\prime} / \sigma_{3}{ }^{\prime}$ (i.e. the maximum value of $\phi$ ) for a fixed value of $I_{1}$ (i.e. for one octahedral plane) it can be shown that $\phi_{\mathrm{ps}}\left(\equiv \phi_{\max }\right)$ is given by

$$
\sec ^{2} \phi_{\mathrm{ps}}+\sec \phi_{\mathrm{ps}}=2 \sec ^{2} \phi_{\mathrm{tc}}
$$

and further that the value of $b$ for planc strain

$$
b_{\mathrm{ps}}=\frac{\sin \phi_{\mathrm{ps}}+\cos \phi_{\mathrm{ps}}-1}{2 \sin \phi_{\mathrm{ps}}}
$$




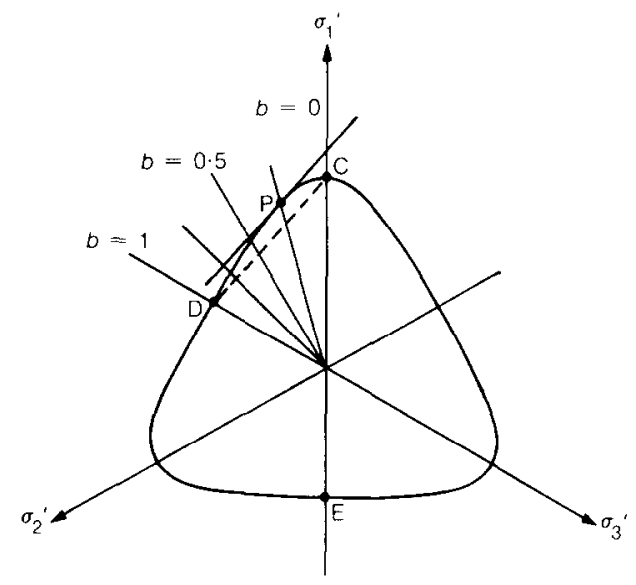

Fig. 2. Plane strain conditions derived from Matsuoka's criterion

or alternatively

$$
\left(\frac{\sigma_{2}^{\prime}}{\sigma_{1}{ }^{\prime}+\sigma_{3}{ }^{\prime}}\right)_{\mathrm{ps}}=\frac{1}{2} \cos \phi_{\mathrm{ps}}
$$

These findings are illustrated in Fig. 2 where $P$ indicates the point on the failure surface corresponding to plane strain conditions. Note that $\mathrm{CD}$ is a line of constant $\phi$ (the Mohr-Coulomb surface), but that the orientation of such a line changes slightly with the value of $\phi$, so that the tangent at $\mathbf{P}$ associated with $\phi_{\max }$ will not be parallel to $\mathrm{CD}$. Taking for example a value of $\sin \phi_{\mathrm{ps}}=0.6\left(\phi_{\mathrm{ps}}=36.87^{\circ}\right)$ then $\phi_{\mathrm{tc}}=32.5^{\circ}$ and $b_{\mathrm{ps}}=1 / 3$.

The relationships of equations (15) and (16) are plotted in Fig. 3. The resulting curves can be approximated for engineering purposes by the linear relationships

$$
8 \phi_{\mathrm{ps}}^{\circ} \approx 9 \phi_{\mathrm{tc}}^{\circ}
$$

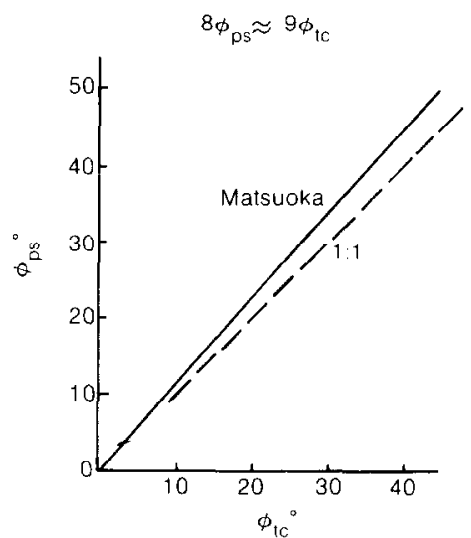

and

$$
2 b_{\mathrm{ps}} \approx 1-\frac{\phi_{\mathrm{ps}}^{\circ}}{100}
$$

Equation (18) will be used for relating the results of plane strain tests with triaxial compression tests for a given soil.

\section{UNDRAINED TRIAXIAL COMPRESSION TFSTS}

The triaxial compression test has become the standard method of obtaining stress-strain and strength properties of soils in the laboratory as part of a conventional site investigation. It is against such a background that the results of in situ tests will be judged in general. Consequently it is valuable to establish a theoretical understanding of the triaxial test, and it is believed that this is best done by means of the framework provided by critical state soil mechanics (CSSM).

The original concepts of this approach to soil behaviour were based on the idea of a critical void ratio conceived by Casagrande (1936), the early triaxial tests on sand by Taylor (1948) and then extended by a detailed analysis of triaxial tests on isotropically consolidated specimens of reconstituted clay by Roscoe, Schofield \& Wroth (1958).

In Fig. 4 is presented a comparison between the classical representation of one-dimensional consolidation of Terzaghi and the modern approach for isotropic consolidation of CSSM. The former has voids ratio $e$ plotted against $\log _{10} \sigma_{v}{ }^{\prime}$, whereas the latter has specific volume $V$ plotted against $\log _{\mathrm{e}} p^{\prime}$, with the consequence that the compression and swelling indices are defined differently.

In one-dimensional swelling the principal stresses do not decrease proportionally, so that

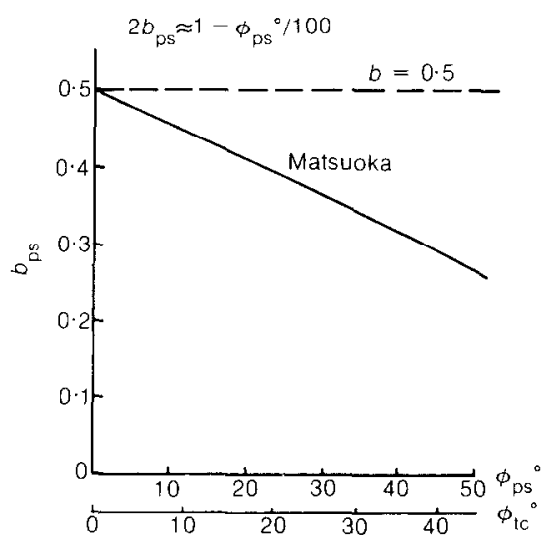

Fig. 3. Relationships for plane strain conditions derived from Matsuoka's failure criterion 


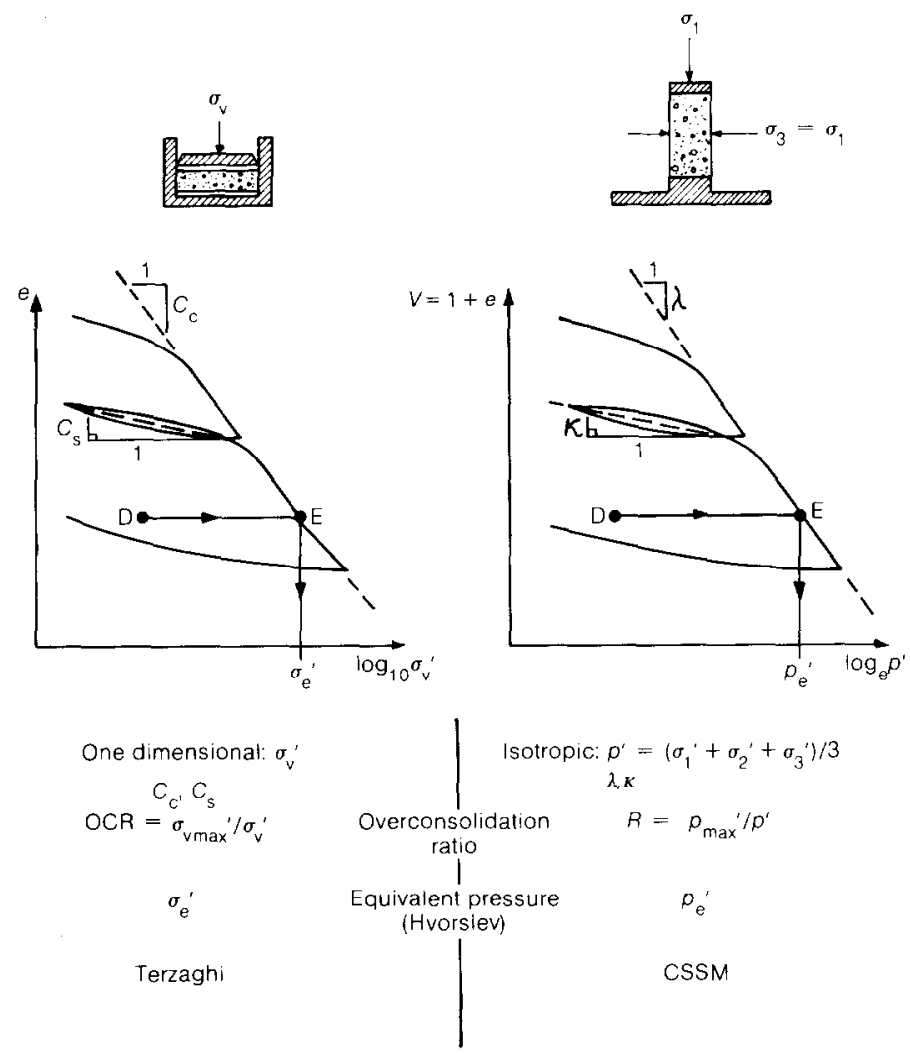

Fig. 4. Definitions of consolidation in one-dimensional and isotropic conditions

care is required with the definition of the overconsolidation ratio which will not be the same in the two plots. For isotropic conditions the overconsolidation ratio is defined as the ratio of the maximum past mean effective stress $p_{\max }$ 'to the current value $p^{\prime}$, and it is given the symbol $R$ in accordance with Atkinson \& Bransby (1978).

The equivalent pressure of a specimen, introduced by Hvorslev (1937), is defined as the pressure on the normal consolidation line, such as at point $\mathrm{E}$, at the same voids ratio as that of the specimen at state $D$. This proves to be an elegant and convenient way of converting from the voids ratio (or water content) of a clay specimen into a pressure variable for comparisons in dimensionless form.

The idealized results of undrained triaxial compression tests are represented in Fig. 5 in terms of the state variables $p^{\prime}, q$ and $V$. A specimen initially normally consolidated at point $C$ undergoes the effective stress path $C D$ whereas an initially overconsolidated specimen at point $\mathrm{R}$ experiences the path $\mathrm{RS}$; it is assumed that both specimens reach undrained failure on the critical state line at $\mathrm{D}$ and $\mathrm{S}$ respec- tively. The critical state line is assumed to be parallel to the isotropic normal consolidation line $A B C$ in the semilogarithmic plot, and its relative position to be given by the spacing ratio $r$ defined as the ratio of the pressures at $\mathrm{C}$ and $\mathrm{X}$ which lie on the same swelling line CXR. For the original Cam clay model $r=2.718(=\mathrm{e}$, the base of natural logarithms), whereas for the modified Cam clay model $r=2$.

In Appendix 1 it is shown that

$$
p_{\mathrm{s}}{ }^{\prime} / p_{\mathrm{r}}{ }^{\prime}=(R / r)^{\Lambda}
$$

where $\Lambda=(\lambda-\kappa) / \lambda$. This parameter was introduced by Schofield \& Wroth (1968) because it plays an important role in realistic elasto-plastic models of soil behaviour which incorporate strain-hardening plasticity. It may be termed the plastic volumetric strain ratio, being the ratio of the plastic component to the total component of the volumetric strain increment in normal consolidation. This parameter $\Lambda$ consistently appears as an exponent in the subsequent analyses.

The undrained shear strength in compression is half the deviator stress at failure so that

$$
s_{\mathrm{utc}}=\frac{1}{2} a_{\mathrm{s}}=\frac{1}{2} \mathrm{Mp}_{\mathrm{s}}^{\prime}
$$




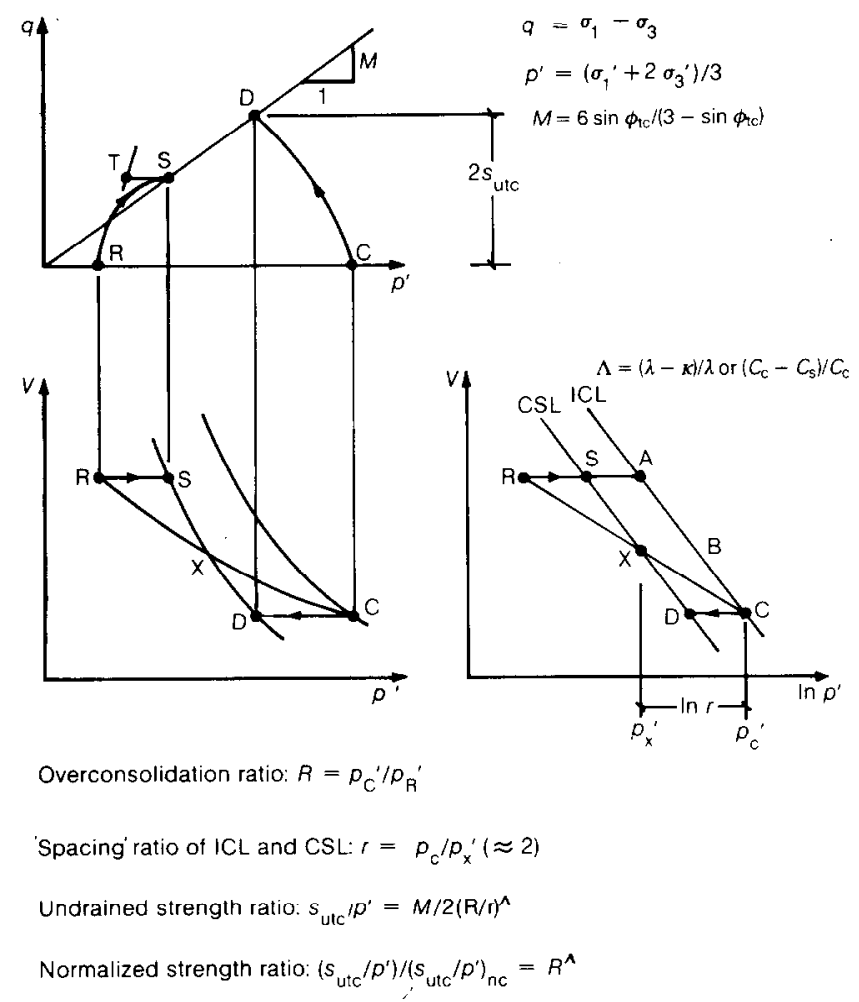

Fig. 5. Theoretical expressions for undrained strength in triaxial compression tests

Substituting for $p_{\mathrm{s}}$ from equation (20) gives

$$
\frac{s_{\mathrm{utc}}}{p^{\prime}}=\frac{M}{2}\left(\frac{R}{r}\right)^{\wedge}
$$

where for triaxial compression

$$
M=\frac{6 \sin \phi_{\mathrm{tc}}}{3-\sin \phi_{\mathrm{tc}}}
$$

This expression is valid for specimens that have been isotropically consolidated, so that at the start of the compression test $\sigma_{\mathrm{vo}}{ }^{\prime} \equiv p_{0}{ }^{\prime}$. Hence equation (22) can be reinterpreted as an expression for the undrained strength ratio

$$
\frac{s_{\mathrm{utc}}}{\sigma_{\mathrm{vo}}}=\frac{M}{2}\left(\frac{R}{r}\right)^{\wedge}
$$

For any given soil $M, r$ and $\Lambda$ will be constants so that in theory the undrained strength ratio is proportional to the overconsolidation ratio raised to the power $\Lambda$. Evidence in support of this finding is presented later.

Experimental evidence supporting these concepts is provided by the results of undrained triaxial compression tests on isotropically con- solidated specimens of reconstituted kaolin by Loudon (1967). The effective stress paths for a set of specimens are presented in Fig. 6 where the stresses have been made dimensionless by dividing by the relevant value of the equivalent pressure $p_{e}^{\prime}$ in each case. In this plot the critical state line is reduced to a single unique critical state point indicated by $\mathrm{C}$.

In the development of the understanding of soil behaviour, the major centres of experimental research in soil mechanics have wisely concentrated their efforts on testing a limited range of soils in a comprehensive manner. Examples that come readily to mind are kaolin, Weald clay, London clay, Boston blue clay and Drammen clay. This philosophy of research has allowed a reliable and detailed picture to be built up of the behaviour of these clays but has the minor disadvantage that there has not been a survey of trends of soil properties for a wide range of clays. In particular there are unfortunately few reliable data on the range of values of the spacing ratio $r$ and the plastic volumetric strain ratio $\Lambda$. On the basis of the limited evidence available it seems that neither of these parameters varies significantly for a wide range 


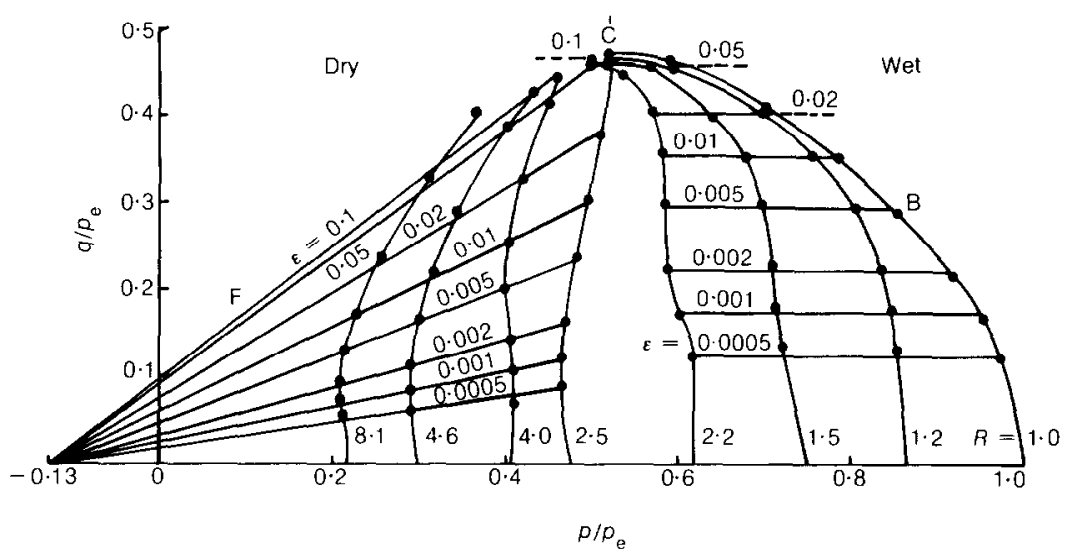

Fig. 6. Effective stress paths for undrained triaxial compression tests on kaolin (after Loudon, 1967)

of clays, and that for present purposes it is reasonable to adopt the approximate values

$$
\left.\begin{array}{rl}
r & \approx 2 \\
\Lambda & \approx 0 \cdot 8
\end{array}\right\}
$$

Use of these values means that the undrained strength ratio for normally consolidated speciments $(R=1)$ can be rewritten by combining equations (23) and (24) to give

$$
\begin{aligned}
\left(\frac{s_{\mathrm{utc}}}{\sigma_{\mathrm{vo}}{ }^{\prime}}\right)_{\mathrm{nc}} & \approx \frac{M}{2}\left(\frac{1}{2}\right)^{0.8} \\
& \approx 0.5743 \frac{3 \sin \phi_{\mathrm{tc}}}{3-\sin \phi_{\mathrm{tc}}}
\end{aligned}
$$

The variation in this ratio with the friction angle $\phi_{\text {tc }}$ is shown in Fig. 7 by the upper curve marked ITC (denoting Isotropically consolidated specimens tested in Triaxial Compression). Note that for a clay that has values of $r$ and $\Lambda$ that differ from those assumed (equation (25)) the conse-

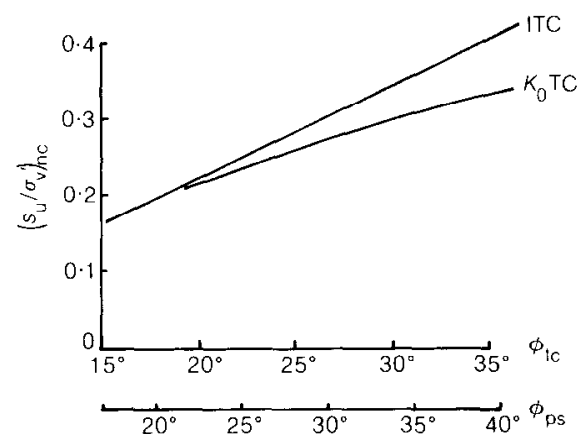

Fig. 7. Variation in the undrained strength ratio with the angle of friction for triaxial tests on normally consolidated clay quence is merely one of scaling the ordinate axis appropriately: the shape of the curve would remain unchanged. For later comparisons the values of the friction angle in plane strain $\phi_{\mathrm{ps}}$ given by equation (18) have been included on the axis.

\section{Specimens consolidated one dimensionally}

In nature, it is usually assumed that soil deposits have become consolidated under one-dimensional conditions. To simulate soil behaviour in the laboratory, it is becoming increasingly the practice to reconsolidate specimens anisotropically to their assumed in situ stresses. The behaviour of such specimens will not be the same as that of isotropically consolidated specimens; this difference must be accounted for when the results are used for predicting field behaviour.

The concepts of CSSM require that the state of an anisotropically normally consolidated specimen of clay lies on the state boundary surface at some point such as B in Fig. 6 (reference can be made to Schofield \& Wroth (1968) or Atkinson \& Bransby (1978)). It is assumed that failure of this specimen will occur at the critical state given by point $C$, with the same undrained shear strength as an isotropically normally consolidated specimen at the same water content (i.e. having the same equivalent pressure). However, because the initial stress states are different, the undrained strength ratios will be different; the actual value for the anisotropic specimen will depend on the shape of the state boundary surface, as well as on the value of $K_{0}$.

In Appendix 2, it is assumed that the state boundary surface is formed by the elliptical yield surface of modified Cam clay. The analysis gives 
the following cumbersome expression for the undrained strength ratio:

$$
\left.\begin{array}{rl}
\left(\frac{s_{\mathrm{utc}}}{\sigma_{\mathrm{vo}}{ }^{\prime}}\right)_{K_{0}} & \approx \frac{\sin \phi_{\mathrm{tc}}}{2 a}\left(\frac{a^{2}+1}{2}\right)^{\wedge} \\
a & =\frac{3-\sin \phi_{\mathrm{tc}}}{2\left(3-2 \sin \phi_{\mathrm{tc}}\right)}
\end{array}\right\}
$$

For $\Lambda=0 \cdot 8$, this expression has been plotted in Fig. 7 as the lower curve marked $K_{0} \mathrm{TC}$.

There is a substantial difference between the two curves, especially for higher friction angles, so that it is important when undrained strength ratios obtained in triaxial tests are quoted that it is clearly stated whether the specimens were initially isotropically or anisotropically consolidated. This distinction is important for all real soils, even if the idealized model of modified Cam clay is not deemed to be relevant.

\section{Overconsolidated specimens}

The undrained strength ratio for overconsolidated specimens is fully specified by CSSM theory and has been expressed by equation (24), i.e.

$$
\frac{s_{\mathrm{utc}}}{\sigma_{\mathrm{v} 0}^{\prime}}=\frac{M}{2}\left(\frac{R}{r}\right)^{\wedge}
$$

The fact that all the effective stress paths in Fig. 6 approach and nearly reach the unique critical state point $\mathrm{C}$ means that this relationship is closely followed by the idealized situation of Loudon's tests on isotropically consolidated specimens of reconstituted kaolin.

For testing its application more widely it is better to normalize the undrained strength ratio in the form

$$
\frac{s_{\mathrm{utc}} / \sigma_{\mathrm{vo}}{ }^{\prime}}{\left(s_{\mathrm{utc}} / \sigma_{\mathrm{vo}}{ }^{\prime}\right)_{\mathrm{nc}}}=R^{\Lambda}
$$

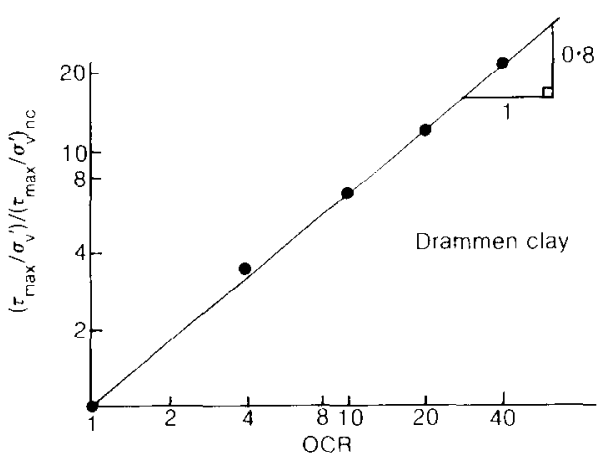

Fig. 8. Variation in the normalized undrained strength ratio with overconsolidation ratio for Drammen clay in simple shear (data from Andresen et al., 1979) which has the advantage of being independent of both the frictional coefficient $M$ and the spacing ratio $r$. This is a powerful relationship well supported by various sets of data, each of which refers to one type of test on one particular clay.

The most comprehensive sets of tests have been carried out at the Massachusetts Institute of Technology where direct simple shear tests have been conducted on a range of clays in the Geonor apparatus (Ladd \& Edgers, 1972). During such a test the maximum value of shear stress applied to the specimen, $\tau_{\max }$, is observed. The specimens have necessarily been consolidated one dimensionally so that the directly analogous expression to equation (28) is

$$
\frac{\tau_{\max } / \sigma_{\mathrm{vo}}{ }^{\prime}}{\left(\tau_{\mathrm{max}} / \sigma_{\mathrm{vo}}\right)_{\mathrm{nc}}}=(\mathrm{OCR})^{\wedge}
$$

The results of tests carried out on Drammen clay at the Norwegian Geotechnical Institute by Andresen, Berre, Kleven \& Lunne (1979) have been replotted in Fig. 8 with both variables plotted with logarithmic scales. These data have been used because the tests are the only ones known to have included specimens with values of OCR as high as 40. Equation (29) suggests that the results should lie on a straight line with gradient $\Lambda$, which is indeed the case with $\Lambda \approx$ $0 \cdot 8$.

Similar data for seven different clays assembled by Ladd \& Edgers (1972) werc presented in the state of the art report by Ladd, Foott, Ishihara, Schlosser \& Poulos (1977) at the International Conference on Soil Mechanics and Foundation Engineering at Tokyo. The bounds to those curves are presented in Fig. 9 in which the

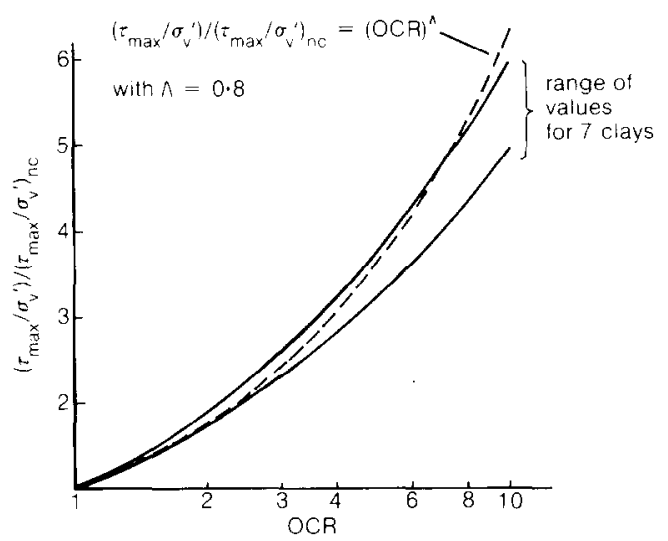

Fig. 9. Variation in the normalized undrained strength ratio with the overconsolidation ratio for various clays in simple shear (data from Ladd \& Edgers, 1972) 
Table 1. Values of exponent $r$ for equation (30) for five clays (data from Ladd \& Edgers, 1972)

\begin{tabular}{l|c|c|c|c}
\hline & LL: $\%$ & PL:\% & OCR $<7$ & All OCR \\
\cline { 3 - 4 } & & & $m_{1}$ & $m_{2}$ \\
\hline Boston blue clay & & 20 & $0 \cdot 802$ & $0 \cdot 776$ \\
Maine organic clay & 41 & 31 & $0 \cdot 866$ & $0 \cdot 802$ \\
Bangkok clay & 65 & 24 & $0 \cdot 800$ & $0 \cdot 767$ \\
Atchafalaya clay & 65 & 20 & $0 \cdot 799$ & $0 \cdot 795$ \\
Connecticut valley varved clay & 65 & 26 & $0 \cdot 752$ & $0 \cdot 685$ \\
\hline
\end{tabular}

LL, liquid limit; PL, plastic limit.

normalized undrained strength ratio is plotted with an arithmetic scale, but the overconsolidation ratio has a logarithmic scale.

Ladd et al. (1977) suggest that the data can be well defined by the expression (using their symbols)

$$
\frac{\left(c_{\mathrm{u}} / \sigma_{\mathrm{vo}}{ }^{\prime}\right)_{\mathrm{oc}}}{\left(c_{\mathrm{u}} / \sigma_{\mathrm{vo}}\right)_{\mathrm{nc}}}=(\mathrm{OCR})^{\mathrm{m}}
$$

'with $m=0 \cdot 8$, though a better fit is obtained if $m$ is decreased from 0.85 to 0.75 with increasing OCR'. Their finding, which was solely based on empiricism, is confirmed by the CSSM theory. Moreover CSSM theory relates the exponent $m$ with well-recognized physical properties of the clay in question by stipulating that $m \equiv \Lambda$, the plastic volumetric strain ratio.

The original data from the report by Ladd \& Edgers (1972) have been replotted in the manner of Fig. 8, and a least-squares regression analysis has been performed to find the best fit of a straight line to each set of data. As Ladd has pointed out, the data do not lie perfectly on a straight line in this plot, but consistently on a shallow convex curve such that a reduced value of $m$ is required for large values of overconsolidation. Accordingly a distinction has been made between excluding all tests with $O C R \geqslant 7$ and obtaining a value for $m=m_{1}$, say, and including all data and obtaining a lower value of $m=m_{2}$. The corresponding values of the gradients $m_{1}$ and $m_{2}$ for the five clays (with sufficient data) are recorded in Table 1; the Boston blue clay was reconstituted, the other four undisturbed.

The importance of the relationship in equation (29) is that if the undrained strength ratio of a clay can be measured or estimated for a normally consolidated specimen then its value can be predicted for other specimens of the clay provided that the degree of overconsolidation is known. This point is returned to later.

\section{RANGE OF IN SITU TESTS}

A good indication of the wide variety of in situ tests that have been developed is provided by Table 2 . This table is taken from a report by Campanella \& Robertson (1983) which forms part of a comprehensive state of the art review of in situ testing. The tests have been listed by the authors in what they consider to be an ascending order of cost and/or complexity.

The list is by no means exhaustive, omitting for example

(a) push-in pressuremeter (Henderson, Smith \& St John, 1979)

(b) push-in spade-shaped pressure cell (Tedd \& Charles, 1981)

(c) self-boring permeameter (Baguelin, Jézéquel \& Le Mehaute, 1974)

(d) self-boring plate test (Mori, 1983)

(e) electrical conductivity probe (Arulanandan, 1977).

More attention deserves to be paid to various in situ geophysical tests. Pile load tests should also be considered to be a special form of in situ tests; more information could be obtained about the elastic properties of the ground by careful observations during the unloading of the test pile.

The compilers of the table have given their views of the applicability of each test for deducing a variety of soil properties. The two instruments that have the best ratings by far are the self-boring pressuremeter and the piezocone (with friction sleeve). The interpretation of typical results from each instrument is discussed in the following sections.

\section{THE SELF-BORING PRESSUREMETER}

The pressuremeter was first conceived by Ménard in 1954 , as a tool which was inserted into a preformed borehole and used for the measurement of the strength and stiffness of soils and rocks. Since Ménard's pioneering work there have been many major developments in the pressuremeter, especially in the last 15 years, which can be conveniently divided into four categories:

(a) techniques of measurement

(b) techniques of insertion

(c) new analyses of the expansion test

(d) new types of test. 
Table 2. Perceived applicability of in situ test methods-update 1982 (after Campanella \& Robertson, 1983)*

\begin{tabular}{|c|c|c|c|c|c|c|c|c|c|c|c|c|c|}
\hline & 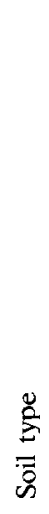 & $\begin{array}{l}\text { D. } \\
\text { D. }\end{array}$ & $\begin{array}{l}0^{-} \\
\frac{2}{0} \\
\frac{2}{0}\end{array}$ & $\begin{array}{l}\theta \\
5 \\
5 \\
0 \\
0 \\
0 \\
0 \\
0 \\
0 \\
0\end{array}$ & 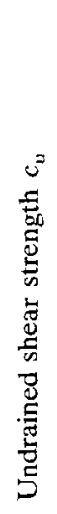 & 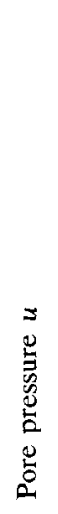 & 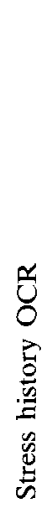 & 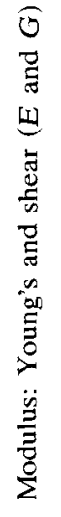 & 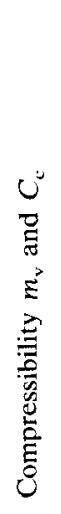 & 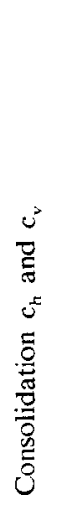 & 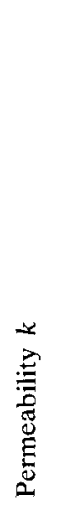 & 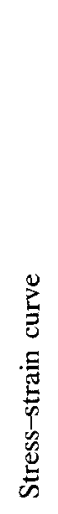 & 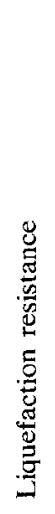 \\
\hline $\begin{array}{l}\text { Dynamic cone } \\
\text { Static cone }\end{array}$ & $\mathrm{C}$ & A & B & $\mathrm{C}$ & $\mathrm{C}$ & - & $\mathrm{C}$ & - & - & - & - & - & $\mathrm{C}$ \\
\hline Mechanical & B & A & $\mathrm{B}$ & $\mathrm{C}$ & B & - & $\mathrm{C}$ & B & $\mathrm{C}$ & - & - & - & B \\
\hline Electrical friction & B & A & $\mathrm{B}$ & $\mathrm{C}$ & $\mathrm{B}$ & - & C & B & $\mathrm{C}$ & - & - & - & $\mathrm{B}$ \\
\hline Electrical piezo & A & A & $\mathrm{B}$ & B & B & A & A & B & B & A & $\mathbf{B}$ & B & A \\
\hline Electrical piezo/friction & A & A & A & B & B & A & A & B & B & A & $\mathbf{B}$ & B & A \\
\hline Acoustic probe & C & B & B & $\mathrm{C}$ & C & - & $\mathrm{C}$ & $\mathrm{C}$ & - & - & - & - & $\mathrm{C}$ \\
\hline Dilatometer & B & A & B & $\mathrm{C}$ & B & - & B & B & C & - & - & C & B \\
\hline Vane shear & B & $\mathrm{C}$ & - & - & A & - & B & & & $\ldots$ & & & $\cdots$ \\
\hline Standard penetration test & B & B & B & $\mathrm{C}$ & $\mathrm{C}$ & - & - & - & $\mathrm{C}$ & - & - & - & A \\
\hline $\begin{array}{l}\text { Seismic cone penetration } \\
\text { test downhole }\end{array}$ & $\mathrm{C}$ & C & C & - & - & - & - & A & - & - & - & B & B \\
\hline$K_{\mathrm{o}}$ blade & - & - & - & - & - & - & B & - & - & - & - & - & - \\
\hline Resistivity probe & B & B & A & $\mathrm{B}$ & $\mathrm{C}$ & - & $\mathrm{C}$ & $\mathrm{C}$ & $\mathrm{C}$ & - & - & $\mathrm{C}$ & A \\
\hline Borehole permeability & $\mathrm{C}$ & - & - & - & - & A & - & - & - & B & A & - & - \\
\hline Hydraulic fracture & - & - & - & - & - & B & B & - & - & $\mathrm{C}$ & $\mathrm{C}$ & - & \\
\hline Screw plate & $\mathrm{C}$ & C & B & C & B & - & B & A & B & C & $\mathrm{C}$ & B & B \\
\hline Seismic downhole & $\mathrm{C}$ & $\mathrm{C}$ & $\mathrm{C}$ & - & - & - & - & A & - & - & - & B & B \\
\hline Impact cone & $\mathrm{C}$ & B & $\mathrm{C}$ & C & $\mathrm{C}$ & - & $\mathrm{C}$ & $\mathrm{C}$ & $\mathrm{C}$ & - & - & - & $\mathrm{C}$ \\
\hline Borehole shear & C & $\mathrm{C}$ & - & B & B & - & $\mathrm{C}$ & $\mathrm{C}$ & - & - & 一 & $\mathrm{C}$ & - \\
\hline Ménard pressuremeter & B & B & $\mathrm{C}$ & B & B & - & $\mathrm{C}$ & B & B & - & - & $\mathrm{C}$ & $\mathrm{C}$ \\
\hline Self-boring pressuremeter & B & B & A & A & A & A & A & A & A & A & $\mathrm{B}$ & A & A \\
\hline Self-boring devices & & & & & & & & & & & & & \\
\hline$K_{0}$ meter & - & - & - & - & - & - & A & - & - & - & - & - & - \\
\hline Lateral penetrometer & $\mathrm{C}$ & $\mathrm{C}$ & B & B & B & - & B & B & $\mathrm{C}$ & - & - & - & - \\
\hline Shear vane & B & $\mathrm{C}$ & - & - & A & - & B & - & - & - & - & - & - \\
\hline Seismic cross-hole & $\mathrm{C}$ & $\mathrm{C}$ & B & - & 一 & - & - & A & - & - & - & B & B \\
\hline Nuclear tests & - & - & A & B & - & - & - & $\mathrm{C}$ & - & - & - & - & $\mathrm{C}$ \\
\hline Plate load tests & $\mathrm{C}$ & $\mathrm{C}$ & $B$ & $\mathbf{B}$ & $\mathrm{C}$ & - & B & A & B & $\mathrm{C}$ & $\mathrm{C}$ & B & $B$ \\
\hline
\end{tabular}

* A, high applicability; B, moderate applicability; C, limited applicability.

In the basic expansion test of the pressuremeter, measurements are made of the pressure and of the increase in volume of the inflatable membrane. In the early equipment used by Ménard these observations were made at the ground surface by monitoring the pressure and volume of the fluid used for inflation. With the development of accurate and reliable electrical transducers placed within the pressuremeter it has been possible to improve the accuracy of these measurements by an order of magnitude or more. For example the feeler gauges incorporated in the Cambridge self-boring pressuremeter are sensitive to movements of the order of $0.005 \mathrm{~mm}$, which is equivalent to less than $0.02 \%$ volumetric strain for an instrument with a diameter of $83 \mathrm{~mm}$ (as in the latest version).

The self-boring pressuremeter has been developed in parallel in France and Britain, where most of the fundamental work has been done at the University of Cambridge by a succession of research students and fully reported in their 
PhD theses: Hughes (1973), Windle (1976), Clarke (1981) and Fahey (1980).

It is presumed that the purpose and details of the self-boring technique are well understood. To minimize the disturbance caused by insertion, various studies have been carried out of the degree of disturbance created by different modes of operation and design of equipment. The geometrical arrangement of the cutting shoe and cutting tool is crucial. Recent work by Clarke (1981) suggests why the push-in pressuremeter may prove to be a successful compromise for offshore use between the complex self-boring pressuremeter and the cruder Ménard instrument.

Initially, the results of pressuremeter tests were interpreted by means of empirical expressions to give parameters for design such as allowable bearing capacity factors and moduli for allowable settlement. The first fundamental interpretation of an expansion test was supplied by Gibson \& Anderson (1961) in which the pressuremeter was considered to be infinitely long so that the deformation of the surrounding soil was assumed to be in conditions of axial symmetry and plane strain. One analysis was applicable to undrained expansion tests in clay in which the soil is assumed to undergo zero volume change and to behave as an elasticperfectly plastic material characterized by a shear modulus $G$ and an undrained shear strength $s_{\mathrm{u}}$. A separate analysis was achieved for expansion tests in cohesionless soils for which the soil is assumed to behave elastically until failure occurs at a constant effective stress ratio (governed by the Mohr-Coulomb criterion in terms of a friction angle $\left.\phi^{\prime}\right)$ and with no volume change.

Both of these analyses have been improved. The undrained expansion test can now be interpreted with no prerequisite assumption of stress-strain properties of the soil being tested, as a result of work independently done by Baguelin, Jézéquel, Le Mée \& Le Mehaute (1972), Ladanyi (1972) and Palmer (1972). Unfortunately the interpretation is very sensitive to the disturbance of the soil caused by insertion and to the datum selected for the strain.

The second case, the drained expansion test in a cohesionless material, has been modified by Hughes, Wroth \& Windle (1977) to take account of the volume change that occurs after failure has been initiated. The relevance of this new analysis has been confirmed by Fahey (1980) by a special series of laboratory tests under carefully controlled conditions.

To date most pressuremeter tests have consisted of a rapid expansion test either conducted with stress increments applied at regular intervals or under constant rates of strain. With the advent of microprocessors and computercontrolled experiments, as well as additional observations, e.g. pore pressure measurements, it is now possible to carry out new types of test. One such possibility is a 'holding' test for measuring in situ the consolidation characteristics of the soil being tested. Clarke, Carter \& Wroth (1979) report the results of such holding tests in which a quick undrained expansion test in a clay to, say, $10 \%$ strain is followed by a phase when the membrane is kept automatically at its (enlarged) radius by adjustment of the applied pressure. During this phase the clay undergoes consolidation with a reduction in the total radial stress and excess pore pressure, both of which are continuously recorded. The coefficient of consolidation can be deduced from the results.

\section{Good quality pressuremeter test in clay}

In this and the next section examples are given from one site of two good quality pressuremeter tests, one in clay and one in sand. The site is part of the outer harbour at Zeebrugge where it was planned to construct large storage tanks for liquefied natural gas. As part of the overall site investigation, PM Insitu Techniques Ltd were commissioned by Distrigas $\mathrm{NV}$ to carry out a profile of self-boring pressuremeter tests; the work was supervised by Tractebel $\mathrm{Z}$ acting as engineers.

The soil profile at this site consists of hydraulic-pumped fill to a depth of $15 \mathrm{~m}$, quaternary formations consisting mainly of sands from $15 \mathrm{~m}$ to $33 \mathrm{~m}$, Bartoon clay from $33 \mathrm{~m}$ to $46 \mathrm{~m}$ and below this Pamiselian deposits, predominantly sandy soils.

The self-boring pressuremeter cannot be drilled through soil containing hard inclusions, such as sandstone layers and gravel which occur at this site. It cannot be drilled continuously through sand deposits as it leaves an unsupported borehole which may collapse and make extraction of the instrument difficult if not impossible.

On this site it was therefore necessary to use a drilling rig to provide a borehole which would not collapse and to cope with hard inclusions. The borehole was drilled and cased using a shell and auger rig to a depth of $1 \mathrm{~m}$ above the level of a proposed test position. The self-boring pressuremeter was lowered down the borehole and drilled beyond the bottom of the casing to at least $1 \mathrm{~m}$ into material presumed to be undisturbed. A pressuremeter test was carried out. In certain instances it was possible to advance the 
self-boring pressuremeter $1 \mathrm{~m}$ further and to carry out a second test. The self-boring pressuremeter was withdrawn from the borehole so that the hole could be drilled further by the shell and auger rig. The one borehole was terminated at a depth of $88 \mathrm{~m}$ and included 24 pressuremeter tests.

The results of a pressuremeter test in clay at a depth of $43.4 \mathrm{~m}$ are reproduced in Fig. 10. The readings arc automatically recorded on site both on magnetic disc and as a hard copy on paper, and subsequently processed and plotted by computer. The pressure $\psi$ applied to the inside of the membrane is plotted against the cavity strain $\varepsilon$ which is the observed expansion of the membrane divided by its initial radius $a_{0}$. The pressure $\psi$ has been corrected for the (small) strength of the membrane itself, represented by the difference between the ordinates of points $O$ and $I$.

At the start of the expansion test the membrane fits tightly over the body of the instrument and has the same diameter as the cutting shoe. In theory no expansion of the membrane should be detected until the applied pressure $\psi$ is equal to the in situ total lateral stress in the ground in contact with the pressuremeter. In reality there will be some small compliance of the instrument itself, until at point $A$ (the lift-off pressure), on the expansion curve, the soil starts to deform under increasing lateral stress.

It is usually assumed (both for convenience

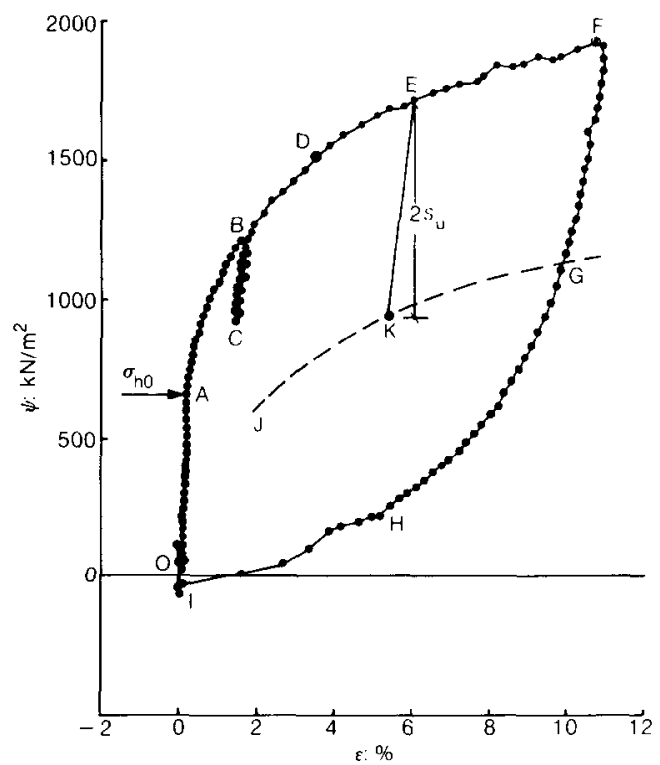

Fig. 10. Results of a pressuremeter test in Bartoon clay, Zeebrugge and for lack of better information) that the lateral stress in the ground is the same in all horizontal directions; this is unlikely to be the case except in very homogeneous deposits subject solely to one-dimensional consolidation during their geological history.

The Cambridge self-boring pressuremeter has three separate feeler arms for measurement of the movement of the membrane, which are symmetrically disposed at $120^{\circ}$ around the section of the instrument. By careful scrutiny at suitably large scale of separate plots of $\psi$ against each of the values of $\varepsilon$, three separate estimates of the in situ total lateral stress can be obtained (on the presumption that there has been negligible disturbance of the ground during insertion of the pressuremeter). The results in Fig. 10 are for one of the three feeler arms and indicate a value of $\sigma_{\mathrm{h} 0}$ of $646 \mathrm{kN} / \mathrm{m}^{2}$. The measurement of in situ lateral stress by the self-boring pressuremeter is discussed in detail by Ghionna, Jamiolkowski \& Lancellotta (1982) and by Lacasse \& Lunne (1982a).

In the original analysis of Gibson \& Anderson (1961) for the interpretation of an undrained pressuremeter test in clay, it was assumed that the clay behaves as a perfectly elastic-perfectly plastic material characterized by a shear modulus $G$, Poisson's ratio $\nu=0 \cdot 5$ and an undrained shear strength $s_{u}$. The analysis leads to the result that, after failure has been initiated in the clay, the applied pressure $\psi$ is linearly related to the logarithm of the current volumetric strain $\Delta V / V$. Moreover, if natural logarithms are used the gradient of the line will be equal to the undrained shear strength, denoted here by $s_{\mathrm{upm}}$.

The field results of the pressuremeter test of Fig. 10 have been replotted in Fig. 11 in the

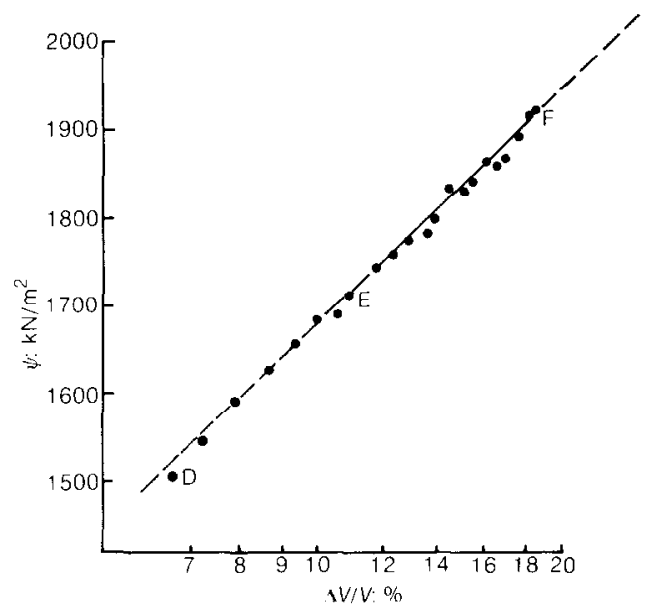

Fig. 11. Processed results of a pressuremeter test in Bartoon clay 
above manner as $\psi$ against $\log (\Delta V / V)$. Note that the volumetric strain is directly related to the observed strain by the relationship

$$
\Delta V / V=1-(1+\varepsilon)^{-2}
$$

The points $D, E$ and $F$ correspond to those selected in Fig. 10. The results lie remarkably close to a straight line, and that selected has a gradient $s_{\mathrm{upm}}=386 \mathrm{kN} / \mathrm{m}^{2}$. The newer and superior analysis of Baguelin et al. (1972), Ladanyi (1972) and Palmer (1972) does not require an assumption to be made about the stress-strain behaviour of the soil. It leads to the result that the local gradient of the curve drawn through the points in Fig. 11 is the shear stress corresponding to the shear strain experienced at that stage of the test by the clay in contact with the pressuremeter. The fact that the curve is so close to a straight line vindicates the assumption implicit in the Gibson-Anderson analysis that the clay behaves as a perfectly elastic-perfectly plastic material.

From experience gained at a large number of sites it is believed that the Gibson-Anderson analysis is satisfactory for design in geotechnical engineering and that the extra sophistication of the 1972 analysis is not warranted, particularly because it is so sensitive to the choice of datum. General experience from a large number of sites indicates that the in situ undrained shear strength obtained in pressuremeter tests is consistently greater than corresponding values from the vane shear test, cone penetrometer test and plate bearing test. This finding is discussed by Mair \& Wood (1984) who cite examples quoted by Hughes, Wroth \& Pender (1975), Windle \& Wroth (1977) and Ghionna, Jamiolkowski, Lacasse, Lancellotta \& Lunne (1983).

The shear modulus of the clay can be measured by arranging for an unloading-reloading cycle such as $\mathrm{BCB}$ to be included in the expansion test. If the clay behaves as a perfectly elastic material in unloading then $\mathrm{BC}$ will be a straight line of gradient $2 G$ (using small strain theory). It should be noted that the cycle BCB is markedly linear with very small hysteresis, and gives a value of the shear modulus $G=$ $47 \mathrm{MN} / \mathrm{m}^{2}$.

In carrying out such an exercise care must be taken not to exceed the elastic limit of the clay during the unloading phase; this restricts the amplitude of the stress cycle that can be applied. For the ideal elastic-plastic material the allowable amplitude is twice the undraincd shear strength, as shown by Wroth (1982).

It is therefore possible to construct a curve such as JKG in Fig. 10, which serves as a

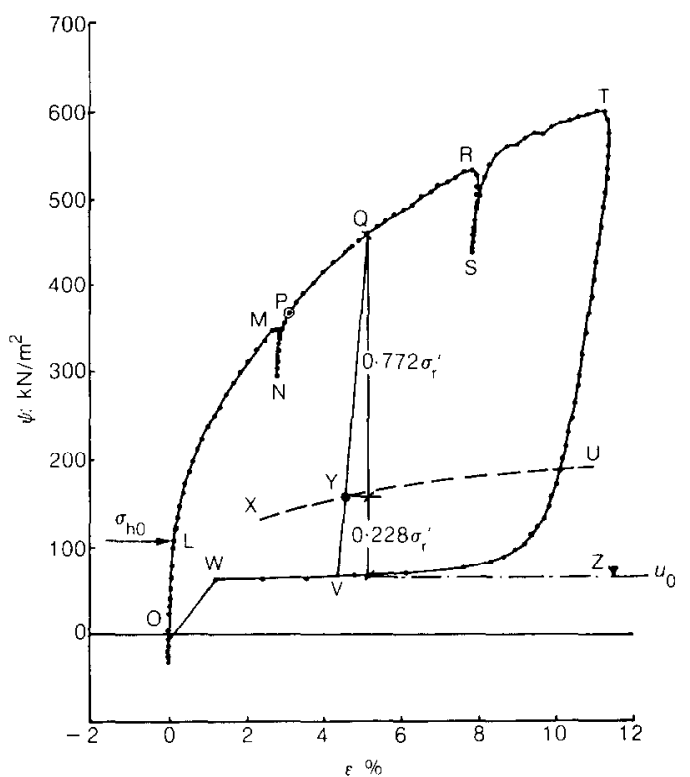

Fig. 12. Results of a pressuremeter test in sand at Zeebrugge

theoretical boundary to the elastic behaviour in unloading. It should be noted that this boundary fits well with the extent of the linear portion of the final unloading part of the test FGHI.

\section{Good quality pressuremeter test in sand}

The results of a pressuremeter test in sand (in the same borehole as that for the test in clay) at a depth of $10.6 \mathrm{~m}$ are reproduced in Fig. 12 . The shape of the curve is different from that of the test in clay of Fig. 10, both in the loading portion MPQRT and in the final unloading portion TUVW. This difference is always observed in good quality tests and can be used as an indicator of the material tested. It can be represented numerically by the factor $\beta$ defined as (Baguelin, 1982)

$$
\beta=\frac{p_{20}-p_{5}}{p_{20}-p_{0}}
$$

where $p_{0}, p_{5}$ and $p_{20}$ are respectively the applied pressure at $0 \%, 5 \%$ and $20 \%$ volumetric strain. Noting that the volumetric strain is approximately twice the plotted strain $\varepsilon$, the value of $\beta$ for the clay in Fig. 10 is 0.45 , whereas that for the sand in Fig. 12 is $0 \cdot 51$.

The same method as that outlined previously can be used for an assessment of the in situ lateral total stress. When the results of Fig. 12 are plotted to a larger scale, the lift-off pressure is given by the point $L$, i.e. a stress of $107 \mathrm{kN} / \mathrm{m}^{2}$. 


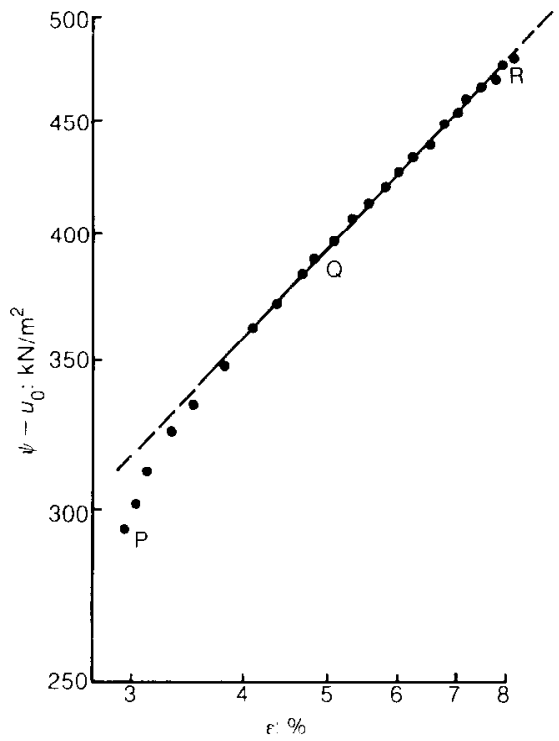

Fig. 13. Processed results of a pressuremeter test in sand at Zeebrugge

In the test on a cohesionless material which is sufficiently permeable, the final part of the unloading curve VW provides valuable information about ground conditions. As the membrane is deflated, ultra-loose sand collapses into the enlarged borehole under very small effective stresses. In the extreme condition at $\mathrm{W}$, the membrane is being pushed back to its initial size by the action of the groundwater, and the pressure recorded inside the membrane is a measure of the ambient pore pressure $u_{0}$ given by the horizontal tangent WVZ. (Note that point $\mathrm{W}$ is the last one automatically recorded during the test, and the computer when producing the plot of Fig. 12 has inappropriately drawn the chord WO instead of continuing the line $\mathrm{VW}$ back to zero strain.)

The value of $u_{0}$ is $62 \mathrm{kN} / \mathrm{m}^{2}$ corresponding to a water-table at a depth of $4.3 \mathrm{~m}$. The watertable in the hydraulic fill was observed to fluctuate between wide limits as the tide level varied. With the estimate that the total vertical stress, at the test depth of $10.6 \mathrm{~m}$, is $160 \mathrm{kN} / \mathrm{m}^{2}$, this suggests a value of the coefficient of earth pressure at rest, $K_{0}$, to be $(107-62) /(160-$ $62)=0 \cdot 46$.

In the analysis of I Iughes, Wroth \& Windle (1977) for the interpretation of a drained pressuremeter test in sand, it is assumed that the sand behaves elastically before failure and fails at a constant ratio of effective stresses and at a constant rate of dilation. The analysis leads to the result that, after failure has been initiated in the sand, the logarithm of the effective radial stress $\psi-u_{0}$ is linearly related to the logarithm of the strain $\varepsilon$; the gradient of the line $s$ is given by the expression

$$
s=\frac{\sin \phi^{\prime}(1+\sin \nu)}{1+\sin \phi^{\prime}}
$$

where $\phi^{\prime}$ is the angle of internal friction and $\nu$ is the angle of dilation.

The field results of the pressuremeter test of Fig. 12 for the range PQR have been plotted in this manner in Fig. 13. They approximate to a linear relationship whose gradient $s=0 \cdot 425$. The adoption of a value of $35^{\circ}$ for the critical state angle of friction at constant volume gives a value of $\phi^{\prime}=39^{\circ}$ and $\nu=9 \cdot 5^{\circ}$ (see Hughes et al., 1977).

The shear modulus of the sand can be measured in the same way as that for the clay, by carrying out small unloading-reloading cycles such as MN and RS in Fig. 12. The corresponding value of the shear modulus for cycle $\mathrm{MN}$ is $31 \mathrm{MN} / \mathrm{m}^{2}$.

As for the clay there is a limit to the elastic range of behaviour during unloading. For the idealized sand behaviour used in the analysis, the allowable amplitude of the stress cycle QY is

$$
\left(\frac{2 \sin \phi^{\prime}}{1+\sin \phi^{\prime}}\right) \sigma_{\mathrm{r}}^{\prime}
$$

as illustrated in Fig. 12 (Wroth, 1982).

It is therefore possible to construct a curve, such as XYU in Fig. 12, which serves as a theoretical boundary to the elastic behaviour in unloading. This has been based on the observed value of $\phi^{\prime}=39^{\circ}$ to give ratios of 0.772 and 0.228 used in the plot. It should be noted that $\sigma_{r}{ }^{\prime}$ varies with the stage of the test so that the distance QY would not be the same if $Q$ were to be chosen elsewhere on the virgin loading curve; care must be taken to subtract the ambient pore pressure $u_{0}$ from the applied pressure $\psi$ to give the relevant value of $\sigma_{r}^{\prime}$ acting on the sand which is in contact with the membrane. The theoretical boundary fits well with the extent of the linear portion of the final unloading part of the test TUVW.

\section{Correlation of undrained shear strength}

The interpretation of undrained shear strength from pressuremeter tests in terms of effective stresses is uncertain with the present state of knowledge. This is because there have been very few attempts to test soil under the relevant combination of consolidation and subsequent shearing. 
To study the pressuremeter expansion test in the laboratory by testing single elements of soil, it is necessary to be able to apply to the element the strain path to which the soil elements in the field are subjected. This strain path involves one-dimensional consolidation followed by shearing under conditions of plane strain, at constant volume, in the plane perpendicular to the direction of consolidation. True triaxial devices are the only types of apparatus that can apply this complete strain path in one continuous operation without the need for unloading, trimming and reorientating the sample.

A limited number of such tests has been reported by Wood \& Wroth (1977), Wood (1981) and Eden \& Law (1980); the results have been compared with those computed from various generalized stress-strain models of soil behaviour, none of which proved to be satisfactory.

For example, one approach is to use the modified Cam clay model, adapted for plane strain conditions, and to dcrive for the undrained strength ratio for anisotropically normally consolidated specimens (see Appendix 2)

$$
\frac{s_{\mathrm{ups}}}{\sigma_{\mathrm{v} 0}{ }^{\prime}} \approx \frac{\sin \phi_{\mathrm{ps}}}{2 c}\left(\frac{c^{2}+1}{2}\right)^{\wedge}
$$

where $c=1 /\left(2-\sin \phi_{\mathrm{ps}}\right)$. This expression fits data of conventional plane strain active tests satisfactorily, e.g. for Boston blue clay, taking $\phi_{\mathrm{tc}}=30^{\circ}$ gives $\phi_{\mathrm{ps}}=33.75^{\circ}, \quad c=0.6923$ and $s_{\mathrm{ups}} / \sigma_{\mathrm{v} 0}{ }^{\prime}=0.315$ which compares with an average value of 0.338 from the results reported by Ladd \& Edgers (1972). However, if this expression is applied to the simulated pressuremeter tests conducted in the true triaxial apparatus on kaolin by Wood then the predictions are not satisfactory. Wood \& Wroth (1977) quote a value of $\phi_{\mathrm{ps}}=26^{\circ}$ which corresponds to $c=$ 0.640 and $s_{\text {ups }} / \sigma_{v 0}{ }^{\prime}=0.259$, whereas the observed value of $s_{\text {ups }} / \sigma_{\mathrm{vq}}{ }^{\prime}$ was as low as $0 \cdot 179$. Clearly the use of the plane strain version of the modified Cam clay model is inappropriate for modelling the data from pressuremeter tests.

Apart from a lack of success in the mathematical modelling of those laboratory tests which simulate pressuremeter tests, there are important differences between the single-element tests conducted under ideal conditions in the laboratory and pressuremeter tests carried out in the field.

The most important difference is that in the ground around the pressuremeter the fields of stress and strain do not remain homogeneous during an expansion test, with the consequence that there are high gradients of excess pore pressure in the radial direction, so that some partial consolidation will occur in a supposedly undrained test. To minimize this effect, most pressuremeter tests are conducted quickly and at strain rates much faster than those normally used in conventional laboratory tests. This, in turn, introduces another undesirable effect in the influence of strain rate on undrained shear strength due solely to increased 'viscosity' which is entirely separate from consolidation effects. Because of the inhomogeneity of stress and strain, the various annuli of soil arounu a pressuremeter experience different rates of strain, so that it is not possible to make a direct allowance for the higher strain rates used in the field.

The arguments about partial consolidation in a pressuremeter test can be illustrated qualitatively in Fig. 14 by considering what would happen in a test on an idealized soil which is elastic-plastic but obeys the Mohr-Coulomb failure criterion. Fig. 14(a) represents a section of the ground perpendicular to the axis of the pressuremeter showing the radial distribution of excess pore pressure given by the curve FH assuming that no consolidation occurs. Figs 14(b) and 14(c) show the effective and total stress paths, and the stress-strain response of elements of soil D, E, F and G at different radial distances from the pressuremeter. The points with suffix 1 relate to theoretical stress states with no consolidation, whereas those with suffix 2 relate to the more realistic situation in which some consolidation has taken place. The important point is that the partial consolidation means that the effective stress states $D_{2}^{\prime}$ and $E_{2}^{\prime}$ move up the effective stress failure envelope, and the corresponding soil elements are failing under continually increasing shear stress, i.e. the instantaneous value of the so-called undrained shear strength is increasing monotonically throughout the pressuremeter test.

Although the precise details of Fig. 14 are not correct, the principles it contains apply to a real test on a real soil. In the early days of the development of the self-boring pressuremeter an analysis was attempted by Wroth \& Hughes (1972) to interpret a slow expansion test in clay in which full consolidation would occur.

There is no doubt that current practice in the interpretation of rapid pressuremeter tests in clay, which does not allow for the effects either of partial consolidation or of strain rate, leads to overestimates of the undrained shear strength of the undisturbed clay. At present it is not possible to know whether the overestimates are by a margin of $10 \%, 20 \%$ or even $50 \%$, and the margin must be a function of the coefficient of consolidation of the clay in question. There is an urgent 


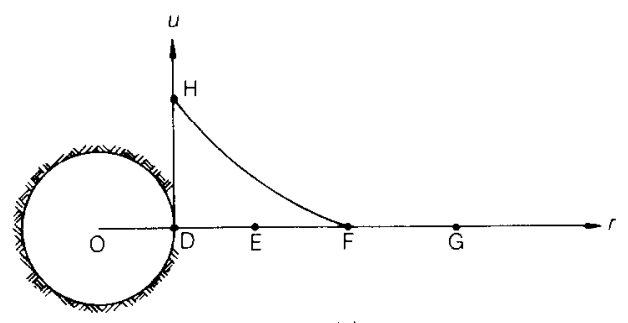

(a)

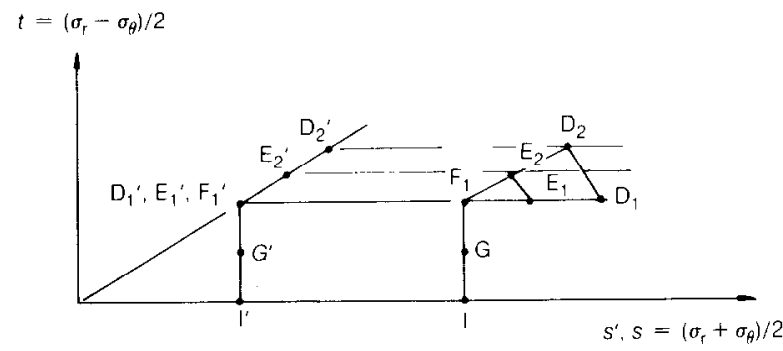

(b)

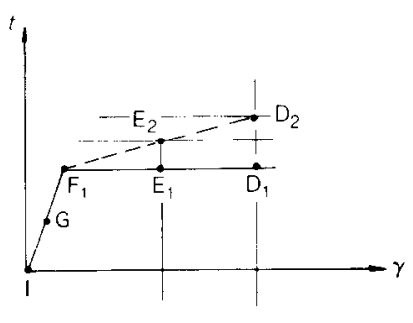

$(c)$

Fig. 14. Changes in the total and effective stress states around a pressuremeter due to partial consolidation during an 'undrained' test

Site near Grangcmouth Test LB1 Depth $1.90 \mathrm{~m}$

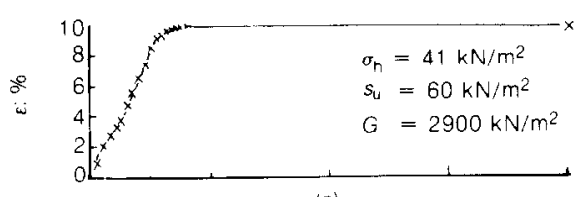

(a)

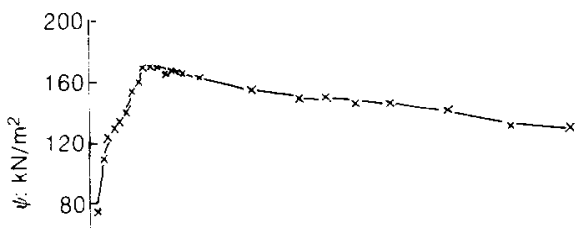

$40 k-$
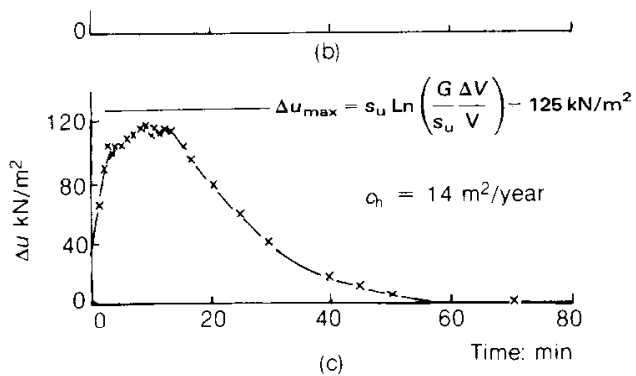

Fig. 15. Typical holding test results (after Clarke $e t$ al., 1979) need for research to be carried out to resolve these uncertainties.

\section{Holding test}

A typical set of results from a holding test carried out in soft clay at a site near Grangemouth is shown in Fig. 15 in which the observed quantities $\varepsilon, \psi$ and $\Delta u$ are plotted against time, where $\Delta u$ is the excess pore pressure measured at the membrane-soil interface.

The initial part of the holding test is carried out in the same manner as an undrained pressuremeter test with a rate of cavity strain of about $1 \%$ per minute. By using the method of interpretation already outlined the values of $\sigma_{\mathrm{h} 0}$, $s_{\mathrm{u}}$ and $G$ can be determined. As well as being important in its own right for design, the value of $s_{u}$ is necessary for the interpretation of the subsequent consolidation data and the rigidity index $G / s_{\mathrm{u}}$ allows a check to be made on the excess pore pressure generated during the expansion phase of the test.

At about $9 \cdot 5 \%$ strain the rate of straining is gradually reduced to zero over about $30 \mathrm{~s}$. The membrane is then held fixed at this inflated radius until completion of the test by automatic reduction of the internal pressure $\psi$ to match the reduction in external total radial stress as consolidation occurs in the surrounding soil. Careful monitoring of the decay of pore pres- 
sure allows an estimate to be made of the consolidation characteristics of the soil.

To interpret the data from a holding test a mathematical solution is required for this particular boundary value problem. In addition to the assumptions for an undrained expansion test in clay, it is assumed that during consolidation movements of the soil skeleton and flow of porewater will be entirely radial.

It has been shown (Gibson \& Anderson, 1961) that the maximum excess pore pressure after undrained cavity expansion occurs at the membrane-soil interface and has a value

$$
\Delta u_{\max }=s_{\mathrm{u}} \ln \left(\frac{G}{s_{\mathrm{u}}} \frac{\Delta V}{V}\right)
$$

Further, it has been shown that the distribution of excess pore pressure, immediately after expansion, is logarithmic with radius within the zone of yielded soil and is zero in the outer elastic region.

Numerical solutions for the consolidation of an elastic, perfectly plastic soil around an expanded cylindrical cavity have been obtained (Carter, Randolph \& Wroth, 1979). These indicate that the total membrane pressure will decrease gradually once membrane expansion stops and as the soil consolidates. This feature is also observed in the field, e.g. see Fig. 15(b).

In principle, it would be possible to use the rate of decay of this total pressure to provide a measure of the horizontal coefficient of consolidation of the soil, $c_{\mathrm{h}}$. However, the magnitude of this pressure drop is not usually large and a more accurate measure of $c_{\mathrm{h}}$ can be obtained by monitoring the dissipation of the excess pore pressure at the membrane-soil interface.

A closed form solution for the time dependence of the excess pore pressures around driven piles, but also relevant to the pressuremeter problem, has been found by Randolph \& Wroth (1979). They assumed that the soil behaves entirely elastically during consolidation. Subsequently, it has been shown that the solution for an elastic soil is sufficiently accurate for an elasto-plastic soil (Carter, Randolph \& Wroth, 1979).

In Fig. 16 solutions for the time for $50 \%$ consolidation have been plotted against the magnitude of the maximum excess pore pressure $\Delta u_{\max }$ (normalized by $s_{\mathrm{u}}$ ). The non-dimensional time factor $T_{50}$ has been used, where

$$
T_{50}=c_{\mathrm{h}} t_{50} / r_{\mathrm{m}}{ }^{2}
$$

and $t_{50}$ is the real-time interval required for the pore pressure at the membrane to reduce to half its maximum value, $r_{\mathrm{m}}$ is the radius of the

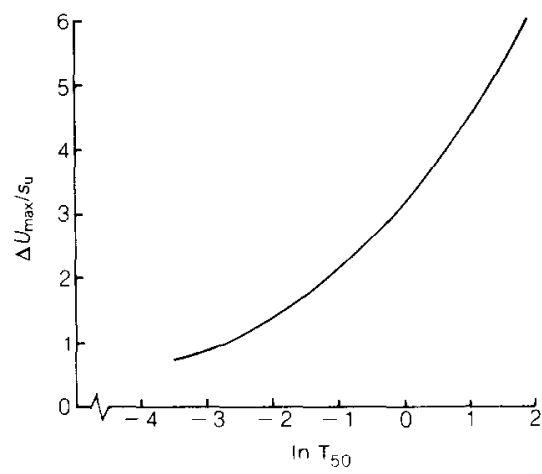

Fig. 16. Time for $50 \%$ pore pressure decay at the membrane-soil interface (after Randolph \& Wroth, 1979)

membrane after expansion and $c_{\mathrm{h}}$ is the horizontal coefficient of consolidation.

The coefficient $c_{\mathrm{h}}$ is related to other soil properties by the equation

$$
c_{\mathrm{h}}=\frac{k_{\mathrm{h}}}{\gamma_{\mathrm{w}}} 2 G \frac{1-\nu^{\prime}}{1-2 \nu^{\prime}}
$$

where $k_{\mathrm{h}}$ is the horizontal permeability of the soil, $\gamma_{w}$ is the unit weight of porewater and $\nu^{\prime}$ is the drained value of Poisson's ratio.

It is possible to fit the theoretical solution for consolidation to the experimental curve of excess pore pressure versus time at the $50 \%$ level. This is directly analogous to the standard laboratory procedure of fitting Terzaghi's solution for one-dimensional consolidation to oedometer results. For example, in Fig. 15(c) the maximum excess pore pressure $\Delta u_{\max }$ is approximately $120 \mathrm{kN} / \mathrm{m}^{2}$ and occurs $10 \mathrm{~min}$ after the start of testing. This excess pore pressure has dropped to half its maximum value $25 \mathrm{~min}$ after the start. Hence the time $t_{50}$ is given by $t_{50}=$ $25-10=15 \mathrm{~min}$. From the expansion portion of this test a value of the undrained shear strength $s_{\mathrm{u}}-60 \mathrm{kN} / \mathrm{m}^{2}$ is deduced in the usual manner (Gibson \& Anderson, 1961). Hence $\Delta u_{\max } / s_{\mathbf{u}}=2$ and a corresponding value of $T_{50} \approx 0.33$ can be read from Fig. 16. The final membrane radius in this test was $r_{\mathrm{m}}=0.0352 \mathrm{~m}$. Thus

$$
\begin{aligned}
c_{\mathrm{h}} & =\frac{T_{50} r_{\mathrm{m}}{ }^{2}}{t_{50}} \\
& \approx \frac{0.33 \times 0.0352 \times 0.0352}{15} \\
& \approx 2.7 \times 10^{-5} \mathrm{~m}^{2} / \mathrm{min} \\
& \approx 14 \mathrm{~m}^{2} / \text { year }
\end{aligned}
$$

Clarke et al. (1979) quote results of holding tests conducted at Canvey Island and make a comparison between values of the coefficient of 


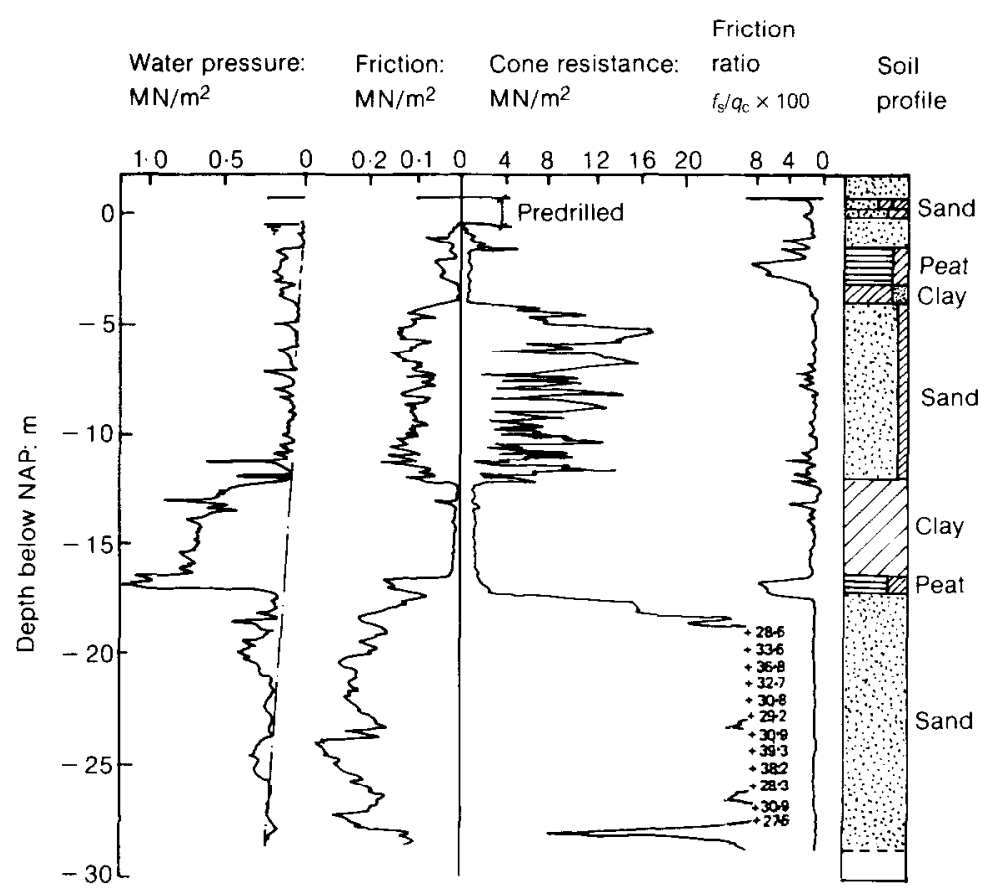

Fig. 17. Results of an onshore piezocone test (after Zuidberg et al., 1982)

consolidation $c_{\mathrm{h}}$ deduced from holding tests with values of $c_{v}$ obtained from conventional oedometer tests; the former values range from a factor of 30 to 300 greater than the latter values. The field values are much more in line with values back calculated from settlement records of engineering structures.

The coefficient of consolidation, or permeability, is an instance of an important soil property where values measured in the laboratory may be seriously misleading and give rise to gross overestimates for times of settlement. It is suggested that the holding test is an important type of pressuremeter test that should be developed. Apart from allowing realistic estimates of consolidation characteristics to be made, it may prove crucial in the interpretation of undrained shear strength to allow for effects of partial consolidation, as discussed in the previous section.

During the past 15 years the self-boring pressuremeter has been developed to the stage where it has become established as a major tool for in situ measurements of the following soil properties: in situ lateral total stress, shear strength, shear modulus and consolidation characteristics. The range of soils and soft rocks in which it can be used has been extended to include boulder clay, loose, dense and weakly cemented sands, and soft rocks such as mudstone, siltstone and chalk.

\section{THE PIEZOCONE TEST}

The basic cone penetrometer test has been used for many years as a standard tool in site investigation especially for establishing quickly and cheaply the soil profile at a particular site. It has grown in importance and acceptance with the recent special needs of offshore site investigation associated with oil exploration.

The first attempts to record porewater pressures during penetration of a probe into the ground were reported separately by Torstensson (1975) and Wissa, Martin \& Garlanger (1975). This pioneering work showed the clear promise of incorporating a pore pressure transducer in a cone penetrometer so that continuous profiles of pore pressure could be obtained at the same time as point resistance of the cone and measurement of sleeve friction. The resulting instrument has become known as the piezocone.

The development since then has been rapid, with a variety of instruments on the market with most applications being offshore. Nearly all instruments have been built to the standard dimensions of the Dutch cone $\left(60^{\circ}\right.$ apex angle and base area $10 \mathrm{~cm}^{2}$ ) but unfortunately the position of the pore pressure transducer has not been standardized. The position has a marked influence on the magnitude of the observations, as discussed later in this section.

Figure 17 shows a typical profile of piezocone 


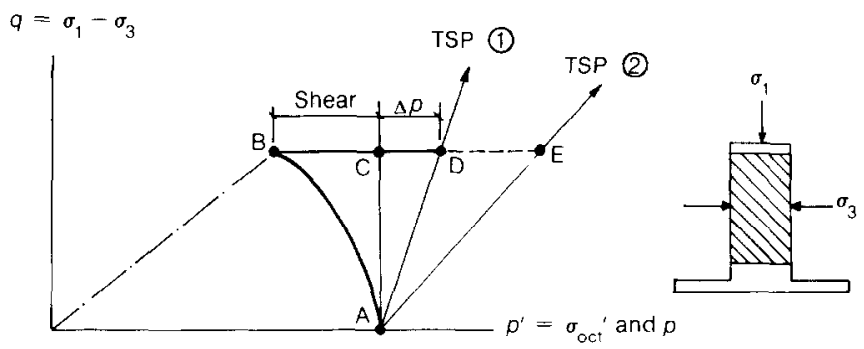

Fig. 18. Interpretation of the excess pore pressures observed in triaxial compression tests

results at an onshore site in the Netherlands reported by Zuidberg, Schaap \& Beringen (1982). The soil profile was obtained from an interpretation of the cone resistance, sleeve friction and friction ratio. In the standard Fugro cone the pore pressure transducer is located half-way up the conical tip. The profile of the pore pressure provides dramatic confirmation of the soil profile. The hydrostatic conditions are shown by the chain-dotted line, so that the offset between that line and the continuous recorded profile represents the excess pore pressure. During penetration of the relatively permeable sand the excess pore pressures are small but just positive, whereas the excess pore pressures recorded in the lower stratum of clay are large and positive. The magnitude of the excess pore pressure is an indication of the type of soil and for clays can be correlated in dimensionless form with the overconsolidation ratio. The sharp fluctuations in the pore pressure act as a sensitive indicator of local variations in the soil such as laminations or fine partings of silt. In special circumstances of a dense cohesionless soil that exhibits dilatancy when sheared the excess pore pressures may be negative; an example of a weakly cemented sand is given by Ventura (1983) and of a silt (after dynamic compaction) by Campanella et al. (1982).

Confirmation of the type of soil can be obtained by stopping penetration of the cone and observing the dissipation of the pore pressure as consolidation occurs, in exactly the same way as a holding test with a pressuremeter.

It is evident that the piezocone provides important data about soil conditions, but at present this is of a qualitative nature. To advance its potential it is necessary to be able to interpret the data in a reliable and consistent quantitative manner. This requires both a standardization of equipment, test procedures and interpretation as well as a clear understanding of soil behaviour and the excess pore pressures generated during shear. To illustrate some essential points reference is made in the next section to basic soil behaviour as observed in triaxial tests. It is suggested that this pattern of behaviour can be used as a framework for the interpretation of data from the piezocone.

\section{Interpretation of pore pressures in the triaxial test}

Consider a saturated specimen of clay that has been isotropically normally consolidated to the stress state represented by point A in Fig. 18. If a conventional undrained triaxial compression test is carried out the effective stress path will be a curve such as $A B$, with the specimen reaching the critical state at $B$ (see for example the data of kaolin in Fig. 6). The total stress path will be the straight line $A D$ which is necessarily of gradient 3 in the chosen stress space. At failure the excess pore pressure generated within the specimen is represented by the difference between the mean total and effective pressures, i.e. the distance BD. This observed magnitude of excess pore pressure is made up of two components: the component $\mathrm{BC}$ due to the response of the clay to the shearing process represented by $\Delta q$ and the component $C D$ due to the change in mean total stress $\Delta p$ applied to the specimen.

If instead an unconventional undrained compression test had been conducted on the specimen such as one with the total stress path $\mathrm{AE}$ (achieved by increasing the cell pressure appropriately as the axial stress is increased) the effective stress path would have remained unchanged as $\mathrm{AB}$. However, the observed magnitude of the excess pore pressure $\mathrm{BE}$ would be greater than the value $B D$ measured in the conventional test. This difference cannot reflect any difference in soil behaviour, but merely provides evidence of the different changes in mean total stress $\Delta p$ in the two tests selected by the operator.

Hence the magnitude of the excess pore pressure measured in a shear test is not a unique property of the soil behaviour but it depends also on the changes in total stress applied externally to the specimen. The first component $\mathrm{BC}$ is a unique property of the soil (when tested in triaxial compression) and can be correlated with 


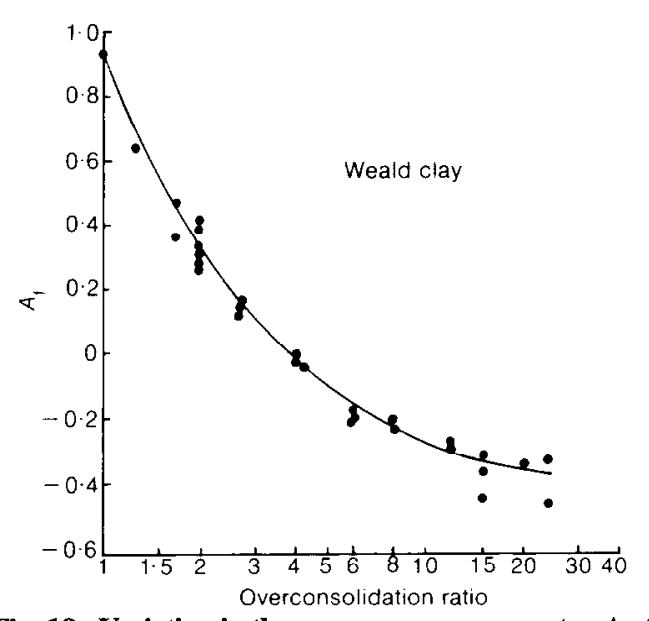

Fig. 19. Variation in the pore pressure parameter $A$ at failure with the overconsolidation ratio for Weald clay (after Bishop \& Henkel, 1957)

other properties of the soil specimen such as its overconsolidation ratio. The second component $\mathrm{CD}$ or $\mathrm{CE}$ gives no information whatsoever about the soil being tested but is just the value of $\Delta p$ experienced by the specimen.

Consequently it is vital in interpreting observations of pore pressure changes to make due allowance for the change in $\Delta p$ which accompanies the application of shear stress. This distinction is normally made in the interpretation of pore pressures observed in triaxial tests.

For a saturated clay the pore pressure parameters originally introduced by Skempton (1954) are such that for triaxial compression tests

$$
A=\frac{\Delta u-\Delta \sigma_{3}}{\Delta \sigma_{1}-\Delta \sigma_{3}}
$$

and $B$ is taken as unity. Essentially the parameter $A$ is a ratio of the pore pressure change to the change in deviator stress, in which allowance has been made in the numerator for any change in cell pressure $\Delta \sigma_{3}$, but not unfortunately for any change in mean total stress $\Delta p$. 'I'his means that the value of $A$ depends on the test conditions as well as soil properties such as the overconsolidation ratio.

To meet this objection Henkel (1960) suggested a revised set of parameters defined so that for a saturated specimen

$$
a=\frac{\Delta u-\Delta \sigma_{\mathrm{oct}}}{\Delta \tau_{\mathrm{oct}}}
$$

where $\Delta \sigma_{\text {oct }} \equiv \Delta p$ is the change in octahedral normal stress (or mean total stress) and $\Delta \tau_{\text {oct }}$ is the change in octahedral shear stress defined as

$$
\tau_{\text {oct }}=\frac{1}{3}\left[\left(\sigma_{2}-\sigma_{3}\right)^{2}+\left(\sigma_{3}-\sigma_{1}\right)^{2}+\left(\sigma_{1}-\sigma_{2}\right)^{2}\right]^{1 / 2}
$$

The concepts of CSSM allow a relationship between $A$ and OCR to be derived as follows. In Fig. 5 the isotropically overconsolidated specimen initially at state $\mathrm{R}$ reaches the critical state at $\mathrm{S}$. For a conventional triaxial compression test in which the cell pressure is kept constant, $\Delta \sigma_{3} \equiv 0$ so that $\Delta p=\frac{1}{3} \Delta q$ and the total stress path is the straight line RT of gradient 3 . The excess pore pressure is given by

$$
\begin{aligned}
\Delta u & =p_{\mathrm{t}}-p_{\mathrm{s}}^{\prime} \\
& =p_{\mathrm{r}}{ }^{\prime}+\Delta p-p_{\mathrm{s}}{ }^{\prime} \\
& =p_{\mathrm{r}}{ }^{\prime}+\frac{1}{3} q_{\mathrm{s}}-p_{\mathrm{s}}{ }^{\prime}
\end{aligned}
$$

Hence the pore pressure parameter $A$ is expressed as

$$
\begin{aligned}
A & =\frac{\Delta u-\Delta \sigma_{3}}{\Delta \sigma_{1}-\Delta \sigma_{3}} \\
& =\frac{\Delta u}{q_{\mathrm{s}}} \\
& =\frac{p_{\mathrm{r}}^{\prime}+\frac{1}{3} q_{\mathrm{s}}-p_{\mathrm{s}}^{\prime}}{M p_{\mathrm{s}}^{\prime}}
\end{aligned}
$$

but using equation (20) this can be written as

$$
A=\frac{1}{M}\left[\left(\frac{R}{r}\right)^{-\Lambda}+\frac{M}{3}-1\right]
$$

which is an expression relating $A$ with the overconsolidation ratio $R$ of the specimen and with the soil properties $\Lambda, M$ and $r$.

The variation in values of $A$ at failure with OCR for remoulded Weald clay reported by Bishop \& Henkel (1957) is reproduced in Fig. 19. The curve drawn by those authors through the experimental points is very closely matched by the prediction of equation (41) with the following values of the soil constants for Weald clay: $\lambda=0.093$ and $\kappa=0.035$ to give $\Lambda=$ $0.6237, M=0.95$ and $r=2$, taken from Table 6.1 of Schofield \& Wroth (1968). The quality of fit should be no surprise, as it is another way of confirming how well a remoulded low plasticity clay, such as Weald clay, tested in triaxial compression after isotropic consolidation satisfies the critical state concept.

The foregoing detailed analysis underlines the important relationship between the two dimensionless quantities, the pore pressure parameter $A$ and the overconsolidation ratio. It suggests 


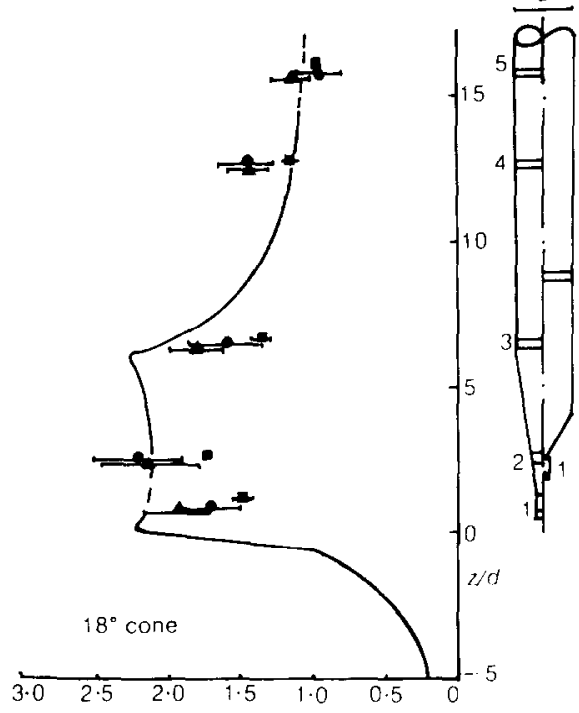

Normalized excess pore pressure $\Delta U_{1} /(\Delta u)_{S H}$

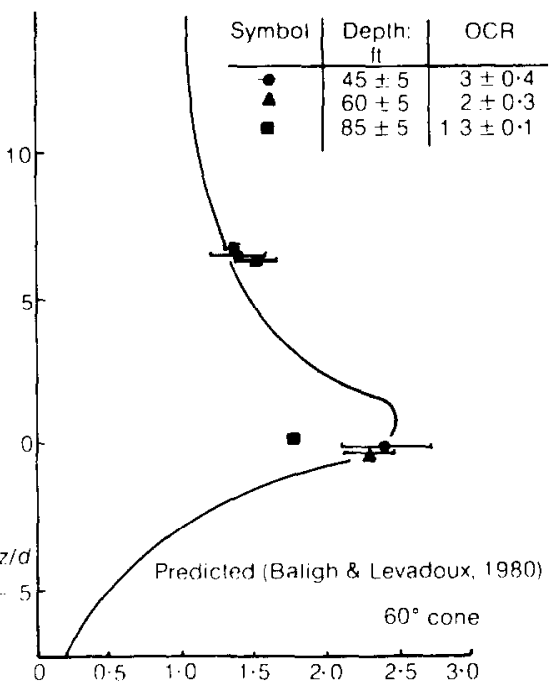

Normalized excess pore pressure $\mathrm{Nu} /(\Delta U)_{S H}$

Fig. 20. Normalized excess pore pressures along the face and shaft of $18^{\nu}$ and $60^{\circ}$ cones during steady penetration in Boston blue clay (after Baligh \& Levadoux, 1980)

that $A$ is linearly related to OCR raised to the power of $-\Lambda$, and further that this can be used as a basis for the interpretation of pore pressure data from tests other than triaxial. This is attempted in the next section.

\section{Interpretation of pore pressures in the piezocone test}

The quantitative and detailed interpretation of the results of conc penetrometer tests has not yet been achieved because of the complex nature of the strain and stress changes induced in the soil around a penetrating cone. The problem has been studied by a number of workers, notably Baligh \& Levadoux (1980), and Fig. 20 is taken from their major report.

In this diagram experimental data are compared with computed results of the distribution of excess pore pressure around a piezocone. The results refer to two different geometries of cone shown in section in the centre of the diagram. The left-hand figure refers to a piezocone with a cone of $18^{\circ}$ apex angle and five separate transducers at the positions indicated. The right-hand figure refers to a piezocone with a standard $60^{\circ}$ cone and two transducers.

The excess pore pressures $\Delta u$ occurring on the boundary of the instrument have been normalized by dividing by the 'steady state' value $\Delta u_{\text {sh }}$ that exists a distance up the shaft of the instrument away from the tip; they are plotted against the axial distance from the tip divided by the shaft diameter.

The value of the excess pore pressure varies markedly with the position of the sensor in relation to the cone. It is important that the position of the sensor should be standardized for all piezocones to optimize the interpretation of data, particularly in view of the uncertainties involved and the unavoidable reliance on empiricism to some extent.

It is tempting to suggest that the sensor should be sited at the tip of the cone where the maximum values of the excess pore pressure occur, but this is not the best position for a number of reasons. Campanella et al. (1982) list several sound practical reasons why the best location is on the shaft (at position such as No. 2 for the $60^{\circ}$ cone on the right-hand side of Fig. 20) rather than on the cone itself. There are three additional and major advantages from a theoretical standpoint in favour of the location on the shaft.

(a) A greater proportion of the excess pore pressure is due to the component induced by shcar compared with the component due to the change in the mean total stress.

(b) The gradients of excess pore pressure with axial distance are smaller, so there is greater accuracy.

(c) The values are less affected by any change in 


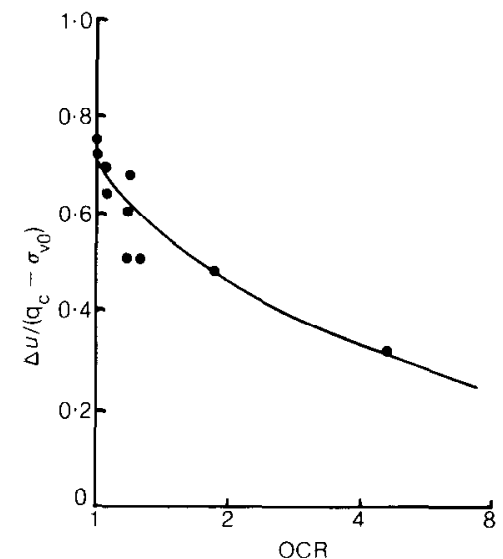

Fig. 21. Variation in the piezocone pore pressure ratio with the overconsolidation ratio at Onsøy

the axial load experienced by the piezocone when the penetration is stopped either for the next drill rod to be added or for a dissipation test to be carried out.

On the basis of the understanding of soil behaviour provided by the long history of experience obtained from high quality triaxial tests, the ideal interpretation of piezocone data would be to derive a pore pressure parameter exactly analogous to Henkel's parameter and to expect this to correlate closely with the overconsolidation ratio, i.e.

$$
a=\frac{\Delta u-\Delta \sigma_{\mathrm{oct}}}{\Delta \tau_{\mathrm{oct}}}=f(\mathrm{OCR})
$$

Unfortunately there is no means of knowing the changes in octahedral normal and shear stresses; indeed, the changes vary spatially around the piezocone and depend on the unknown properties of the soil which is being penetrated.

In place of $a$, a dimensionless parameter is required which must be a ratio of excess pore pressure to some measure of shear stress. Robertson \& Campanella (1983) discuss the ratios that have been used including

(a) $u / q_{\mathrm{c}}$ (Baligh, Azzouz, Wissa, Martin \& Morrison, 1981: Tumay, Bogges \& Acar, 1981)

(b) $\Delta u / q_{\mathrm{t}}$ (Campanella \& Robertson, 1981)

(c) $\Delta u /\left(a_{\mathrm{c}}-u_{0}\right)$ (Smits, 1982)

(d) $\Delta u /\left(q_{\mathrm{c}}-\sigma_{\mathrm{v} 0}\right)$ (Senesset, Janbu \& Svan $\phi$, 1982; Jones \& Rust, 1982; Jefferies \& Funegard, 1983)

where $q_{c}$ is the measured cone end bearing pressure and $q_{t}$ is the corrected end bearing allowing for the effects of pore pressure acting on the back of the cone. Robertson \& Cam- panella (1983) rightly point out the importance of making this correction, especially as it will vary markedly with the precise mechanical design of the piezocone, and with depth below the water-table.

The first three ratios are all unacceptable, the first because it has the total not the excess pore pressure in the numerator, and all three because the denominators cannot be a proper measure of the shear stress. In an undrained situation the maximum shear stress can only be expressed in terms of principal stresses as a difference of two total stresses or a difference of two effective stresses. It is for this reason that the variable $q_{\mathrm{c}}-\sigma_{\mathrm{v} 0}$ and not $q_{\mathrm{c}}$ is used for deriving values of undrained shear strength from cone penetration tests.

The last ratio, $\Delta u /\left(q_{c}-\sigma_{v 0}\right)$, denoted $B_{4}$ by Senneset et al. (1982), is the one recommended, therefore, for adoption as the standard parameter for interpretation of piezocone data. It is assumed that proper calibration and corrections have been made so that $q_{c}$ here replaces $q_{t}$.

There are few reported instances of sites where piezocone data can be correlated with reliable data of OCR. One of the best researched sites is that at Ons $\phi y$ used by the Norwegian Geotechnical Institute. From the information reported by Lacasse \& Lunne (1982b) values of $B_{4}$ have been calculated from the plotted profiles of $\Delta u, q_{\mathrm{c}}$ and $\sigma_{\mathrm{vo}}$ for depths at intervals of $2 \mathrm{~m}$ up to $20 \mathrm{~m}$. These have been plotted in Fig. 21 against the relevant value of OCR taken from the profiles resulting from conventional oedometer tests. The data are given in Table 3.

There is a striking similarity between the results of the piezocone data presented in Fig. 21 and the results of triaxial data in Fig. 19. Indeed, the theoretical background to the triaxial test suggests that $B_{a}$ might vary linearly with OCR raised to the power $-\Lambda$, in a manner

Table 3. Processed data from piezocone tests from Onsøy

\begin{tabular}{r|l|c|c|c|c}
\hline $\begin{array}{c}z: \\
\mathrm{m}\end{array}$ & $\begin{array}{c}\sigma_{\mathrm{vo}}: \\
\mathrm{kN} / \mathrm{m}^{2}\end{array}$ & $\begin{array}{c}q_{c}: \\
\mathrm{kN} / \mathrm{m}^{2}\end{array}$ & $\begin{array}{c}\Delta u: \\
\mathrm{kN} / \mathrm{m}^{2}\end{array}$ & $B_{\mathrm{c}}$ & OCR \\
\hline 2 & $32 \cdot 5$ & 200 & 56 & $0 \cdot 334$ & 4.58 \\
4 & 65 & 240 & 84 & $0 \cdot 48$ & 1.88 \\
6 & $97 \cdot 5$ & 280 & 92 & $0 \cdot 506$ & $1 \cdot 25$ \\
8 & 130 & 320 & 122 & $0 \cdot 64$ & $1 \cdot 04$ \\
10 & $162 \cdot 5$ & 440 & 141 & $0 \cdot 507$ & $1 \cdot 17$ \\
12 & 195 & 500 & 185 & 0.607 & $1 \cdot 18$ \\
14 & $227 \cdot 5$ & 600 & 252 & 0.677 & $1 \cdot 19$ \\
16 & 260 & 680 & 292 & $0 \cdot 696$ & $1 \cdot 04$ \\
18 & $292 \cdot 5$ & 750 & 330 & 0.721 & $1 \cdot 0$ \\
20 & 325 & 810 & 365 & 0.752 & $1 \cdot 0$ \\
\hline
\end{tabular}


analogous to equation (41). If a value for $\Lambda$ were known, then such a plot could be made with an expected linear relationship. In practice, field data will not warrant such involved processing, because the variation in OCR in any one stratum is not likely to be great and because of the likely experimental scatter in the data. A plot similar to Fig. 21 should be adequate for correlation.

It has been argued in this section that to derive the maximum benefit from the development of the piezocone

(a) the position of the pore pressure transducer should be standardized and should be on the shaft of the instrument and not within the conical tip

(b) the interpretation of the data should be standardized by use of the pore pressure parameter $B_{\mathrm{q}}=\Delta u /\left(q_{\mathrm{c}}-\sigma_{\mathrm{v} 0}\right)$ in which $q_{\mathrm{c}}$ is the correct total end bearing pressure of the cone.

No attempt is made to consider the derivation of values of undrained shear strength from end bearing data of cone penetrometer tests. At present the interpretation is usually empirical, being based on comparisons with other means of measurement of $s_{\mathrm{u}}$. Much current research is aimed at a properly formulated method of interpretation, such as that of Senesset et al. (1982).

\section{DIRECT SIMPLE SHEAR TESTS}

It was pointed out earlier that there will be major differences between tests in which the principal axes of stress and/or strain increment are prevented from rotating and those in which they are free to rotate. The former category of test includes the oedometer, the conventional triaxial tests, most versions of laboratory plane strain apparatus and the triaxial apparatus, and the pressuremeter. The latter category includes the direct simple shear test and most forms of in situ test, i.e. the vane shear test, the plate bearing test and the cone penetration test.

Since most in situ tests, allowing freedom of the principal axes to rotate, are correlated with laboratory tests in which the principal axes are constrained, it is important to assess the differences in behaviour of soil under the two circumstances. Additionally in all real engineering situations individual soil elements experience stress and strain increments such that the principal axes rotate, whereas nearly all mathematical models of soil behaviour are based on data from single-element tests in which no rotation is presumed.

Consequently a detailed study has been made of the results of undrained direct simple shear tests, and it is presented in this section. This study takes further the work of Randolph \& Wroth (1981) concerned with the axial capacity of driven piles in clay and is based on the comprehensive series of tests reported by Ladd \& Edgers (1972), which have already been referred to.

The tests were carried out in the Geonor apparatus in which cylindrical samples of soil are containcd in a rubber membranc reinforced internally by a fine helical wire and subjected to simple shear. 'Undrained' tests are carried out as drained tests in which the total volume of the sample is held constant by suitable adjustment of the vertical (effective) stress.

\section{Undrained tests on normally consolidated specimens}

The results of a test on a specimen of normally consolidated resedimented Boston blue clay are shown in the upper half of Fig. 22 in which the observed shear stress $\tau_{\mathrm{h}}$ (applied to the horizontal top surface of the specimen) is plotted against the vertical effective stress $\sigma_{v}{ }^{\prime}$. Both stress variables have been made dimensionless by dividing by the original consolidation pressure $\sigma_{v \mathrm{c}}{ }^{\prime}$. The individual points have been plotted directly from the tabulated data in the Massachusetts Institute of Technology report.

The effective stress path $\mathrm{ABC}$ traced by these points has two marked features. The first is the very substantial reduction in effective vertical stress that occurs during the test, which would require very large positive excess pore pressures to be generated in an equivalent undrained test. The second is that the maximum value of observed shear stress $\tau_{\max }$ occurs at point B (after a shear strain of about $5 \%$ (see Fig. 25, later)), whereas the maximum stress ratio on the horizontal plane of the specimen occurs at point $\mathrm{C}$ (after 30\% shear strain).

This raises the question whether 'failure' of the specimen should be identified with state B or state $C$. It will be shown later that state $B$ does not represent the maximum shear stress on any plane within the specimen; other planes can experience greater values of shear stress at other stages in the test. It is suggested therefore that failure in a frictional material should be associated with the conditions of maximum stress ratio.

The path $\mathrm{ABC}$-and all other such paths on tests of seven normally consolidated clays reported by Ladd \& Edgers (1972) -is nearly elliptical in shape. Without attempting a physical explanation of why this might be so, it is worth exploring the consequences of assuming that all such paths can be closely matched by ellipses. 


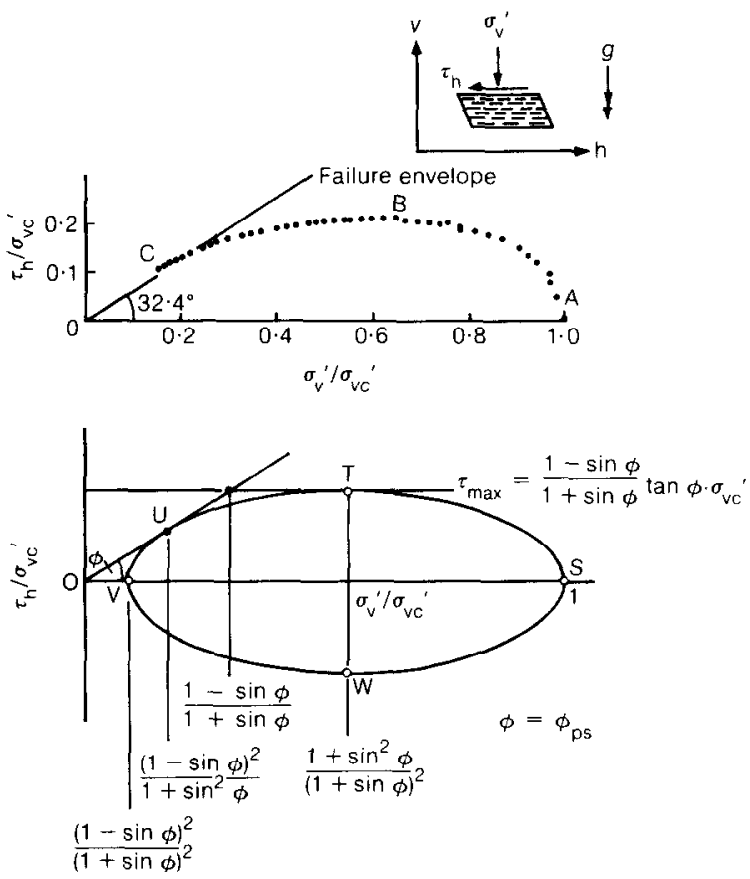

Fig. 22. Undrained simple shear test on normally consolidated Boston blue clay (data from test 204, Ladd \& Edgers, 1972)

In the lower half of Fig. 22 a particular ellipse STUVW has been drawn which passes through the initial point $S$ and touches the failure envelope $\mathrm{OU}$ at point $\mathrm{U}$. To match the experimental data as closely as possible the ellipse has been drawn to the same scale and the failure envelope has been chosen with the observed value of $\phi=\phi_{\mathrm{ps}}=32 \cdot 4^{\circ}$. In theory there is an infinite family of ellipses which satisfy these criteria each having a different centre and a different oblateness represented by the relative length of the minor axis TW.

The particular ellipse chosen for simulation is given by the expression

$$
4 \tau^{2}+(\sigma-h)^{2}=(\sigma+h)^{2} \sin ^{2} \phi_{\mathrm{ps}}
$$

where for convenience $\tau=\tau_{\mathrm{l}} / \sigma_{\mathrm{vc}}{ }^{\prime}, \sigma=\sigma_{\mathrm{v}}{ }^{\prime} / \sigma_{\mathrm{v}}{ }^{\prime}$ and $h=\left(1-\sin \phi_{\mathrm{ps}}\right) /\left(1+\sin \phi_{\mathrm{ps}}\right)$. This ellipse has some special properties, which are discussed later, and the abscissae of the main points in explicit form are included in Fig. 22. In particular the maximum value of shear stress, which occurs at point $T$, is given by the equation

$$
\frac{\tau_{\max }}{\sigma_{\mathrm{vc}}{ }^{\prime}}=\frac{1-\sin \phi_{\mathrm{ps}}}{1+\sin \phi_{\mathrm{ps}}} \tan \phi_{\mathrm{ps}}
$$

The observations made in a direct simple shear test in a Geonor apparatus only provide information about the effective stresses on one plane-the horizontal plane-in a supposedly homogeneous soil specimen. It is not possible to deduce the complete state of stress within the specimen and to draw the relevant Mohr circle. Attempts have been made to meet this deficiency, notably by Soydemir (1976), by using the helical reinforcement encased in the membrane as a transducer for measurement of radial, i.e. horizontal, stress.

As part of a grand strategy of fundamental research into stress-strain behaviour of soils, Roscoe (1953) devised the simple shear apparatus (SSA) in an attempt to be able to subject a soil specimen to uniform conditions of simple shear. The apparatus was developed by a succession of research students who worked predominantly on sand. The two major developments have been

(a) the construction of boundary load cells capable of measuring both normal and shear forces acting on the boundaries of the specimen in the SSA

(b) the use of the X-ray technique for studying the non-homogeneous strain fields that inevitably develop within the specimen. 


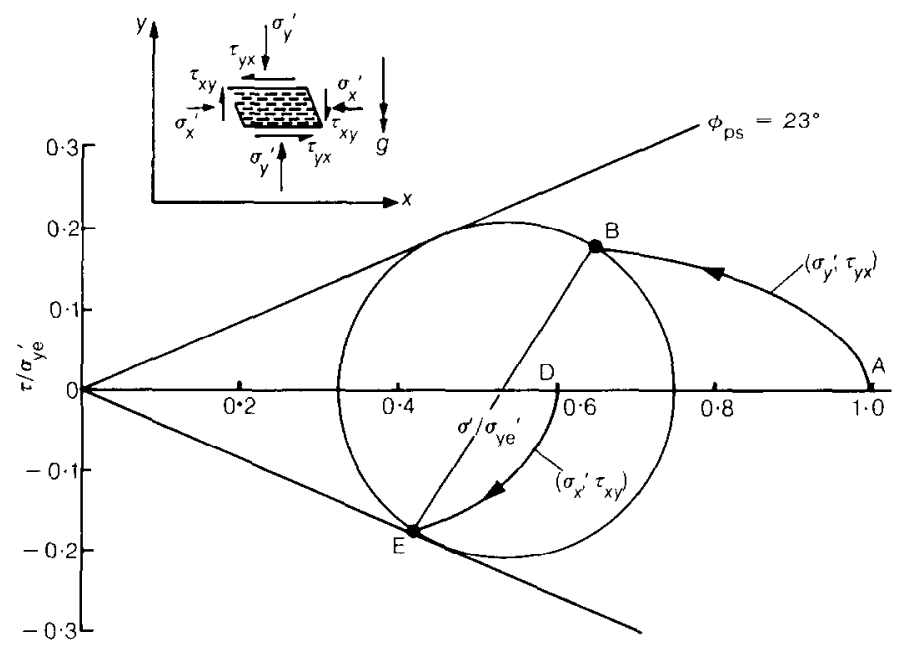

Fig. 23. Effective stress paths and the failure state from an undrained simple shear test on kaolin (data from test 10, Borin, 1973)

The boundary load cells provide enough information for the stress state in the SSA specimen to be estimated.

Little work has been done on clay in the SSA, the only major study to date being that of Borin (1973). The results of one undrained test on normally consolidated reconstituted kaolin are reproduced in Fig. 23. A schematic section through the SSA is shown to define the reference set of co-ordinate axes $(x, y)$. The observed value of stresses on the horizontal and vertical planes respectively $\left(\sigma_{y}{ }^{\prime}, \tau_{y x}\right)$ and $\left(\sigma_{x}{ }^{\prime}, \tau_{x y}\right)$ have heen made dimensionless hy dividing by the equivalent pressure $\sigma_{\mathrm{ye}}{ }^{\prime}$, which for an undrained test on a normally consolidated specimen is the same as the consolidation pressure $\sigma_{v c}{ }^{\prime}$.

The effective stress path traced out by $\left(\sigma_{y}{ }^{\prime}, \tau_{y x}\right)$ is the curve $\mathrm{AB}$; the test, unlike those of Ladd and Edgers, was terminated just after the maximum shear stress $\tau_{y x}$ was reached at point $B$. The path AB is essentially the same as that shown in Fig. 22 for a distinctly different type of simple shear test on a different clay, which provides important confirmation of this facet of soil behaviour.

Of more importance is the effective stress path DE traced by the stresses $\left(\sigma_{x}{ }^{\prime}, \tau_{x y}\right)$ on the vertical (or constant $x$ ) planes in Fig. 23, in which the usual sign convention has been adopted for Mohr's circle with compressive stresses taken as positive. Because the kaolin specimen was normally consolidated the initial state D corresponds to a value of $K_{0}$ of $0 \cdot 6$.

The Mohr circle of stress is drawn for the condition of maximum $\tau_{\mathrm{yx}}$ with $\mathrm{BE}$ as diameter, and it appears to touch the failure envelope given by $\phi_{\mathrm{ps}}=23^{\circ}$ but at point $\mathrm{E}$ (or close to it) and not at point $\mathrm{B}$. This suggests that the condition of maximum stress obliquity relates to the vertical and not the horizontal planes within the specimen.

Such a supposition is contrary to longestablished beliefs in soil mechanics and was first put forward as a possibility by de Josselin de Jong (1972). The essential features of his arguments are presented in Fig. 24 regarding interpretation of failure conditions in direct shear tests. For ease of discussion, the case of a drained test on a soil under constant effective vertical stress is considered. The top part of the figure represents the conventional understanding in which the horizontal planes are ones of relative sliding within the specimen, on which the maximum ratio of shear stress to normal effective stress occurs; the stress state is the point $G$ of maximum stress obliquity.

The bottom part of the figure is related to an alternative mechanism of failure in which the vertical planes are ones of relative sliding within the specimen, on which the maximum stress ratio occurs represented by point $\mathrm{K}$. The sliding on vertical planes is accompanied by a body rotation of magnitude $\gamma$ in the anticlockwise direction, where $\gamma$ is the amount of engineering strain applied to the specimen externally. It should be noted that this second mechanism of failure is kinematically compatible with the boundary conditions and requires the application of a smaller shear stress.

de Josselin de Jong argues that either mechanism is possible, and that, if the boundary conditions of the test-or the engineering 
situation-allow the soil element a choice between the two modes, the selected mode is the one which requires the least resistance, i.e. the second mechanism.

The vectors of the principal stress have been sketched in Fig. 24 showing clearly for the two cases the different amounts of rotation of the principal axes of stress and the different magnitudes.

The hypothesis of de Josselin de Jong is confirmed experimentally by the single relevant test carried out by Borin (1973) and plotted in Fig. 23. There is every reason to expect the hypothesis to be valid for the tests on Boston blue clay and the other clays reported by Ladd and Edgers. These ideas have been applied in Fig. 25 to the interpretation of the stress path of Fig. 22.

In Fig. 25, three stages of the test have been examined:

(a) the start of the test

(b) the condition of maximum shear stress $\tau_{y x}$

(c) the ultimate stage of the test.

To match the direction of the effective stress path $\mathrm{ABC}$, the stages and the observed stress-
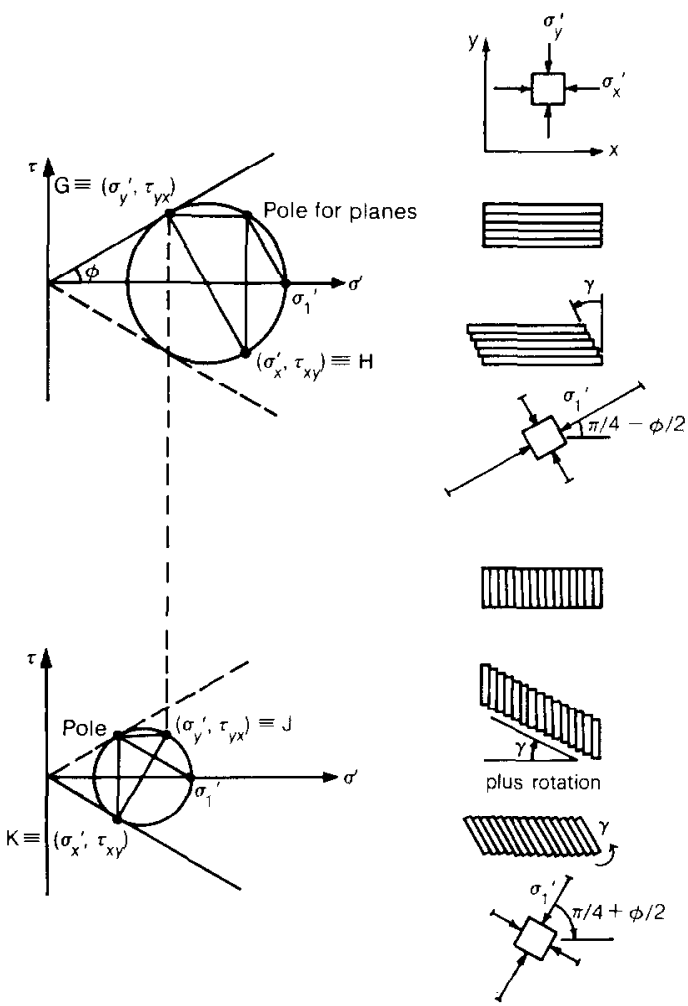

Fig. 24. Possible modes of failure in simple shear (after de Josselin de Jong, 1972) strain curve have been intentionally placed from right to left in the diagram.

For the first stage, the Mohr circle has AD as its diameter and the major principal stress is vertical. For the test in question the initial horizontal effective stress $\sigma_{\mathrm{hc}}{ }^{\prime}$ is not known, but from many one-dimensional consolidation tests on Boston blue clay an average value of $K_{0}$ is 0.5 and this has been assumed to apply to this test also. As soon as shear is applied to the specimen, the Mohr circle moves to the left, reduces in size and rotates. By the time stage $(b)$ is reached, the maximum measured shear stress has been attained at point $B$, the stress state for the vertical planes $\left(\sigma_{x}{ }^{\prime}, \tau_{x y}\right)$ at point $E$ is on the failure envelope (with sliding on these vertical planes) and the direction of the major principal stress has rotated clockwise through an angle of $\pi / 4-\phi_{\mathrm{nd}} / 2$.

Further straining of the specimen causes the Mohr circle to continue to move to the left, and to rotate, but it is now constrained to touch the failure envelope and its point of tangency to move down the envelope towards the origin. During this phase it is believed that the effective horizontal stress $\sigma_{x}{ }^{\prime}$ does not change, with the consequence that the effective stress path EF for the vertical planes is parallel to the $\tau$ axis as shown. This particular feature (although not
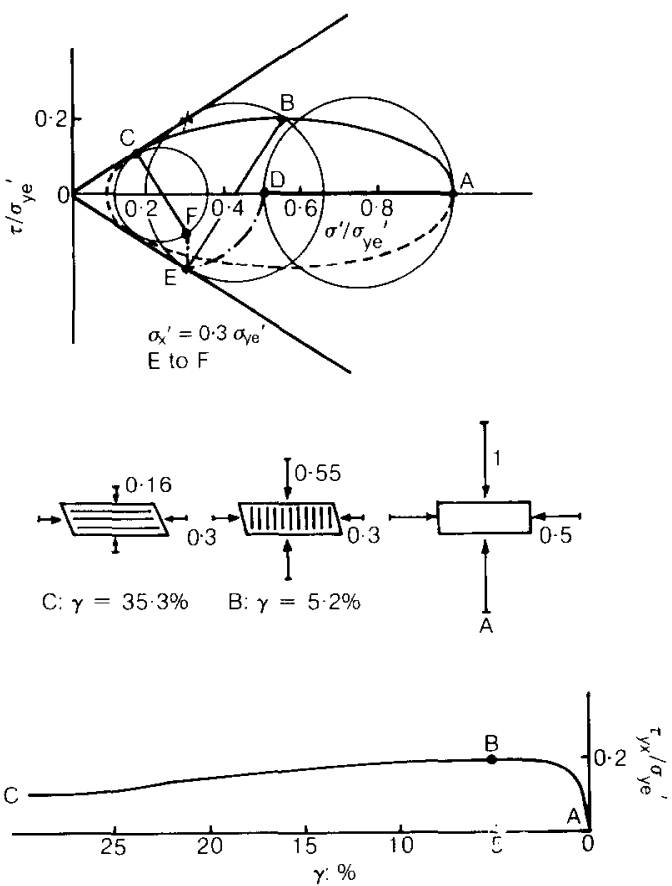

Fig. 25. Behaviour of normally consolidated Boston blue clay in undrained simple shear 
supported by physical arguments) is a consequence of the particular choice of ellipse in equation (43).

At the ultimate stage (c), the horizontal planes have become the sliding planes experiencing the maximum stress ratio (point $\mathrm{C}$ ) which satisfies the kinematic requirement of large shear displacements in the horizontal direction. The direction of the major principal stress has rotated clockwise further through an angle $\phi_{\mathrm{ps}}$ to a total rotation of $\pi / 4+\phi_{\mathrm{ps}} / 2$. There is no reason for any change now in the Mohr circle for subsequent shear deformation.

The magnitude of the ultimate shear stress at point $\mathrm{C}$ is given by the elliptical representation (see Fig. 22 and equation (43)) as

$$
\frac{\tau_{\mathrm{ult}}}{\sigma_{\mathrm{vc}}}=\frac{\left(1-\sin \phi_{\mathrm{ps}}\right)^{2}}{1+\sin ^{2} \phi_{\mathrm{ps}}} \tan \phi_{\mathrm{ps}}
$$

This suggests an apparent sensitivity $S$ for the resedimented Boston blue clay in the direct simple shear test of

$$
\begin{aligned}
S & =\frac{\tau_{\max }}{\tau_{\mathrm{ult}}} \\
& =\frac{1+\sin ^{2} \phi_{\mathrm{ps}}}{1-\sin ^{2} \phi_{\mathrm{ps}}}
\end{aligned}
$$

For Boston blue clay with $\phi_{\mathrm{ps}}=32 \cdot 4^{\circ}$, this gives $S=1 \cdot 8$. The same resedimented normally consolidated clay tested in undrained triaxial compression would give a stress-strain curve which monotonically increases to an ultimate (critical state) condition and displays no sensitivity.

This suggestion has the important implication that an apparent sensitivity may occur in tests in which the principal axes are free to rotate, for a soil which would not display any sensitivity in, say, a conventional triaxial test. The consequence is that a greater sensitivity for an undisturbed soil is likely to be observed in a vane shear test than in a triaxial test.

\section{Undrained strength ratios}

On reversion to values of the maximum shear stress observed in an undrained direct simple shear test, the assumptions made about the elliptical stress path lead to the expression in equation (44) for the ratio $\tau_{\max } / \sigma_{v c}{ }^{\prime}$. The relevance of this expression has been tested against all the data reported by Ladd \& Edgers (1972) in the plot of Fig. 26. For each test on a normally consolidated specimen, the observed value of this ratio has been plotted against the individual value of $\phi_{\mathrm{ps}}$ observed in that test at the ultimate condition.

A distinction has becn made between the four

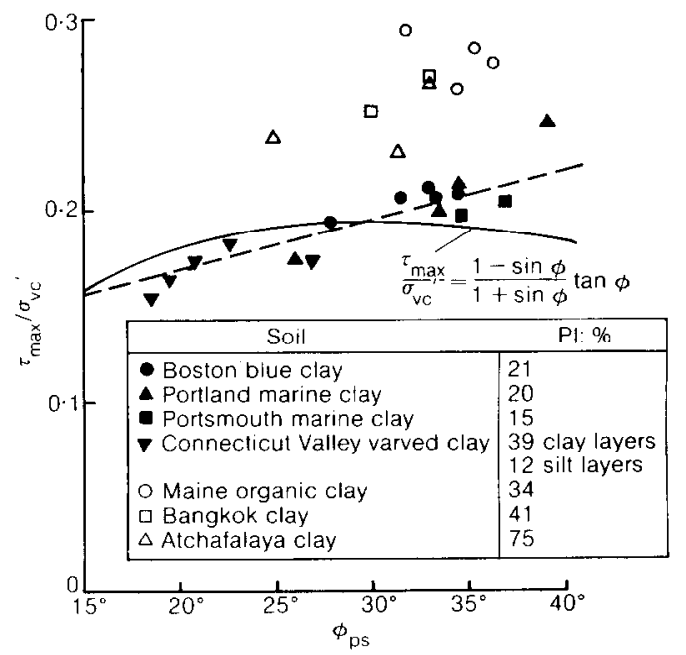

Fig. 26. Undrained strength ratios of seven normally consolidated clays in simple shear tests (data from Ladd \& Edgers, 1972)

low plasticity clays displayed by full symbols and the other three higher plasticity clays by open symbols. The former clays show consistently lower strength ratios which are reasonably close to the curve given by equation (44). However, without this speculative theoretical background, the data might have been represented by the broken straight line-which in fact gives a better fit. No suggestion is offered why the three clays of higher plasticity have greater strength ratios.

The discussion so far regarding direct shear tests has been about the maximum value of the observed shear stress $\tau_{\max }$. Although this stress may be used appropriately in a limit analysis, it is not the greatest shear stress experienced by the specimen being tested, as pointed out earlier. By definition the greatest shear stress sustained by the specimen is the undrained shear strength $s_{\text {udss }}$ given by the radius of the largest Mohr circle.

From Fig. 25 it appears that the largest Mohr circle is the initial one which has a radius $r_{\mathrm{mc}}$ such that

$$
\begin{aligned}
\frac{r_{\mathrm{mc}}}{\sigma_{\mathrm{vc}}^{\prime}} & =\frac{1}{2}\left(1-K_{0}\right) \\
& \approx \frac{1}{2} \sin \phi_{\mathrm{tc}}
\end{aligned}
$$

However, the radius of the second Mohr circle (the first occasion that failure has been induced within the specimen) can be obtained by relating it to the stress state at $B$

$$
\frac{r_{\mathrm{mf}}}{\sigma_{\mathrm{vc}}^{\prime}}=\frac{\tau_{\mathrm{max}}}{\sigma_{\mathrm{vc}}{ }^{\prime}} \sec \phi_{\mathrm{ps}}=\frac{\sin \phi_{\mathrm{ps}}}{\left(1+\sin \phi_{\mathrm{ps}}\right)^{2}}
$$




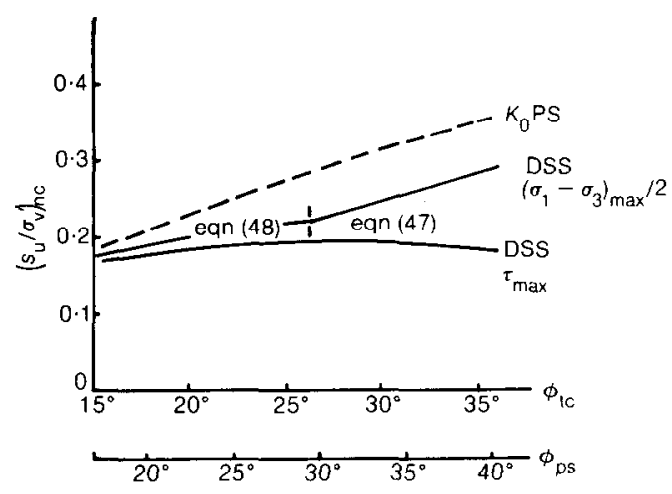

Fig. 27. Variation in the undrained strength ratio with the angle of friction for direct shear tests on normally consolidated clay

Computations show that the first expression is the greater for $\phi_{\mathrm{ps}} \approx \frac{9}{8} \phi_{\mathrm{tc}} \geqslant 29 \cdot 5^{\circ}$. Speculation about what might happen between these stages is not warranted, hut it is hard to believe that there would be an even larger Mohr circle.

The resulting predictions for the undrained strength ratio for direct shear tests on normally consolidated clay as a function of friction angle are shown in Fig. 27. For comparison the relationship predicted for plane strain tests on anisotropically normally consolidated clay from equation (34) is included. Although these relationships are of questionable accuracy they emphasize the likely differences in undrained shear strength obtained from different tests and the need to take account of these when comparisons are being made.

\section{VANE SHEAR TEST}

\section{Basic interpretation}

The vane shear test has formed a central role in site investigation, particularly in soft clays, for over 60 years having first been used by Olsson in 1919 according to Flodin \& Broms (1981). It is surprising that it is only recently that the test and its interpretation have been studied critically.

The standard method of interpretation (BS 1377 ) is to assume

(a) that the shear stress distribution on both the cylindrical (vertical) surface and the top and bottom (horizontal) surfaces is rectangular, i.e. uniform

(b) that the shear strength of the soil being measured is isotropic.

Both of these assumptions need to be examined carefully.

Donald, Jordan, Parker \& Toh (1977) have conducted a critical appraisal of the vane test and report results of a three-dimensional finite element analysis of the stress distributions on the putative failure surface created by a vane in an elastic material. Their important finding is reproduced in Fig. 28(a) from which it can be seen that the computed elastic stress distribution, although reasonably rectangular on the sides of the vane, is far from uniform on the top and bottom edges.

Menzies \& Merrifield (1980) have carried out some experiments with an ingeniously instrumented vane both in sand and in overconsolidated London clay. Their results naturally show some scatter, but after using regression analysis to give best-fit curves these are compared suitably normalized in Figs 28 (b) and 28 (c). In each case half the symmetrical distribution is shown, the vane blade having dimensions of $240 \mathrm{~mm} \times 120 \mathrm{~mm}$. The observed shear stress distributions are pleasingly similar to those computed by Donald et al. (1977).

In London clay, the assumption of a rectangular shear stress on the vertical cylindrical failure surface is confirmed as reasonable, whereas there is a major difference between the observed distribution on the horizontal failure surfaces and the assumed condition of uniformity. The possible consequences of this departure from the assumptions are now investigated.

Consider a vane of diameter $d$ and height $h$, and suppose that the shear stress on the top and bottom surfaces is given by the single polynomial expression

$$
\frac{\tau}{\tau_{\mathrm{m}}}=\left(\frac{r}{d / 2}\right)^{n}
$$

where $r$ is the radial distance from the centre line and $\tau_{m}$ is the maximum value of the shear stress, which is assumed to occur simultaneously along the entire vertical failure surface. The contribution to the torque $T_{h}$ provided by both top and bottom surfaces is given by the straightforward integration

$$
\begin{aligned}
T_{\mathrm{h}} & =2 \int_{0}^{d / 2} 2 \pi r^{2} \tau \mathrm{d} r \\
& =\frac{\pi d^{3} \tau_{\mathrm{m}}}{2(n+3)}
\end{aligned}
$$

The conventional assumption of a uniform distribution of shear stress gives a value of $T_{h}=$ $\pi d^{3} \tau_{\mathrm{m}} / 6$ which is a special case of equation (50) for $n=0$.

The contribution to the torque $T_{\mathrm{v}}$ provided by the vertical surface is the same as the conven- 


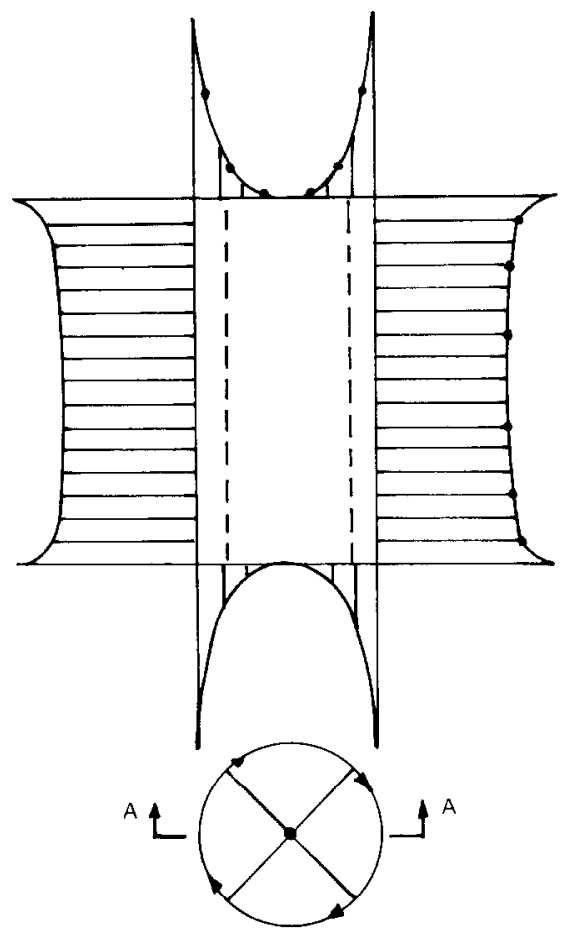

(a)

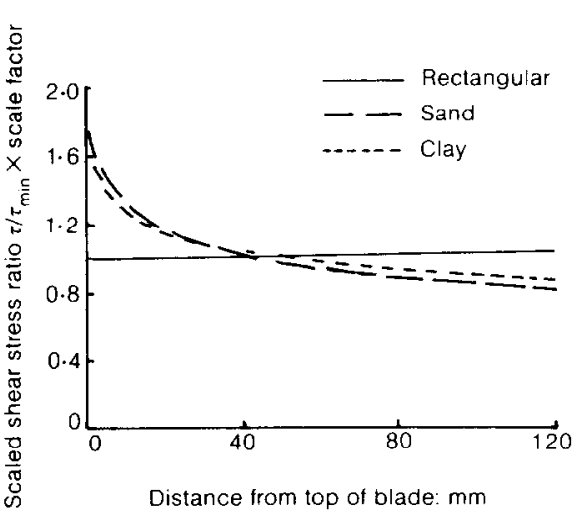

(b)

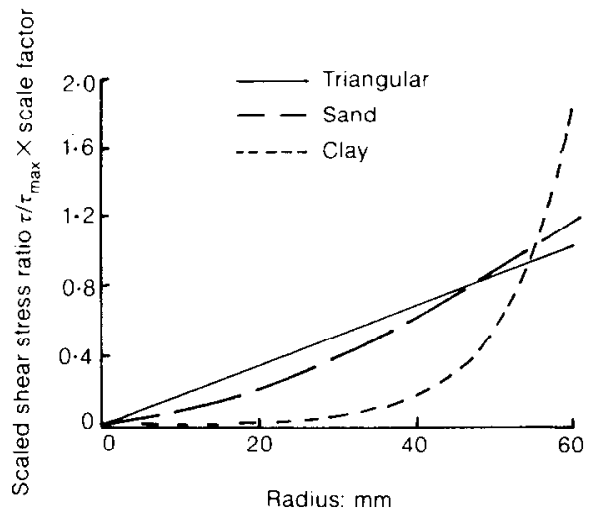

(c)

Fig. 28. Theoretical and experimental distributions of shear stress around the blades of a vane: (a) computed elastic shear stress distribution (after Donald et al., 1977); (b) vertical edge; (c) horizontal edge ((b) and (c) are normalized distributions of equivalent shear stress scaled to give equal torque (after Menzies \& Merrifield, 1980))

tional, i.e.

$$
T_{\mathrm{v}}=\frac{\pi d^{2} h \tau_{\mathrm{m}}}{2}
$$

Hence the relative proportions of the torques are

$$
\frac{T_{\mathrm{h}}}{T_{\mathrm{v}}}=\frac{1}{(n+3)} \frac{d}{h}
$$

For the London clay data of Menzies \& Merrifield (1980) in Fig. 28(c) an approximate value of $n$ is 5 . With the adoption of this value, then for the standard vane with $d / h=1 / 2$, the value of $T_{\mathrm{h}} / T_{\mathrm{v}}$ will be $1 / 16$ compared with $1 / 6$ for the conventional interpretation.

This revised interpretation based on equation (49) has two major consequences. The first is 


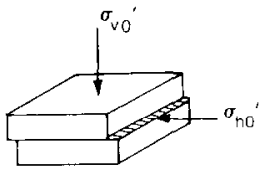

Direct shear

(a)

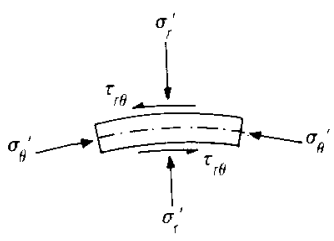

(c)

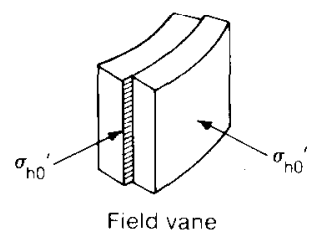

(b)

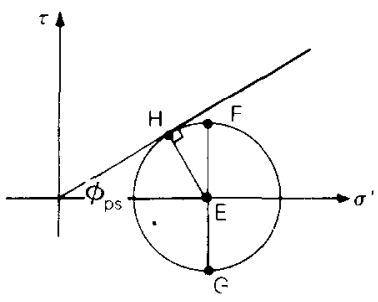

(d)

Fig. 29. Possible state of stress around the cylindrical failure surface caused by a vane shear test

that approximately $94 \%$ of the resistance to torque is provided by the vertical failure surface compared with $86 \%$ in the conventional interpretation. This means that

(a) the assumption of isotropy of shear strength is less crucial, and that the dominant shear strength measured is that on vertical planes

(b) the method of deducing the degree of anisotropy of strength by using a suite of vanes with different $d / h$ ratios will be strongly affected.

The second major consequence is that the value of the (isotropic) shear strength deduced from a given value of peak torque will be underestimated by a factor of $(6 / 7) \times(17 / 16)$, i.e. $102 / 112$ or by about $9 \%$. This error is doubly fortunate in that it is conservative and it compensates to some extent for errors caused by rate effects. The standard vane test is carried out at a speed of rotation such that the strain rates applied to the failing soil are considerably higher than in, say, conventional triaxial tests and are thereby associated with higher undrained strengths. It is not possible to calculate the strain rates around the vane without a complete knowledge of the strain field, so the magnitude of the effect cannot be sensibly estimated.

\section{Undrained strength ratio}

For a proper comparison with the results of other tests, it is necessary to know the effective stresses that are controlling the undrained shear strength generated at the edges of the vane. The mode of failure is one of direct simple shear. However, it has been shown previously that all but $6 \%$ of the resistance is provided by the vertical failure surface, so that it is the mode of failure around the cylindrical surface that dominates events.

Although this failure is one of direct shear, it is not the same as that caused in a conventional direct shear test because of the different orientation of the specimens. This is illustrated in Fig. 29 for normally consolidated clay where the different combinations of effective stress which affect subsequent behaviour are shown. The only attempt at a fundamental study of the vane test under controlled laboratory conditions found in the literature is that by Law (1979); the few data he reported are insufficient for a definite theory to be established.

The following analysis is an attempt to resolve the problem, but it is speculative, not well based on experimental data, and so it must be viewed with caution until further research validates it or not. Fig. 29(c) is a horizontal section through a segment of the vertical cylindrical failure surface around the vane, for which polar co-ordinates are used. Initially the direct effective stresses of concern* are equal to the lateral stress in the ground, $\sigma_{\mathrm{r} 0}{ }^{\prime}=\sigma_{\theta 0}{ }^{\prime}=\sigma_{\mathrm{h} 0}{ }^{\prime}$, so that the Mohr circle or interest in Fig. 29(d) is the single point E. As

\footnotetext{
* Initially the major principal effective stress is the vertical stress, but this is expected to reduce locally to become the intermediate effective stress since plane strain conditions are assumed.
} 
shearing starts it is assumed that these direct stresses do not alter so that, as the shear stress increases, the Mohr circle enlarges (retaining $E$ as its centre) until failure occurs when the circle touches the failure envelope at $\mathrm{H}$.

This means that the maximum shear stress experienced by the vane is given by the simple formula

$$
\tau_{\max }=\sigma_{\mathrm{h} 0}{ }^{\prime} \sin \phi_{\mathrm{ns}}
$$

which is not at variance with the limited results reported by Law (1979).

If this is so then the maximum value of the observed shear stress $\tau_{\max }$ is identical with the definition of undrained shear strength, and hence the undrained strength ratio is

$$
\begin{aligned}
\frac{s_{\mathrm{ufv}}}{\sigma_{\mathrm{vo}}{ }^{\prime}} & =\frac{\sigma_{\mathrm{ho}}{ }^{\prime} \sin \phi_{\mathrm{ps}}}{\sigma_{\mathrm{vo}}{ }^{\prime}} \\
& \approx\left(1-\sin \phi_{\mathrm{ps}}\right) \sin \phi_{\mathrm{ps}}
\end{aligned}
$$

since for a normally consolidated soil $K_{0} \approx$ $\left(1-\sin \phi_{\mathrm{ps}}\right){ }^{*}$ The relationship given by equation (54) is plotted in Fig. 30 and compared with the relationship proposed in equation (44) for the ratio $\tau_{\max } / \sigma_{\mathrm{vo}}{ }^{\prime}$ obtained in a direct simple shear test. Note that the expressions are such that the ratio

$$
\frac{s_{\mathrm{ufv}} / \sigma_{\mathrm{v} 0^{\prime}}}{\tau_{\max } / \sigma_{\mathrm{v} 0^{\prime}}}=\left(1+\sin \phi_{\mathrm{ps}}\right) \cos \phi_{\mathrm{ps}}
$$

is nearly constant at a value of $1 \cdot 28 \pm 0.02$ over the likely range of $20^{\circ}<\phi_{\mathrm{ps}}<40^{\circ}$.

\section{Overconsolidated soils}

It has been well established both theoretically and experimentally that the undrained strength

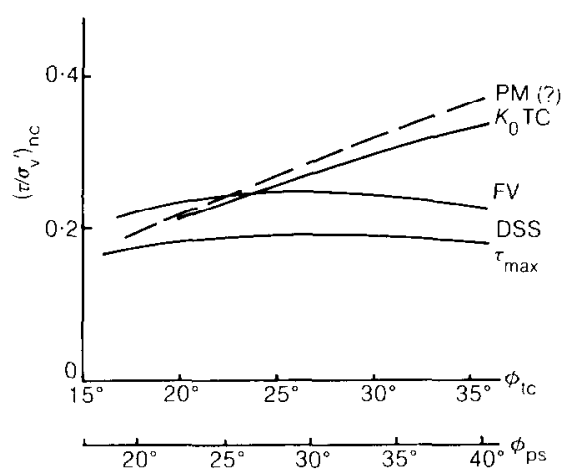

Fig. 30. Variation in the undrained strength ratio with the angle of friction for tests on normally consolidated clay

\footnotetext{
* Note the preference for $K_{0} \approx\left(1-\sin \phi_{t c}\right)$ in Appendix 2 and equation (47).
}

ratio of a soil, when normalized by the value for the normally consolidated condition, is proportional to OCR to the power $\Lambda$ (see equation (28)). This finding has been applied to the proposed expression for vane shear tests of equation (54) to generate the family of curves in Fig. 31 for a soil with $\Lambda$ equal to the typical value of 0.8 .

Although the details of this chart are open to question, it is claimed that the general pattern presented is correct. It shows the importance of a small degree of overconsolidation $c_{1 .}$ the undrained strength ratio. Many soft clay sites, supposedly normally consolidated, show small degrees of overconsolidation due to such causes as

(a) erosion followed by deposition

(b) fluctuating water-table

(c) desiccation.

Care must therefore be exercised in correlating the value of the undrained strength ratio for normally or lightly overconsolidated soils with other properties; in particular this applies to Skempton's much used relationship with plasticity index of equation (4).

\section{ENGINEERING APPLICATION}

The efforts made in this Paper to correlate measurements of undrained shear strength from different tests have led to a confusing picture of soil behaviour. To put this into perspective an example of an engineering application is presented-that of an embankment (or other

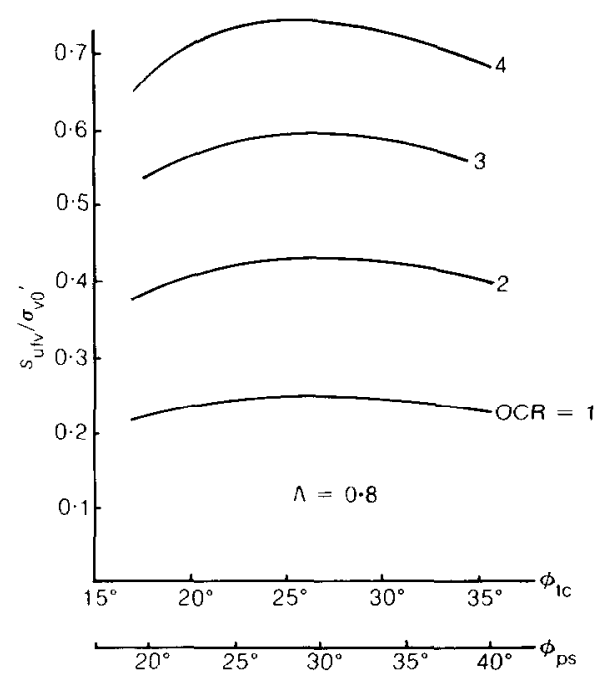

Fig. 31. Possible variation in the undrained strength ratio measured in vane shear tests with the angle of friction and overconsolidation ratio 


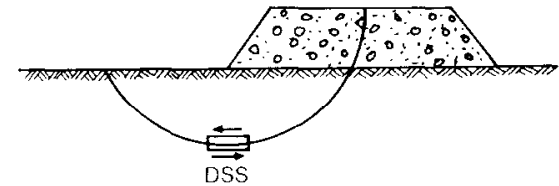

(a)

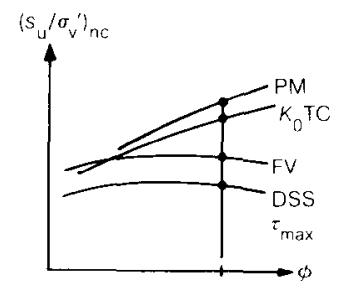

(b)

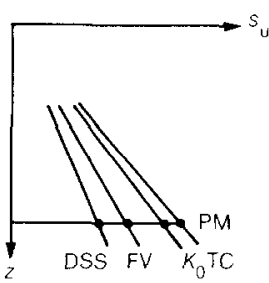

(c)
Fig. 32. Possible profiles of the undrained shear strength in a soft clay deposit measured in different tests

surface loading) constructed on a deposit of soft clay, illustrated schematically in Fig. 32(a).

The two major design problems are likely to be the short-term stability of the embankment and foundation, and the long-term settlement and deformations due to consolidation. Amongst other properties, the profile of undrained shear strength will be required, and a decision will face the designer of how this is to be obtained. A choice* of test or tests must be made from among a suite of in situ tests and laboratory tests; for this example two of each are considered-pressuremeter and field vane tests, triaxial tests (on anisotropically reconsolidated samples) and direct simple shear tests.

On the basis of the theoretical expressions developed in this Paper Fig. 32(b) has been prepared. The curve for the pressuremeter test has not been specified, but it is contended that it will be similar to that for plane strain tests on anisotropically reconsolidated samples from equation (34) and Fig. 27 but directly scalcd by a factor of say 1.2 owing to strain rate effects and partial consolidation. The curves for the other three tests are those given by equations (27), (44) and (54).

For a given clay, with a given value of $\phi$ the four tests will give different values of $\left(s_{\mathrm{u}} / \sigma_{\mathrm{vo}}\right)_{\mathrm{nc}}$. If the clay is lightly overconsolidated then each

\footnotetext{
* The cone penetration test has been omitted intentionally because, unlike the other tests, a value of the undrained shear strength cannot be derived directly from the observations; a value for the cone factor $N$. has to be uscd which can only be based on previous comparisons with other tests.
}

value of the undrained strength ratio should be multiplied by the factor $(\mathrm{OCR})^{\Lambda}$. At a given depth, i.e. for a given value of $\sigma_{v 0}^{\prime}$, the undrained strengths will form a hierarchy as indicated in Fig. 32(c). The same argument will apply for all depths, resulting in the pattern of profiles that have been sketched. The spacing and even the relative positions of the profiles will depend on the value of $\phi$ for the deposit investigated.

It is argued that each of these apparently conflicting values of undrained shear strength is correct in its own right, and the designer must choose whichever he considers to be the most appropriate to the problem being analysed and apply to it an appropriate factor of safety.

Two examples of sites which support these ideas are shown in Fig. 33 with profiles of strengths at Porto Tolle (Fig. 33(a)) and Panigaglia (Fig. 33(b)) obtained by Ghionna et al. (1983), who were concerned in interpreting and comparing the results of pressuremeter tests with other tests, so that the individual points and scatter bars refer only to pressuremeter data and the straight lines to best-fit profiles of the other test results.

For a classic limit analysis of the short-term stability of the embankment, the direct simple shear test would be the most relevant test, simulating most closely the soil behaviour around the postulated failure surface; due allowance would need to be made for any anisotropy of strength of elements of soil at different positions around the failure surface. The hierarchy of strengths displayed would also rationalize the use of correction factors of less than unity applied to strengths derived from field vane tests as proposed by Bjerrum, Frimann Clausen \& Duncan (1972).

In contrast, if a finite element analysis is made for predicting deformations and/or excess pore pressures then the values of soil properties chosen should be the ones relevant to the mathematical model of soil behaviour used in the computer program. Indeed if the model was specified in terms of effective stresses, or was perfectly elastic, a value of undrained shear strength would be irrelevant. If the model is an elastic-perfectly plastic model expressed in total stresses then the undrained shear strength would need to be the radius of Mohr's circle at failure in either axially symmetric or more likely plane strain conditions; the value of $\tau_{\text {max }}$ on a particular plane from a direct shear test or field vane test would not be appropriate.

It should be clear that there is no unique value of the undrained shear strength, and that whatever the circumstances the engineer must 


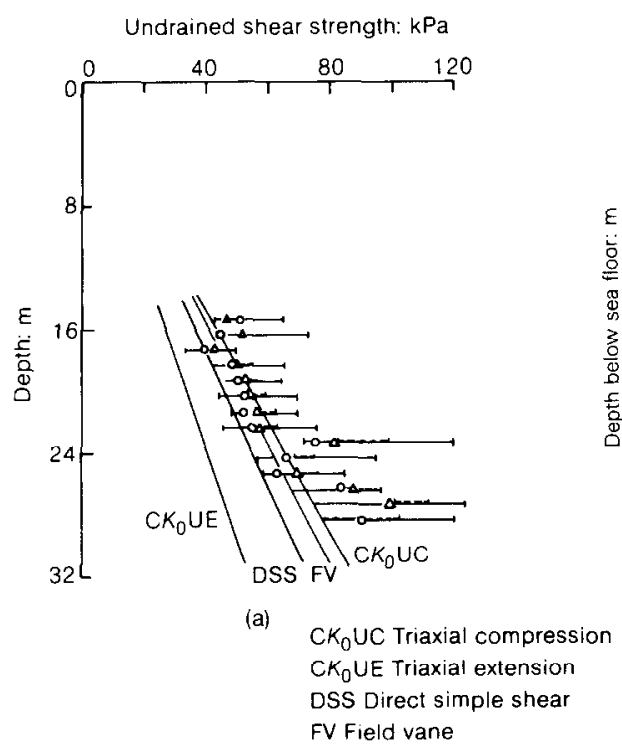

Fig. 33. Profiles of the undrained shear strength measured in different tests at two soft clay sites in Italy (after Ghionna et al., 1983): (a) Porto Tolle; (b) Panigaglia

recognize the differences that exist between data from the various types of test. If the relationships proposed in this Paper are substantiated by further research and experience, then they can be used as a framework for enhancing the interpretation of data from site investigations.

\section{CONCLUSIONS}

The present period in the steady development of soil mechanics and foundation engineering is seeing a rapid growth in the range and quality of in situ tests available for site investigation and the measurement of soil properties. The main purpose of this Paper has been to consider the interpretation of the more important and more widely used tests, and to make recommendations for the improvement of their analysis and interpretation. The whole tenor and philosophy of the Paper has been of a speculative nature, attempting to build on established experience and accepted knowledge so that previously unrelated facts can be brought together as part of a broad picture of soil behaviour.

In attempting this ambitious task, the outcome of the work raises more questions than answers, underlines the very complex nature of soil behaviour and exposes the large gaps in current understanding.

The reasons and virtues of carrying out in situ tests have been set out and the need to use dimensionless parameters has been emphasized, particularly when relationships are based on empiricism, without being hacked up by thenry.

The soil property most often measured in the field is the so-called undrained shear strength of clays, and most of the discussion has centred on this. The definitions of undrained shear strength $s_{\mathrm{u}}$ and the angle of shearing resistance $\phi$ have been shown to be deficient in that they are defined in terms of the major and minor principal stresses, and they take no account of the effect of intermediate principal stress. Consequently there cannot be a unique undrained shear strength of a soil, and different values will be observed in different tests.

Since the fundamental stress-strain behaviour of soils is of a frictional nature controlled by the effective stresses, it is only possible to link measurements of strength in different tests by means of the friction angle and with a knowledge of the effective stresses. This requires the use of a failure law expressed in terms of all three principal effective stresses.

The failure criterion suggested by Matsuoka has been chosen, from which an expression for $\phi$ can be found for any stress state on the failure envelope. In particular it allows a simple (approximate) relationship between the observed friction angle in triaxial compression and plane strain tests, namely $\phi_{\mathrm{ps}} \approx \frac{9}{8} \phi_{\mathrm{tc}}$.

The concepts of CSSM have been used to provide theoretical confirmation

(a) of the important relationship between the undrained strength ratio $s_{\mathrm{u}} / \sigma_{\mathrm{vo}}{ }^{\prime}$ and the overconsolidation ratio

(b) that the normalized undrained strength ratio varies as OCR to the power $m$ where $m$ lies 
in the narrow range $0.68-0.86$ and is typically $0 \cdot 8$. Moreover it has been shown that $m$ is equal to $\Lambda$ so that it is related physically to the compression indices and is not merely an empirical constant.

The analysis shows that different values of the undrained strength ratio will be observed in triaxial tests according to the type of consolidation, isotropic or one dimensional, so that great care is necessary when results of such tests are used for comparison with field tests.

The major difference between tests in which the principal axes of stress are fixed in direction and those in which they are free to rotate has been emphasized. An attempt has been made to understand the effective stress paths observed in direct shear tests which has exposed two important anomalies, both concerning failure. The first of these is that the maximum value of the applied shear stress observed in the test is not the undrained shear strength as properly defined. The second is that at this stage of the test failure is occurring within the sample but with the planes of maximum stress obliquity perpendicular to those usually assumed, as suggested by de Josselin de Jong. These findings have great importance for the proper interpretation of direct shear tests and the vane shear test. Mathematical expressions to represent the data from both types of test have been suggested, but these are based on slender evidence and urgently require further research.

The two modern in situ tests that hold the most promise are the self-boring pressuremeter and the piezocone. The self-boring technique of insertion-which can be used for other devices also-causes minimal disturbance and allows the possibility of "near perfect" testing of undisturbed soil.

The pressuremeter test is relatively expensive and sophisticated, but it has the great advantage of leading to direct evaluation (without the need for empirical relationships) of the following important soil conditions and properties: in situ lateral total stress $\sigma_{\mathrm{h} 0}$, shear modulus $G$, undrained shear strength of clays $s_{u}$, angle of friction $\phi$ and angle of dilation $\nu$ of sands, and the horizontal coefficient of consolidation of clays $c_{\mathrm{h}}$.

The piezocone is a tool of great promise for obtaining a rapid and reliable soil profile. The measurement of pore pressures during the penetration of a cone has enhanced its importance considerably. For the civil engineering profession to gain the maximum advantage from this (and other in situ tests) it is essential that the following three aspects are standardized:

(a) the geometry of the instrument and in par- ticular the location of the pore pressure transducer

(b) the operation of the test, i.e. methods of calibration, rates of testing ctc.

(c) the interpretation of the results and in particular the choice of the dimensionless parameters to be used.

Theoretical relationships have been developed in this Paper for the undrained strength ratio of normally consolidated clay, each of which can be extended to other values of the overconsolidation ratio by the power law mentioned earlier. Although these relationships can only approximate real soil behaviour (and may be found to be wanting in a quantitative sense) it is claimed that they are relevant qualitatively. They indicate a pattern of behaviour, which leads to a hierarchy of strengths that will be observed in different laboratory and field tests. Consequently it is imperative for a designer to recognize this hierarchy, and to select a strength which is appropriate to the analysis or design procedure being used, and to choose a factor of safety or load factor accordingly.

Finally, it is concluded that there is an important need for further research and development in the conduct and interpretation of both laboratory and in situ testing of soils; this must go hand in hand with practice, so that field experience of full-scale structures can be used to test new theories, new equipment and better interpretation.

\section{ACKNOWLEDGEMENTS}

In preparing the Rankine Lecture I wish to acknowledge the substantial help and information that I have received from many people in many countries too numerous to mention individually. Constraints of time and space prevented discussion of other topics of importance in the execution and interpretation of in situ testing of soils, and of other new developments in types of test and of equipment. Their exclusion is regretted but indicates the vigorous expansion that is presently occurring in this area of geotechnical engineering.

The results of pressuremeter tests at Zeebrugge included in this Paper are quoled by kind permission of PM Insitu Techniques Ltd and their clients for the job, Distrigas NV and Tractebel $\mathrm{Z}$.

\section{REFERENCES}

Andresen, A., Berre, T., Kleven, A. \& Lunne, T. (1979). Procedures used to obtain soil parameters for foundation engineering in the North Sea. Mar. Geotechnol. 3, 201-266.

Arulanandan, K. (1977). Method and apparatus for 
measuring in situ density and fabric of soils. Patent Application, Regents of University of California.

Atkinson, J. H. \& Bransby, P. L. (1978). The mechanics of soils - an introduction to critical state soil mechanics. London: McGraw-Hill.

Baguelin, F. (1982). Rules of foundation design using self boring pressuremeter test results. Proc. Symp. Pressuremeter and its Marine Applications, pp. 347360.

Baguelin, F., Jézéquel, J. F., Le Mée, E. \& Le Mebaute, $\Lambda$. (1972). Expansion of cylindrical probes in cohesive soils. J. Soil Mech. Fdns Div. Am. Soc. Civ. Engrs 98, SM11, 1129-1142.

Baguelin, F., Jézéquel, J. F. \& Le Mehaute, A. (1974). Le perméamètre autoforeur. Can. Geotech. J. 11, 624-628.

Baligh, M. M., Azzouz, A. S., Wissa, A. Z. E., Martin, R. T. \& Morrison, M. J. (1981). The piezocone penetrometer. Proc. Am. Soc. Civ. Engrs Symp. Cone Penetration Testing and Experience, St Louis, pp. 247-263.

Baligh, M. M. \& Levadoux, J. N. (1980). Pore pressure dissipation after cone penetration. MIT Research Report MITSG 80-11. Massachusetts Institute of Technology.

Bishop, A. W. (1966). The strength of soils as engineering materials. Géotechnique 16, 91-128.

Bishop, A. W. \& Henkel, D. J. (1957). The measurement of soil properties in the triaxial test. London: Arnold.

Bjerrum, L., Frimann Clausen, C. J. \& Duncan, J. M. (1972). Earth pressures on flexible structures a state of the art report. Proc. 5th Eur. Conf. Soil Mech. 2, 169-196.

Borin, D. L. (1973). The behaviour of saturated kaolin in the simple shear apparatus. $\mathrm{PhD}$ thesis, University of Cambridge.

British Standards Institution (1975). Methods of test for soils for civil engineering purposes. BS 1377. London: British Standards Institution.

Burland, J. B. \& Hancock, R. J. R. (1977). Underground car park at the House of Commons, London: geotechnical aspects. Struct. Engr 55, 87-100.

Campanella, R. G., Gillespie, D. \& Robertson, P. K. (1982). Pore pressures during cone penetration testing. Proc. 2nd Eur. Symp. Penetration Testing, Amsterdam 2, 507-512.

Campanella, R. G. \& Robertson, P. K. (1981). Applied cone research. Am. Soc. Civ Engrs Symp. Cone Penetration Testing and Experience, St Louis, pp. 343-362.

Campanella, R. G. \& Robertson, P. K. (1983). Flat plate dilatometer testing: research and development. Soil Mech. Report 68. University of British Columbia.

Carter, J. P., Randolph, M. F. \& Wroth, C. P. (1979). Stress and pore pressure changes in clay during and after the expansion of a cylindrical cavity. Int. $J$. Numer. Analyt. Meth. Geomech. 3, 305-322.

Casagrande, A. (1936). Characteristics of cohesionless soils affecting the stability of slopes and earth fills. J. Boston Soc. Civ. Engrs 257-276.

Clarke, B. G. (1981). In situ testing of clays using the Cambridge self-boring pressuremeter. $\mathrm{PhD}$ thesis, University of Cambridge.
Clarke, B. G., Carter, J. P. \& Wroth, C. P. (1979). In situ determination of the consolidation characteristics of saturated clays. Proc. 7th Eur. Conf. Soil Mech. 2, 207-213.

Donald, I. B., Jordan, D. O., Parker, R. J. \& Toh, C. T. (1977). The vane test-a critical appraisal. Proc. 9th Int. Conf. Soil Mech. 1, 81-88.

Eden, W. J. \& Law, K. T. (1980). Comparison of undrained shear strength results obtained by different test methods in soft clay. Can. Geotech. J. 17, 369-381.

Fahey, M. (1980). A study of the pressuremeter test in dense sand. PhD thesis, University of Cambridge.

Flodin, N. \& Broms, B. (1981). History of civil engineering in soft clay. In Soft clay engineering, Chap. 1, pp. 27-156 (eds. E. W. Brand \& R. P. Brenner). Amsterdam: Elsevier.

Ghionna, V., Jamiolkowski, M., Lacasse, S., Lancellota, R. \& Lunne, T. (1983). Evaluation of selfboring pressuremeter. Proc. Int. Symp. In Situ Testing, Paris, 2, 294-301.

Ghionna, V. N., Jamiolkowski, M. \& Lancellotta, R. (1982). Characteristics of saturated clays as obtained from SBP tests. Prnc. Symp. Pressuremeter and its Marine Applications, Paris, pp. 165-185.

Gibson, R. E. \& Anderson, W. F. (1961). In situ measurement of soil properties with the pressuremeter. Civ. Engng Pub. Wks Rev. 56, No. 658, 615-618.

Henderson, G., Smith, P. D. K. \& St John, H. D. (1979). The development of a pressuremeter for offshore use. Proc. Int. Conf. Offshore Site Investigation, London. Paper No. 10.

Henkel, D. J. (1960). The shear strength of saturated remoulded clays. Proc. Am. Soc. Civ. Engrs Conf. Shear Strength of Cohesive Soils, Boulder, pp. 533554.

Hughes, J. M. O. (1973). An instrument for in-sim measurement in soft clays. $\mathrm{PhD}$ thesis, University of Cambridge.

Hughes, J. M. O., Wroth, C. P. \& Pender, M. J. (1975). A comparison of the results of special pressuremeter tests with conventional tests on a deposit of soft clay at Canvey Island. Proc. 2nd Aust.-N.Z. Conf. Geomech., Brisbane, pp. 292296.

Hughes, J. M. O., Wroth, C. P. \& Windle, D. (1977). Pressuremeter tests in sands. Géotechnique 27, $455-477$.

Hvorslev, M. J. (1937). Über die Festigkeitseigenschaften Gestörter Bindiger Boden. Doctoral thesis, Kфpenhavn.

Jefferies, M. G. \& Funegard, E. (1983). Cone penetration testing in the Beaufort Sea. Am. Soc. Civ. Engrs Spec. Conf. Geotechnical Practice in Offshore Engineering, Austin, 10. 220-243.

Jones, G. A. \& Rust, E. A. (1982). Piezometer penetration testing CUPT. Proc. 2nd Eur. Symp. Penetration Testing, Amsterdam 2, 607-613.

de Josselin de Jong, G. (1972). Roscoe Memorial Symp. Stress-Strain Behaviour of Soils, Discussion to session II, pp. 258-261 (ed. R. H. G. Parry). Cambridge: Foulis.

Lacasse, S. \& Lunne, T. (1982a). In situ horizontal stress from pressuremeter tests. Proc. Symp. 
Pressuremeter and its Marine Applications, Paris, pp. 187-208.

Laccasse, S. \& Lunne, T. (1982b). Penetration tests in two Norwegian clays. Proc. 2nd Eur. Symp. Penetration Testing, Amsterdam 2, 661-669.

Ladanyi, B. (1972). In situ determination of undrained stress-strain behaviour of sensitive clays with the pressuremeter. Can. Geotech. J. 9, 313-319.

Ladd, C. C. \& Edgers, L. (1972). Consolidatedundrained direct-simple shear tests on saturated clays. MIT Research Report R72-82. Massachusetts Institute of Technology.

Ladd, C. C., Foott, R., Ishihara, K., Schlosser, F. \& Poulos, H. G. (1977). Stress-deformation and strength characteristics: state of the art report. Proc. 9th Int. Conf. Soil Mech., Tokyo 2, 421-494.

Lade, P. (1972). The stress-strain and strength characteristics of cohesionless soils. PhD thesis, University of California, Berkeley.

Law, K. T. (1979). Triaxial-vane tests on a soft marine clay. Can. Geotech. J. 16, 11-18.

Loudon, P. A. (1967). Some deformation characteristics of kaolin. PhD thesis, University of Cambridge.

Mair, R. J. \& Wood, D. M. (1984). A review of the use of pressuremeters for in situ testing. London: CIRIA.

Marsland, A. (1973). Laboratory and in situ measurement of the deformation moduli of London Clay. Proc. Symp. Interaction of Structure and Foundation, pp. 7-17. Birmingham: Midland Soil Mechanics and Foundation Engineering Society.

Matsuoka, H. (1974). Stress-strain relationships of sands based on the mobilized plane. Soils Fdns 14, $47-61$.

Matsuoka, H. \& Nakai, T. (1977). Stress-strain relationship of soil based on the spatially mobilized plane. Proc. 9th Int. Conf. Soil Mech., Tokyo, Special Session 9, pp. 153-162.

Matsuoka, H. \& Nakai, T. (1982). A new failure criterion for soils in three dimensional stresses. Proc. IUTAM Symp. Deformation Failure of Granular Materials, Delft.

Menzies, B. K. \& Merrifield, C. M. (1980). Measurements of shear stress distribution on the edges of a shear vane blade. Géotechnique 30, 314-318.

Mori, H. (1983). In situ plate loading test for dense sandy soil using a self boring instrument. Proc. Int. Symp. In Situ Testing, Paris 2, 353-357.

Palmer, A. C. (1972). Undrained plane strain expansion of a cylindrical cavity in clay: a simple interpretation of the pressuremeter test. Géotechnique 22, 451-457.

Ramamurthy, T. \& Rawat, P. C. (1973). Shear strength of sand under general stress system. Proc: 8th Int. Conf. Soil Mech., Moscow, 1-2, 339-342.

Randolph, M. F. \& Wroth, C. P. (1979). An analytical solution for the consolidation around a driven pile. Int. J. Numer. Analyt. Meth. Geomech. 3, 217-229.

Randolph, M. F. \& Wroth, C. P. (1981). Application of the failure state in undrained simple shear to the shaft capacity of driven piles. Géotechnique 31, No. 1, 143-157.

Robertson, P. K. \& Campanella, R. G. (1983). Interpretation of cone penetration tests, Parts 1 \& 2 .
Soil Mech. Report Series No. 60. University of British Columbia.

Roscoe, K. H. (1953). An apparatus for the application of simple shear to soil samples. Proc. 3rd Int. Conf. Soil Mech., Zurich 1, 186-191.

Roscoe, K. H., Schofield, A. N. \& Wroth, C. P. (1958). On the yielding of soils. Géotechnique $\mathbf{8}$, 22-53.

Satake, M. (1982). On equivalent Mohr's circle for granular materials. Report No. R-205. University of New South Wales.

Schofield, A. N. \& Wroth, C. P. (1968). Critical state soil mechanics. London: McGraw-Hill.

Sennesset, K., Janbu, N. \& Svanø, G. (1982). Strength and deformation parameters from cone penetration tests. Proc. 2nd Eur. Symp. Penetration Testing, Amsterdam 2, 863-870.

Shihata, T. \& Karube, D. (1965). Influence of the variation of the intermediate principal stress on mechanical properties of normally consolidated clay. Proc. 6th Int. Conf. Soil Mech., Montreal 1, 359-363.

Skempton, A. W. (1954). The pore-pressure coefficients $A$ and $B$. Géotechnique 4, 143-147.

Skempton, A. W. (1957). Discussion on the planning and design of the new Hong Kong airport. Proc. Instn Civ. Engrs 7, 306.

Smits, F. P. (1982). Penetration pore pressure measured with piezometer cones. Proc. 2nd Eur. Symp. Penetration Testing, Amsterdam 2, 877-881.

Soydemir, C. (1976). Strength anisotropy observed through simple shear tests. In Laurits Bjerrum memorial volume, pp. 99-113. Norwegian Geotechnical Institute.

Sutherland, H. B. \& Mesdary, M. S. (1969). The influence of the intermediate principal stress on the strength of sand. Proc. 7th Int. Conf. Soil Mech., Mexico 1, 391-399.

Taylor, D. W. (1948). Fundamentals of soil mechanics. London: Wiley, 358-359.

Tedd, P. \& Charles, J. A. (1981). In situ measurement of horizontal stress in overconsolidated clay using push-in spade-shaped pressure cells. Géotechnique 31, No. 4, 554-558.

Torstensson, B.-A. (1975). Pore pressure sounding instrument. Proc. Am. Soc. Civ. Engrs Spec. Conf. In Situ Measurement of Soil Properties 2, 48-54.

Tumay, M. T., Bogges, R. L. \& Acar, Y. (1981). Subsurface investigations with piezocone penetrometer. Proc. Am. Soc. Civ. Engrs Symp. Cone Penetration Testing and Experience, St Louis, pp. 325-342.

Ventura, P. (1983). Le pénétromètre pièzométrique dans les profils des sous-sols marins. Proc. Symp. Soil and Rock Investigations by In Situ Testing, Paris 2, 425-430.

Windle, D. (1976). In situ testing of soils with a selfboring pressuremeter. $\mathrm{PhD}$ thesis, University of Cambridge.

Windle, D. \& Wroth, C. P. (1977). The use of a self-boring pressuremeter to determine the undrained properties of clays. Ground Engng 10, No. $6,37-46$.

Wissa, A. E. Z., Martin, R. T. \& Garlanger, J. E. 
(1975). The piezometer probe. Proc. Am. Soc. Civ. Engrs Spec. Conf. In Situ Measurement of Soil Properties 1, 536-545.

Wond, D. M. (1981). True triaxial tests on Boston Blue Clay. Proc. 10th Int. Conf. Soil Mech., Stockholm 1, 825-830.

Wood, D. M. \& Wroth, C. P. (1977). Some laboratory experiments related to the results of pressuremeter tests. Géotechnique 27, 181-201.

Wroth, C. P. (1982). British experience with the self boring pressuremeter. Proc. Symp. Pressuremeter and its Marine Applications, Paris, pp. 143-164.

Wroth, C. P. \& Hughes, J. M. O. (1972). An instrument for the in situ measurement of the properties of sofi clays. Technical Report Soils TR13. University of Cambridge.

Zuidberg, H. M., Schaap, L. H. J. \& Beringen, F. L. (1982). A penetrometer for simultaneously measuring cone resistance, sleeve friction and dynamic pore pressure. Proc. 2nd Eur. Symp. Penetration Testing, Amsterdam, pp. 963-970.

\section{APPENDIX 1}

Relationship between pressures in triaxial tests

In Fig. 5 the points $A$ and $C$ lie on the normal consolidation line

$$
V_{\mathrm{a}}-V_{\mathrm{c}}=\lambda \ln \left(p_{\mathrm{c}}{ }^{\prime} / \mathrm{p}_{\mathrm{a}}{ }^{\prime}\right)
$$

Points $\mathrm{R}$ and $\mathrm{C}$ lie on a swelling line

$$
V_{\mathrm{r}}-V_{\mathrm{c}}=\kappa \ln \left(p_{\mathrm{c}}{ }^{\prime} / p_{\mathrm{r}}{ }^{\prime}\right)=\kappa \ln R
$$

But $V_{\mathrm{r}} \equiv V_{\mathrm{a}}$, therefore

$$
\lambda \ln \left(p_{\mathrm{c}}^{\prime} / p_{\mathrm{a}}{ }^{\prime}\right)=\kappa \ln R
$$

Points $S$ and $X$ lie on the critical state line, and by similar triangles

$$
\lambda \ln \left(p_{\mathrm{x}}^{\prime} / p_{\mathrm{s}}^{\prime}\right)=\kappa \ln \left(p_{\mathrm{x}}^{\prime} / \mathrm{p}_{\mathrm{r}}^{\prime}\right)
$$

Subtraction of both sides from $\lambda \ln \left(p_{x}{ }^{\prime} / p_{r}{ }^{\prime}\right)$ gives

$$
\begin{aligned}
& \lambda \ln \left(p_{\mathrm{s}}^{\prime} / p_{\mathrm{r}}^{\prime}\right)=(\lambda-\kappa) \ln \left(p_{\mathrm{x}}^{\prime} / p_{\mathrm{r}}^{\prime}\right) \\
& \text { i.e. } \\
& \lambda \ln \left(p_{\mathrm{s}}^{\prime} / p_{\mathrm{r}}{ }^{\prime}\right)=(\lambda-\kappa) \ln (R / r) \\
& \frac{p_{s}^{\prime}}{p_{r}^{\prime}}=\left(\frac{R}{r}\right)^{\Lambda}
\end{aligned}
$$

where

$$
\Lambda=\frac{\lambda-\kappa}{\lambda}
$$

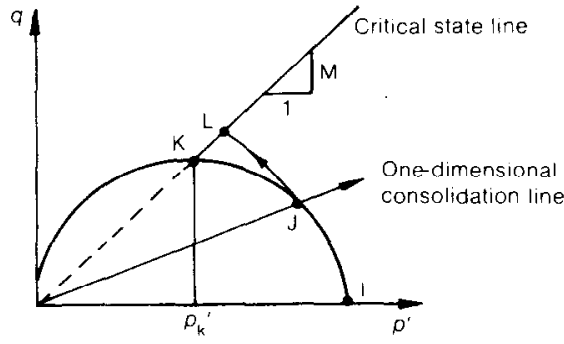

\section{APPENDIX 2}

Undrained strength ratio of a one-dimensionally normally consolidated clay tested in triaxial compression

The concepts of critical state soil mechanics allow an estimate to be made of the ratio of the undrained strength $s_{\mathrm{utc}}$ to the consolidation pressure $\sigma_{\mathrm{vo}}$ of a specimen which has been one-dimensionally normally consolidated.

Figure 34 shows the consolidation and stress space plots for interpretation of triaxial tests used in critical state soil mechanics together with the elliptical yield envelope of modified Cam clay. The equation of this envelope is

$$
q^{2}+M^{2} p^{\prime 2}=2 M^{2} p_{k}{ }^{\prime} p^{\prime}
$$

where $q$ is the deviator stress and $p^{\prime}$ the mean principal effective stress. It is assumed that when the specimen is normally consolidated at state $J$ the coefficient of earth pressure at rest is given by the widely adopted expression $K_{0} \approx\left(1-\sin \phi_{\mathrm{tc}}\right)$ so that the ratio of stresses at $\mathrm{J}$ is given by

$$
\begin{aligned}
\eta_{j} & =\frac{q_{\mathrm{j}}}{p_{\mathrm{j}}{ }^{\prime}}=\frac{3\left(1-K_{0}\right)}{1+2 K_{0}} \\
& =\frac{3 \sin \phi_{\mathrm{tc}}}{3-2 \sin \phi_{\mathrm{tc}}}
\end{aligned}
$$

but point $\mathbf{J}$ must lie on the yield envelope and satisfy equation (64) so that

$$
\left(\tau_{j}{ }^{2}+M^{2}\right) p_{j}{ }^{\prime 2}-2 M^{2} p_{k}{ }^{\prime} p_{j}{ }^{\prime}
$$

An undrained compression test on the specimen will bring the specimen to failure at point $\mathrm{L}$ on the critical state line at the same specific volume (or water content). Hence the undrained strength, by definition, is

$$
s_{\text {utc }}=\frac{1}{2} q_{1}=\frac{M}{2} p_{1}^{\prime}
$$

but this needs to be related to the initial consolidation pressure $\sigma_{\mathrm{v0}}$ ', i.e. $\sigma_{1 \mathrm{i}}{ }^{\prime}$ which can be done by expressing $p_{1}^{\prime}$ in turn as a function of $\left(p_{i}{ }^{\prime}, p_{k}{ }^{\prime}\right)$ then $\eta_{i}$ and then $\sigma_{1 j}{ }^{\prime}$. The relationship between the pressures at points $\mathrm{R}, \mathrm{S}, \mathrm{X}$ of Fig. 5 established in Appendix 1, equation (60), can be invoked to relate the pressures at points $J$, $\mathrm{K}$ and $\mathrm{L}$ as

$$
\frac{p_{1}^{\prime}}{p_{\mathrm{i}}^{\prime}}=\left(\frac{p_{\mathrm{k}}{ }^{\prime}}{p_{\mathrm{j}}^{\prime}}\right)^{\wedge}
$$

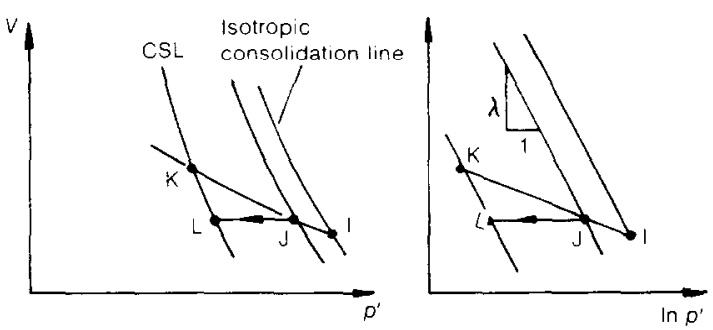

Fig. 34. Yield envelope and critical state line for modified Cam clay 
but from equation (66)

$$
\frac{p_{k}{ }^{\prime}}{p_{j}{ }^{\prime}}=\frac{\eta_{j}{ }^{2}+M^{2}}{2 M^{2}}
$$

and from equation (65)

$$
\begin{aligned}
\frac{\eta_{\mathrm{i}}}{M} & =\frac{3 \sin \phi_{\mathrm{tc}}}{3-2 \sin \phi_{\mathrm{tc}}} \frac{3-\sin \phi_{\mathrm{tc}}}{6 \sin \phi_{\mathrm{tc}}} \\
& =\frac{3-\sin \phi_{\mathrm{tc}}}{2\left(3-2 \sin \phi_{\mathrm{tc}}\right)}=a \text { (say) }
\end{aligned}
$$

and by definition

$$
\begin{aligned}
\frac{p_{\mathrm{j}}{ }^{\prime}}{\sigma_{1 \mathrm{j}}{ }^{\prime}} & =\frac{1+2 K_{0}}{3} \\
& =\frac{3-2 \sin \phi_{\mathrm{tc}}}{3}
\end{aligned}
$$

Combining these results

$$
\begin{aligned}
\frac{s_{\mathrm{utc}}}{\sigma_{1 \mathrm{j}}{ }^{\prime}} & =\frac{s_{\mathrm{utc}}}{p_{1}^{\prime}} \frac{p_{1}^{\prime}}{p_{\mathrm{j}}^{\prime}} \frac{r_{\mathrm{j}}^{\prime}}{\sigma_{1 \mathrm{j}}{ }^{\prime}} \\
& =\frac{M}{2}\left(\frac{p_{\mathrm{k}}{ }^{\prime}}{p_{\mathrm{j}}^{\prime}}\right)^{\wedge} \frac{3-2 \sin \phi_{\mathrm{tc}}}{3} \\
& =\frac{3 \sin \phi_{\mathrm{tc}}}{3-\sin \phi_{\mathrm{tc}}}\left(\frac{a^{2}+1}{2}\right)^{\wedge} \frac{3-2 \sin \phi_{\mathrm{tc}}}{3} \\
& =\frac{\sin \phi_{\mathrm{tc}}}{2 a}\left(\frac{a^{2}+1}{2}\right)^{\wedge}
\end{aligned}
$$

Undrained strength ratio of a one-dimensionally normally consolidated clay tested in plane strain active conditions

An exactly similar analysis to that for the triaxial test can be carried out for plane strain active tests. The same basic assumptions are made except that the stress variables $p^{\prime}$ and $q$ are replaced by $s^{\prime}=$ $\frac{1}{2}\left(\sigma_{1}{ }^{\prime}+\sigma_{3}{ }^{\prime}\right)$ and $t=\frac{1}{2}\left(\sigma_{1}{ }^{\prime}-\sigma_{3}{ }^{\prime}\right)$, and $\phi_{\mathrm{tc}}$ by $\phi_{\mathrm{ns}}$ for failure conditions. However, for one-dimensional normal consolidation, for which the conditions are axially symmetric, it is considered both more appropriate and more convenient to relate the value of $K_{0}$ with $\phi_{\mathrm{tc}}$ (not $\phi_{\mathrm{ps}}$ ) and use the approximation $K_{0} \approx 1-\sin \phi_{\mathrm{tc}}$. Hence

$$
\begin{aligned}
\theta_{\mathrm{j}} & =\frac{t_{\mathrm{j}}}{s_{\mathrm{j}}{ }^{\prime}}=\frac{1-K_{0}}{1+K_{0}} \\
& =\frac{\sin \phi_{\mathrm{tc}}}{2-\sin \phi_{\mathrm{tc}}}
\end{aligned}
$$

and since $\mathrm{J}$ must lie on the yield envelope

$$
\left(\theta_{\mathrm{j}}{ }^{2}+m^{2}\right) s_{\mathrm{j}}{ }^{2}=2 m^{2} s_{\mathrm{k}}{ }^{\prime} s_{\mathrm{j}}{ }^{\prime}
$$

where $m=\sin \phi_{\mathrm{ps}}$ and

$$
\mathrm{s}_{\mathrm{ups}}=t_{1}=m s_{1}^{\prime}
$$

As above,

$$
\frac{s_{1}^{\prime}}{s_{j}^{\prime}}=\left(\frac{s_{\mathrm{k}}{ }^{\prime}}{s_{\mathrm{j}}{ }^{\prime}}\right)^{\wedge}
$$

and

$$
\begin{gathered}
\frac{s_{\mathrm{k}}{ }^{\prime}}{s_{\mathrm{j}}^{\prime}}=\frac{\theta_{\mathrm{j}}{ }^{2}+m^{2}}{2 m^{2}} \\
\frac{\theta_{\mathrm{j}}}{m}=\frac{1}{2-\sin \phi_{\mathrm{ps}}}=c \text { (say) }
\end{gathered}
$$

and

$$
\begin{aligned}
\frac{s_{j}^{\prime}}{\sigma_{1 j}{ }^{\prime}} & =\frac{1+K_{0}}{2} \\
& =\frac{2-\sin \phi_{\mathrm{tc}}}{2}
\end{aligned}
$$

Combining these results

$$
\begin{aligned}
\frac{s_{\mathrm{ups}}}{\sigma_{1 \mathrm{j}}{ }^{\prime}} & =\frac{s_{\mathrm{ups}}}{s_{1}{ }^{\prime}} \frac{s_{1}{ }^{\prime}}{s_{\mathrm{j}}{ }^{\prime}} \frac{s_{\mathrm{i}}{ }^{\prime}}{\sigma_{1 \mathrm{i}}{ }^{\prime}} \\
& =m\left(\frac{c^{2}+1}{2}\right)^{\wedge} \frac{2-\sin \phi_{\mathrm{tc}}}{2} \\
& =\frac{\sin \phi_{\mathrm{ps}}}{2 c} \frac{2-\sin \phi_{\mathrm{tc}}}{2-\sin \phi_{\mathrm{ps}}}\left(\frac{c^{2}+1}{2}\right)^{\wedge}
\end{aligned}
$$

In reality the middle factor is very near to unity; using the relationship of equation (15) or equation (18) it varies from 1.025 for $\phi_{\mathrm{tc}}=20^{\circ}$ to 1.045 for $\phi_{\mathrm{tc}}=35^{\circ}$. Within the likely accuracy of all the assumptions it can be taken as unity and the undrained strength ratio in plane strain active conditions reduces to

$$
\frac{s_{\mathrm{ups}}}{\sigma_{\mathrm{v} 0}^{\prime}}=\frac{\sin \phi_{\mathrm{ps}}}{2 c}\left(\frac{c^{2}+1}{2}\right)^{\wedge}
$$

where $c=1 /\left(2-\sin \phi_{\mathrm{ps}}\right)$.

Similarly it can be shown that for isotropically normally consolidated clay tested in plane strain active conditions the undrained strength ratio would be

$$
\frac{s_{\mathrm{ups}}}{\sigma_{\mathrm{vo}}{ }^{\prime}}=\sin \phi_{\mathrm{ps}}\left(\frac{1}{2}\right)^{\Lambda}
$$

\section{VOTE OF THANKS}

In proposing a vote of thanks to Professor Wroth, Professor J. B. Burland made the following remarks.

'There are two characteristics which distinguish Professor Wroth's work and his presentations. The first is clarity and the second is elegance. The lecture we have just heard displays both of these characteristics in full measure. When I was a research student at "The other place" I well remember Peter Wroth's insistence that diagrams should always be kept simple and that in presenting them the axes should first be clearly indicated. This evening's lecture has been an object lesson in its clarity of presentation.

'Few would question the importance of determining directly and with a minimum of disturbance the in situ properties of the ground. There 
is inevitably an element of competition, even tension, between in situ and laboratory testing and I believe that this is a thoroughly healthy situation. Laboratory testing has the advantage of flexibility in the control of the stress path but suffers the disadvantage of sampling and preparation. Good in situ testing minimizes the disturbance but lacks the flexibility of stress path control. Moreover a careful interpretation of the results is required and this has been the important theme of this evening's lecture.

'In the first part of his lecture Professor Wroth has concentrated on two types of in situ teststhe self-boring pressuremeter and the piezocone. He was one of the first to recognize the potential of the self-boring pressuremeter and the development of the Camkometer, and its interpretation has taken place largely under his direction. I would like to take this opportunity of paying tribute to him for this important contribution. If I may express a personal view I believe that the capability of measuring the in situ horizontal effective stress is still one of the most important features of the Camkometer. The piezocone is less familiar in the UK and Professor Wroth has given us a clear insight into the advantages it offers over the traditional cone test.
'In the last part of his lecture Professor Wroth has tackled one of the most fascinating and fundamental problems of soil mechanics, the undrained strength of clays-a topic which has been touched on by many previous Rankine lecturers. Not only do in situ measurements of undrained strength require careful interpretation but so also do laboratory measurements. His analysis of the simple shear test has been most elegantly presented and I have no doubt that it will be the subject of very careful study and debate.

'Earlier I referred to the healthy tension that exists between laboratory and in situ testing. Professor Wroth has demonstrated that both have a vital role to play and that developments in the one can have important implications for the other. He has also disposed of once and for all any notion that there is such a thing as the undrained strength of a clay. Ladies and gentlemen I know that you will agree with me that the lecture has been stimulating, thought provoking and of great value. It is with the greatest pleasure that I propose a hearty vote of thanks to Professor Wroth for delivering the twentyfourth Rankine Lecture.'

The vote of thanks was accorded with acclamation. 